\title{
ESTUDO DE TENDÊNCIAS NAS SÉRIES TEMPORAIS DE QUALIDADE DE ÁGUA DE RIOS DO ESTADO DE SÃO PAULO COM DIFERENTES GRAUS DE INTERVENÇÃO ANTRÓPICA
}

\author{
JULIANO DANIEL GROPPO
}

Dissertação apresentada à Escola Superior de Agricultura "Luiz de Queiroz", Universidade de São Paulo, para obtenção do título de mestre em Ecologia de Agroecossistemas.

PIRACICABA

Estado de São Paulo - Brasil

Março - 2005 


\title{
ESTUDO DE TENDÊNCIAS NAS SÉRIES TEMPORAIS DE QUALIDADE DE ÁGUA DE RIOS DO ESTADO DE SÃO PAULO COM DIFERENTES GRAUS DE INTERVENÇÃO ANTRÓPICA
}

\author{
JULIANO DANIEL GROPPO \\ Engenheiro Ambiental
}

Orientador: Prof. Dr. LUIZ ANTONIO MARTINELLI

Dissertação apresentada à Escola Superior de Agricultura "Luiz de Queiroz", Universidade de São Paulo, para obtenção do título de mestre em Ecologia de Agroecossistemas.

PIRACICABA

Estado de São Paulo - Brasil

Março - 2005 
Dados Internacionais de Catalogação na Publicação (CIP) DIVISÃO DE BIBLIOTECA E DOCUMENTAÇÃO - ESALQ/USP

Groppo, Juliano Daniel

Estudo de tendências nas séries temporais de qualidade de água de rios do Estado de São Paulo com diferentes graus de intervenção antrópica / Juliano Daniel Groppo. - Piracicaba, 2005.

72 p. : il.

Dissertação (mestrado) - - Escola Superior de Agricultura Luiz de Queiroz, 2005. Bibliografia.

1. Água doce - Qualidade 2. Análise de séries temporais 3. Bacia hidrográfica 4. Biogeoquímica 5. Ecologia aquática 6. Monitoramento ambiental 7. Poluição da água I. Título

CDD 574.526323

"Permitida a cópia total ou parcial deste documento, desde que citada a fonte - O autor" 
Á minha família,

GERSON, IVANI e VANESSA

E minha namorada FABIANA

\section{OFEREÇO}

Á memória do meu primo,

RODRIGO

DEDICO 


\section{AGRADECIMENTOS}

Aos Profs. Drs. Luiz Antonio Martinelli, Jorge Marcos de Moraes e Abel Maia Genovez, pela oportunidade e orientação, amizade e paciência, imprescindíveis na realização deste trabalho; além do constante apoio à carreira científica.

Agradeço aos Pesquisadores, Doutorandos, Mestrandos, Técnicos, Estagiários e Funcionários do Laboratório de Ecologia Isotópica, pelo convívio e amizade.

À CETESB, em especial ao Dr. Evandro Gaiad Fischer, pela colaboração imprescindível na realização desse trabalho.

Ao Centro de Energia Nuclear na Agricultura (CENA), por fornecer os meios necessários para a realização desse trabalho.

Á ESALQ/USP, através do Programa de Pós-Graduação em Ecologia de Agroecossistemas pela oportunidade de aprendizado.

Agradeço à Fundação de Amparo à Pesquisa no Estado de São Paulo FAPESP (Processo nº 02/04932-0), pela bolsa de concedida. 


\section{SUMÁRIO}

Página

LISTA DE FIGURAS …................................................................................ vii

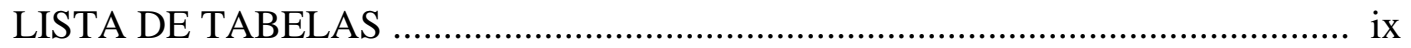

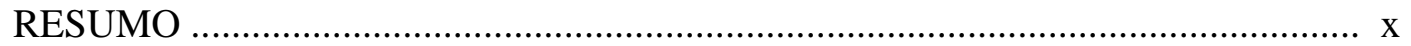

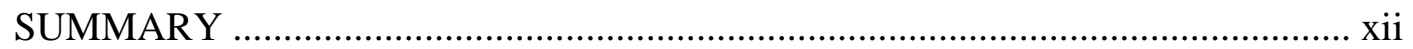

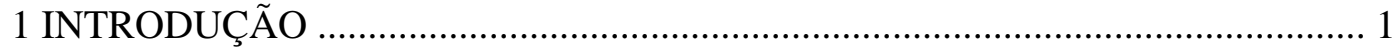

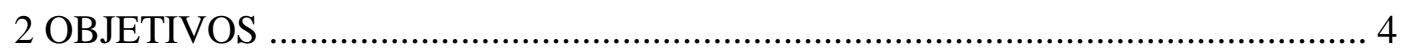

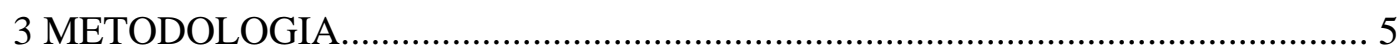

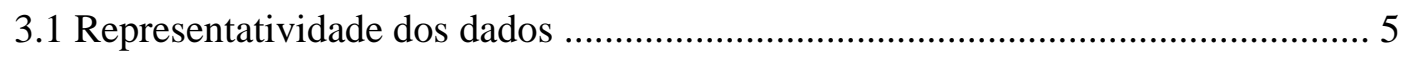

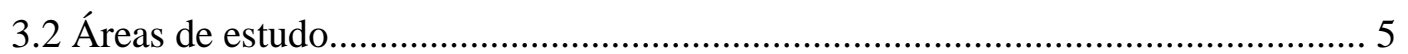

3.3 Metodologia de análise de tendência ................................................................. 8

3.4 Descrição da metodologia estatística empregada............................................... 11

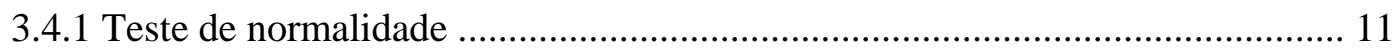

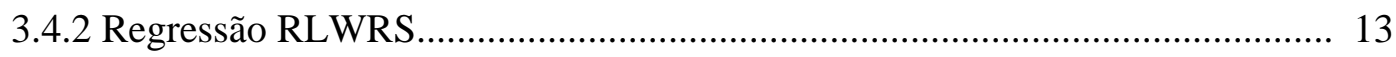

3.4.3 Teste de sazonalidade de Kruskal-Wallis .................................................... 15

3.4.4 Testes de tendência não sazonal e sazonal......................................................... 16

3.5 Metodologia para determinação da magnitude .................................................... 19

3.6 Metodologia de análise estatística de mudança brusca em séries temporais..........19

3.7 Metodologia de Análise de Agrupamento ........................................................... 20

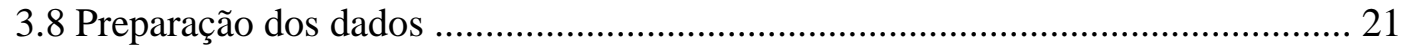

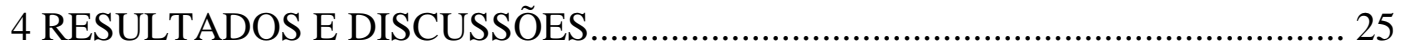

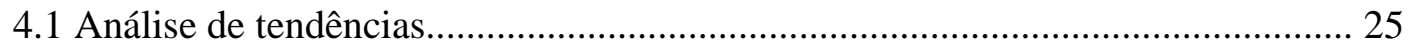




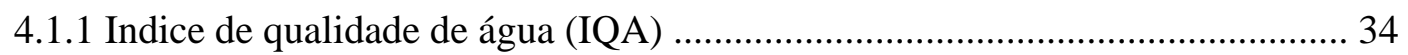

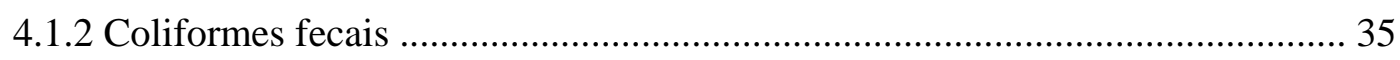

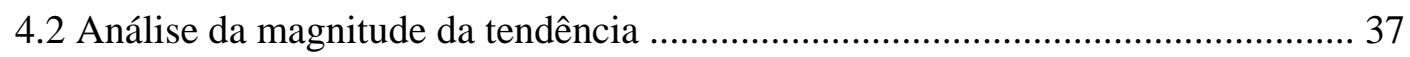

4.3 Análise estatística de mudanças bruscas............................................................. 39

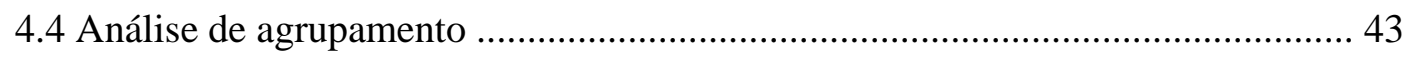

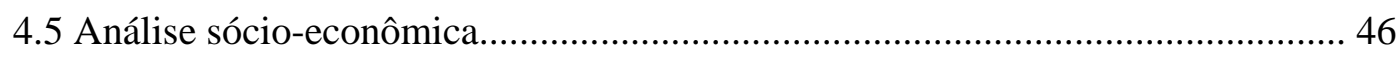

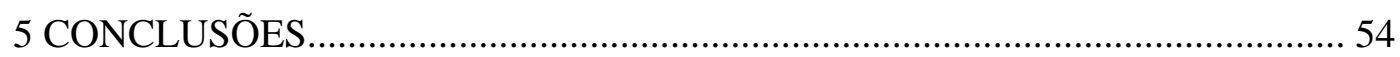

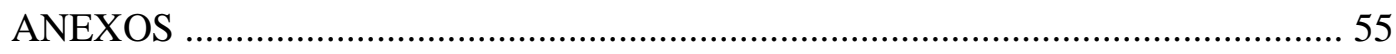

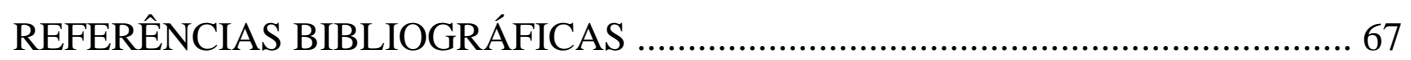




\section{LISTA DE FIGURAS}

Página

1 Mapa do Estado de São Paulo, com divisões das bacias hidrográficas estudadas e os postos de monitoramento

2 Verificação de anomalias nas series temporais de OD na bacia do rio Piracicaba mostrando a série original (a) e a corrigida (b). Os número de desvios padrão (stdev) apresentados são 1, 2, e 3

3 Teste de normalidade para Oxigênio Dissolvido

4 Regressão RLWRS para o posto de vazão do rio Piracicaba 4D-007, (19792001)

5 Regressão RLWRS para OD, posto do rio Piracicaba (PI)

6 Gráfico "Box-Plot”, com a finalidade de mostrar a variabilidade do OD ao longo do ano

7 Valores de coliformes fecais em relação ao tempo. Os valores apresentados nos intervalos abaixo da figura representam a média do período

8 Dendrogramas resultantes da análise de agrupamento entre as bacias: a) OD; b) DBO; c) nitrogênio; d) nitrato; e) amônio; f) fósforo total

9 Dendrogramas resultantes da análise de agrupamento entre as bacias: a) cloreto; b) coliformes fecais; c) IQA

10 Evolução da população nas bacias estudadas e suas respectivas equações de regressão: a) Piracicaba; b) Mogi-Guaçu; c) Peixe; d) Aguapeí; e) Turvo Grande; f) São José dos Dourados; g) Alto Paranapanema 
11 Evolução da população nas bacias estudadas e suas respectivas equações de regressão: a) Turvo Grande; b) São José dos Dourados; c) Alto Paranapanema ... 


\section{LISTA DE TABELAS}

Página

$1 \quad$ Parâmetros agrupados por bacias hidrográficas abordadas nesse estudo .......... 7

2 Relação dos postos de vazão das bacias do projeto BIOTASP ......................... 10

3 Relação dos postos de precipitação das bacias do projeto BIOTASP .............. 10

$4 \quad$ Relação dos postos de qualidade de água das bacias do projeto BIOTASP .... 11

5 Sumário dos resultados das análises de tendências, nível de significância de 5\% , no período de 1979 e 2001. Sendo que + representa tendência positiva, - tendência negativa, s tendência significativa, ns tendência não significativa e st não apresenta tendência .......................................................................... $\quad 30$

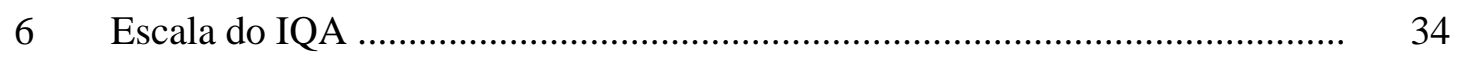

$7 \quad$ Distribuição bimestral dos resultados do IQA ................................................. 35

8 Resultados do coeficiente "Sen’s slope” (Sen) e valores médios (VM) dos parâmetros estudados, no período de 1979 a 2001 ........................................... 37

9 Sumário das análises estatísticas de mudança brusca: $\mathrm{CP}=$ ano de ocorrência; ns = não significativo, SL=nível de significância do teste de Pettitt

10 Média dos parâmetros antes e depois da mudança brusca ............................... 41

11 Área e histórico de atributos sócio-econômicos das bacias estudadas .................... 47

12 Uso do solo das bacias estudadas referente ao ano de 1997 (Silva et al, submetido)

13 Correlação da população com os parâmetros estudados: $\mathrm{r}^{2}=$ coeficiente de correlação, SL = nível de significância; $\mathrm{s}=$ significativo; ns = não significativo, considerando $\alpha=0,05$ 


\title{
ESTUDO DE TENDÊNCIAS NAS SÉRIES TEMPORAIS DE QUALIDADE DE ÁGUA DE RIOS DO ESTADO DE SÃO PAULO COM DIFERENTES GRAUS DE INTERVENÇÃO ANTRÓPICA
}

\author{
Autor: JULIANO DANIEL GROPPO \\ Orientador: Prof. Dr. LUIZ ANTONIO MARTINELLI
}

\section{RESUMO}

O conhecimento das tendências temporais da qualidade das águas é importante no diagnóstico ambiental de bacias hidrográficas, permitindo avaliar como os corpos d’água vem respondendo ao longo dos anos, em termos qualitativos, à crescente intervenção antrópica. O objetivo deste trabalho é caracterizar a qualidade das águas dos rios das bacias do Piracicaba, Mogi-Guaçu, Turvo Grande, Peixe, Aguapeí, São José dos Dourados e Alto Paranapanema utilizando postos monitorados pela CETESB (Companhia de Tecnologia de Saneamento Ambiental), no período entre 1979 e 2001. Os parâmetros biogeoquímicos avaliados quanto a sua tendência temporal e magnitude foram: oxigênio dissolvido (OD), demanda bioquímica de oxigênio (DBO), nitrogênio total, nitrato, fósforo total, cloreto, amônio e coliformes fecais.

A análise de tendência temporal exige uma metodologia específica, uma vez que as séries temporais obtidas não seguem uma distribuição normal, as amostragens são realizadas irregularmente, os dados apresentam sazonalidade e são dependentes da vazão dos rios. Essa metodologia é dividida em análise gráfica e aplicação de testes de tendência, onde inicialmente realiza-se uma análise exploratória dos dados, seguida da confirmação através de testes estatísticos. 
Os resultados mostraram que de uma maneira geral existe uma degradação da qualidade das águas na maior parte das bacias, representado pelas tendências positivas nos parâmetros (DBO, nitrogênios, fósforo total, cloreto e coliformes fecais) e negativa no parâmetro (OD). Dentre as bacias hidrográficas analisadas a bacia do rio Piracicaba é a mais severamente afetada com variações mais acentuadas na magnitude representada pelo coeficiente de regressão, seguida pelas bacias dos rios Mogi-Guaçu, Turvo Grande, Peixe e Aguapeí, sendo que por outro lado, as bacias do Alto Paranapanema e São José dos Dourados são as menos afetadas. 


\title{
TREND ANALYSIS IN WATER QUALITY TIME SERIES OF RIVERS WITH DIFFERENT DEGREES OF ANTHROPOGENIC INTERVENTION IN SÃO PAULO STATE
}

\author{
Author: JULIANO DANIEL GROPPO
}

Adviser: Prof. Dr. LUIZ ANTONIO MARTINELLI

\section{SUMMARY}

The knowledge of time trends of water quality is important for the environmental diagnosis of hydrographic basins, allowing the evaluation of how water bodies are responding through the years, in qualitative terms, to the growing antropogenic interventions (actions).

The aim of this work is to characterize the water quality of rivers of the Piracicaba, Mogi-Guaçu, Turvo Grande, Peixe, Aguapeí, São José dos Dourados and Alto Paranapanema basins using stations monitored by CETESB (Companhia de Tecnologia de Saneamento Ambiental), in the period from 1979 to 2001. The biogeochemical parameters evaluated concerning its time trend and magnitude were: dissolved oxygen (DO), biochemical oxygen demand (BOD), total nitrogen, nitrate, total phosphorus, chloride, ammonia and fecal coliforms.

Time trend analysis demands a specific methodology, since the time series obtained are not normally distributed, the sampling are performed irregularly, it can present seasonal periodicities and dependence on the rivers discharges. This methodology is divided in graphical analysis and application of trend tests, where initially an exploratory analysis of data is performed, followed by confirmation through statistical tests. 
The results showed that in a general there exists degradation of the water quality in most of the basins, represented by the positive trends of the parameters (BOD, nitrogens, total phosphorus, clorate and fecal coliforms) and negative trend of the parameter (DO). Among the analysed hydrographic basins, the Piracicaba river basin is the most severely affected with higher variations in the magnitude represented by the regression coeficient, followed by the basins of the Mogi-Guaçu, Turvo Grande, Peixe and Aguapeí rivers. On the other hand, the Alto Paranapanema and São José dos Dourados basins are the least affected. 


\section{INTRODUÇÃO}

O acelerado crescimento populacional e das atividades agro-industriais nas últimas décadas no Estado de São Paulo, vem acarretando o aumento do consumo de água urbana, industrial e agrícola, e uma sensível deterioração da qualidade desse recurso natural. Esse quadro vem ocorrendo em diversas bacias hidrográficas de interesse no cenário estadual, com diferentes graus de intervenção do homem no seu funcionamento natural, indicando a necessidade de estudos integrados que contemplem a compreensão do funcionamento básico dessas bacias.

A composição das águas superficiais resulta das interações destas com fases sólidas, líquidas e gasosas do entorno (Stumm \& Morgan, 1996) e de processos bióticos (Likens et al., 1977), que ocorrem durante o ciclo hidrológico. Entretanto, os rios que percorrem regiões onde há grande aporte de efluentes humanos e industriais, podem apresentar alterações drásticas que modificam completamente sua química (Krusche et al., 1997; Martinelli et al., 1999), seu metabolismo (Ballester et al., 1999) e a distribuição e sobrevivência de espécies aquáticas (Ometto et al., 2000; Goldstein, 1988). A presença desses efluentes representa, portanto, um risco a todos os seres vivos que utilizam essa água para sobreviver e o seu monitoramento é de extrema importância na regulamentação do aporte e no acompanhamento das mudanças ocorridas nos corpos d'água.

A CETESB implantou, no ano de 1978, um sistema de amostragem de água, que em 1993 já incluía 101 estações de monitoramento da qualidade da água ${ }^{1}$ em 29 bacias (São Paulo, 1993). O número de estações de monitoramento é atualmente de 135 (CETESB, 2002). Esse banco de dados, extremamente valioso, é base apenas para

\footnotetext{
${ }^{1} \mathrm{O}$ termo "qualidade de água" nesse estudo refere-se ao conjunto de parâmetros biogeoquímicos estudados.
} 
avaliações instantâneas da qualidade da água, ou ainda sanções aos poluidores, porém muito pouco explorado no exame das variações dos diversos parâmetros em relação ao tempo e na influência das mudanças regionais nas propriedades da água. Apenas a análise de tendências nos parâmetros oxigênio dissolvido (OD), demanda bioquímica de oxigênio (DBO), concentração de nitrato e coliforme fecal na bacia do rio Piracicaba, extraídos desse banco de dados, foi realizada no período de 1978 a 1993 (Krusche et al., 1997), apontando para uma clara deterioração da qualidade da água nessa bacia, apresentando tendência negativa para o OD e positivas para a DBO, nitrato e coliformes fecais.

O estudo de tendências nos dados de qualidade de água, associado à análise das possíveis causas, é importante no diagnóstico ambiental de bacias hidrográficas, permitindo avaliar como os corpos d'água vêm respondendo ao longo dos anos, em termos qualitativos, à crescente intervenção antrópica (Park \& Park ,2000, Cun \& Vilagiges, 1997; Maasdam \& Classen, 1998; Comber \& Gardner, 1999; Larsen et al., 1999; Lundin et al., 1999). Existe uma carência de tais estudos no Brasil, apesar de sua extrema importância na compreensão da estrutura e funcionamento de bacias hidrográficas. O presente projeto vem ao encontro dessa necessidade, propondo a sua realização na avaliação da qualidade da água de alguns rios do Estado de São Paulo com diferentes graus de intervenção antrópica.

Os métodos estatísticos para a análise de qualidade de água necessitam avaliar a influência das vazões dos rios e da sazonalidade sobre as medidas dos parâmetros (Hirsch, 1982), portanto exigem um tratamento especial. Hirsch et al (1982) desenvolveram uma extensão do teste de Kendall (1938), chamado de Kendall Sazonal, teste não paramétrico para detectar tendências temporais, que leva em consideração a sazonalidade dos dados. Posteriormente McLeod et al (1991) propôs um melhoramento do teste Kendall Sazonal chamado de teste de hierarquização ("rank") dos dados. Essa metodologia vem sendo aplicada com sucesso em diversos estudos (Krusche et al., 1997; Westmacott, 1997; Larsen et al, 1999). 
Para avaliar a magnitude das mudanças, Hirsch et al (1982), também observaram que o valor do coeficiente angular obtido pela regressão linear é muito mais sensível a valores extremos que o valor do estimador sazonal de inclinação de Kendall (“Seazonal Kendall Slope Estimator”). Este estimador, desenvolvido por Hirsch et al. (1982), é uma extensão do coeficiente de regressão “Sen’s slope” (Sen, 1968) para séries temporais com sazonalidade, e vem sendo utilizado na quantificação de tendências em diversos estudos (Burn, 1994; Osburn et. al., 2002; Langrand et al., 1998).

A técnica classificatória multivariada da análise de Agrupamento ("Cluster Analysis") é utilizada quando se deseja explorar as similaridades entre indivíduos ou entre variáveis, definindo-os em grupos (Johnson \& Wichern, 1982). Para tal finalidade consideram-se simultaneamente, no primeiro caso, todas as variáveis medidas em cada indivíduo e, no segundo, todos os indivíduos nos quais foram feitas as mesmas medidas. Essa análise agrupa um conjunto de $\mathrm{n}$ amostras com $\mathrm{m}$ variáveis, de acordo com as suas similaridades, utilizando conceitos geométricos (Martins, 1994).

A presente proposta faz parte do projeto Temático: "Estrutura e funcionamento de bacias hidrográficas de meso e microescala do Estado de São Paulo: Bases para gerar e sustentar a biodiversidade" (processo FAPESP: 99/05279-4), que faz parte do programa BIOTA. Esse projeto tem como principais objetivos: (1) conhecer a estrutura e o funcionamento de bacias hidrográficas de médio $\left(1.000\right.$ a $\left.50.000 \mathrm{~km}^{2}\right)$ e pequeno porte $\left(<1.000 \mathrm{~km}^{2}\right)$, onde estejam se desenvolvendo atividades relevantes do projeto BIOTAFAPESP, visando compreender os processos geradores, mantenedores e impactantes da biodiversidade; (2) continuar os estudos de comparação entre bacias hidrográficas do Estado de São Paulo, iniciado com o estudo das bacias do rio Piracicaba e rio MogiGuaçu (Projeto PIRACENA, FAPESP: 94/0529-9), estendendo-se para as bacias dos rios São José dos Dourados, Turvo Grande, Alto do Paranapanema, Aguapeí, Peixe. 


\section{OBJETIVOS}

- Avaliar as tendências temporais dos rios Piracicaba, Mogi-Guaçu, Peixe, Aguapeí, São José dos Dourados, Turvo Grande e do Paranapanema, utilizando postos monitorados pela CETESB, de alguns parâmetros biogeoquímicos, entre eles: oxigênio dissolvido (OD), demanda bioquímica de oxigênio (DBO), nitrogênio total, nitrato, amônio, fósforo total, cloreto, coliformes fecais e indíce de qualidade de água (IQA), monitorados pela CETESB, no período de 1979 a 2001;

- Investigar os possíveis agentes causadores de eventuais tendências, correlacionandose parâmetros de qualidade de água com atributos físicos e sócio-econômicos das bacias hidrográficas. 


\section{METODOLOGIA}

\subsection{Representatividade dos dados}

O presente trabalho foi realizado a partir de informações disponíveis no banco de dados da CETESB. Os parâmetros estudados foram publicados em relatórios anuais, tornando-se portanto de domínio público, sendo a qualidade dos métodos empregados na determinação dos mesmos avalizados por aquela instituição. $\mathrm{O}$ monitoramento dos parâmetros de qualidade de água teve inicio em 1978 e era realizado mensalmente até 1984, passando a ser bimestral a partir de 1985. Como são medidas instantâneas e com intervalo de tempo considerável entre coletas, inúmeras situações podem influenciar nessa medida, entre elas: (1) o período do ano da coleta; (2) o dia da semana em que as coletas foram realizadas; (3) lançamentos próximos aos pontos de coleta da CETESB no dia de coleta e (4) a vazão do rio.

\section{2 Áreas de estudo}

As bacias estudadas foram selecionadas a partir do projeto BIOTA-FAPESP, que escolheu bacias hidrográficas de médio e pequeno porte no Estado de São Paulo com diferentes graus de intervenção antrópica, visando compreender os processos geradores, mantenedores e impactantes da biodiversidade. 
A bacia do rio Piracicaba, incluindo os seus rios formadores Jaguari, Atibaia e Corumbataí foi a mais estudada(Cristofoletti, 1991; Prochnow, 1981; Salati, 1996; Pellegrino, 1995; Moraes et. al, 1998, 1997; Schuler et al. 2000; Krusche et al., 1997; Martinelli, 1999; Groppo et al , 2001, entre outros). Já as bacias dos rios São José dos Dourados, Turvo Grande, Alto do Paranapanema, Aguapeí e Peixe, mais distantes das regiões econômicas mais importantes do Estado de São Paulo, são tema apenas de estudos e planos de gestão de recursos hídricos (São Paulo, 1990; CRH-SIGRH, 2001), que caracterizaram todas as bacias hidrográficas do Estado de São Paulo. A localização dessas bacias é mostrada na Figura 1. Alguns aspectos da caracterização dessas bacias, extraídos de Martinelli et al. (2003), são apresentadas na Tabela 1.

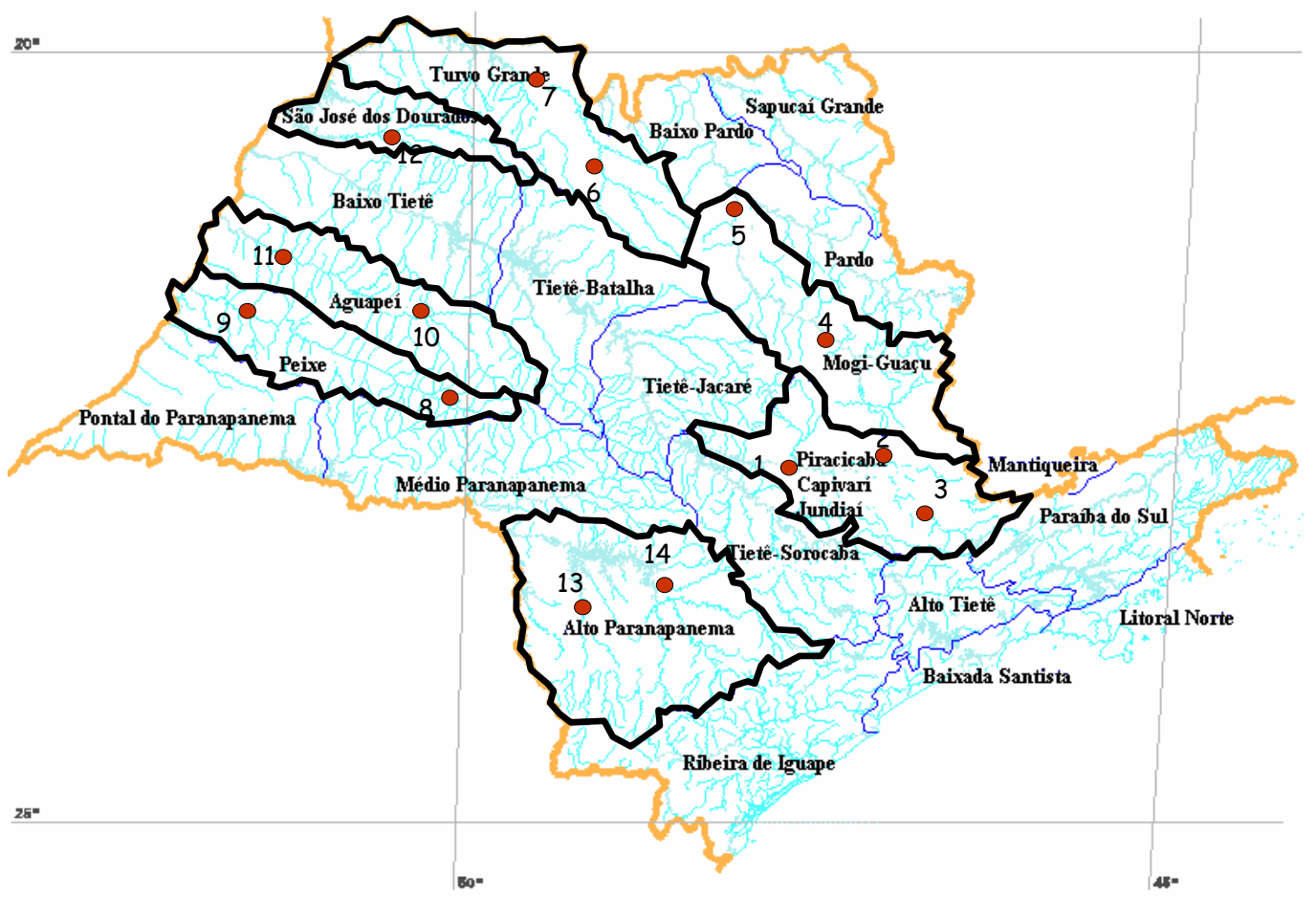

Figura 1 - Mapa do Estado de São Paulo, com divisões das bacias hidrográficas estudadas e os postos de monitoramento 
Tabela 1. Parâmetros agrupados por bacias hidrográficas abordadas neste estudo ${ }^{2}$

\begin{tabular}{|c|c|c|c|c|c|c|c|c|c|c|c|}
\hline & Piracicaba & Mogi & Turvo & Peixe & Aguapeí & SJDourados & Itapetininga & Apiaí & Taquari & Paranapanema & ESP \\
\hline Número de habitantes & 3.406 .561 & 1.283 .114 & 869.857 & 791.262 & 587.425 & 206.056 & 179.568 & 145.731 & 111.224 & 77.427 & 36.909 .200 \\
\hline População Urbana & 3.222 .223 & 1.167 .129 & 796.511 & 725.402 & 523.471 & 175.856 & 146.873 & 93.216 & 73.685 & 54.468 & 34.472 .706 \\
\hline Taxa de urbanização & 95 & 91 & 92 & 92 & 89 & 85 & 82 & 64 & 66 & 70 & 93 \\
\hline Área $\left(\mathrm{km}^{2}\right)$ & 11.538 & 13.314 & 11.497 & 12.976 & 12.235 & 5.785 & 3.384 & 4.424 & 2.943 & 2.551 & 248.600 \\
\hline Densidade demográfica (hab/km²) & 341 & 96 & 84 & 110 & 74 & 61 & 58 & 34 & 38 & 31 & 148 \\
\hline Percentagem de esgoto tratado $(\%)$ & 12 & 20 & 18 & 29 & 36 & 63 & 86 & 22 & 11 & 97 & 17 \\
\hline Cobertura da rede sanitária $(\%)$ & 84 & 96 & 93 & 80 & 84 & 80 & 81 & 75 & 53 & 80 & 80 \\
\hline Volume de esgoto gerado $\left(\mathrm{m}^{3} /\right.$ dia $)$ & 384.818 & 200.681 & 145.860 & 72.760 & 53.335 & 25.315 & 21.473 & 12.635 & 10.621 & 7.878 & 4.979 .884 \\
\hline Volume de esgoto tratado $\left(\mathrm{m}^{3} / \mathrm{dia}\right)$ & 37.825 & 32.070 & 20.817 & 16.780 & 15.392 & 12.797 & 14.838 & 2.174 & 974 & 5.994 & 835.538 \\
\hline Carga poluidora domiciliar potencial (kgDBO/dia) & 134.493 & 60.204 & 40.108 & 21.828 & 15.555 & 7.595 & 6.442 & 3.790 & 3.186 & 2.363 & 1.493 .965 \\
\hline Carga poluidora domiciliar remanescente $(\mathrm{kgDBO} / \mathrm{dia})$ & 121.947 & 50.584 & 34.563 & 16.794 & 10.937 & 3.756 & 1.991 & 3.138 & 2.894 & 565 & 1.243 .304 \\
\hline Participação em relação ao Estado (\%) & 9,8 & 4,1 & 2,8 & 1,4 & 0,9 & 0,3 & 0,2 & 0,3 & 0,2 & 0,05 & 100,0 \\
\hline Carga equivalente remanescente de carbono ( $\mathrm{kgC} / \mathrm{dia})$ & 49.023 & 20.335 & 13.824 & 6.751 & 4.397 & 1.510 & 800 & 1.262 & 1.163 & 227 & 366.796 \\
\hline Carga equivalente remanescente de $\mathrm{N}$ (kgN/dia) & 21.957 & 8.066 & 6.019 & 3.989 & 2.884 & 468 & 147 & 498 & 472 & 11 & 152.766 \\
\hline Descarga média no ponto mais à jusante da bacia $\left(\mathrm{m}^{3} / \mathrm{s}\right)$ & 142,00 & 266,00 & 99,92 & 75,76 & 87,12 & 30,75 & 20,15 & 13,09 & 10,30 & 20,20 & \\
\hline Carga de COD no ponto mais à jusante da bacia ( $\mathrm{kgC} / \mathrm{dia})$ & 88.425 & 75.449 & 30.548 & 31.598 & 36.246 & 9.782 & 7.629 & 4.067 & 3.375 & 11.806 & \\
\hline IQA no ponto mais à jusante da bacia & 40 & 62 & 66 & 59 & 68 & 67 & & & 53 & 78 & \\
\hline
\end{tabular}

\footnotetext{
${ }^{2}$ Dados de descarga foram obtidos junto à base de dados do DAEE (www.daee.sp.gov.br) e são valores médios referentes às séries históricas de cada ponto de medida. O IQA é o índice de qualidade de água para o ano 2000 estimado pela CETESB (www.cetesb.sp.gov.br) e representa a média das coletas feitas pela CETESB nos meses de fevereiro, abril, junho, agosto, outubro e dezembro. A carga de COD refere-se à carga de carbono orgânico dissolvido e foi obtida pelo produto da descarga média pela concentração média de COD obtida por Martinelli (dados não publicados) nos mesmos pontos em que foram medidas as descargas durante o ano de 2001 (coletas mensais).
} 


\subsection{Metodologia de análise de tendência}

O estudo de tendências dos dados de qualidade de água necessita de metodologia específica, uma vez que as séries temporais obtidas não seguem uma distribuição normal; as amostragens são realizadas irregularmente; os dados apresentam sazonalidade e ainda são dependentes da vazão dos rios (McLeod et al. 1991). A metodologia adequada para checar a presença de tendências em séries temporais de qualidade de água deve, portanto, avaliar a influência das vazões dos rios e da sazonalidade sobre as medidas dos parâmetros de qualidade de água (McLeod et al, 1991; Hipel \& McLeod, 1994).

A análise de tendências a ser utilizada neste estudo é descrita em detalhes nos trabalhos de Hirsch et al. (1991), McLeod et al. (1991); Hipel \& McLeod (1994) e já foi empregada com sucesso no estudo de tendências do rio Piracicaba (Krusche et al., 1997). Em linhas gerais, essa metodologia é dividida em duas principais categorias de análise gráfica e aplicação de estudos de gráficos e testes de tendência que refletem a idéia de uma análise exploratória seguida da confirmação através de testes estatísticos. Esse procedimento é sumarizado abaixo:

1. Visualização dos dados brutos: A série pode ser plotada em relação ao tempo em sua forma bruta ou transformado pela "transformação Box-Cox" (equação 1), numa tentativa de modificar a série temporal não normalmente distribuída em normalmente distribuída. A necessidade ou não dessa transformação será baseada em testes estatísticos que verificam a distribuição normal da série temporal (Hipel \& McLeod, 1994).

$$
x_{t}^{(\lambda)}= \begin{cases}\lambda^{-1}\left[\left(x_{t}+c\right)^{\lambda}-1\right] & \lambda \neq 0 \\ \log \left(x_{t}+c\right) & \lambda=0\end{cases}
$$

2. Remoção de tendência da vazão: Certos parâmetros de qualidade são diretamente dependentes da vazão. Conseqüentemente, uma tendência na série de vazão pode acarretar uma falsa tendência no parâmetro. A tendência da série de vazão é eliminada traçando-se o hidrograma juntamente com uma curva de regressão RLWRS ("Robust Locally Wighted Regression Smooth”, Cleveland, 1979; Hipel \& McLeod, 1994). A curva residual, que é a diferença entre os valores observados e a regressão, é a série 
temporal da vazão sem tendências (Hipel \& McLeod, 1994) que será chamada aqui VST.

3. Obtenção da série do parâmetro ajustado à série da vazão sem a tendência (VST): Traçando-se a curva "VST x parâmetro" e a respectiva regressão RLWRS, podese observar se existe dependência entre o parâmetro e a vazão. Essa dependência é eliminada pela obtenção do residual que é a série final do parâmetro (PAV, parâmetro ajustado à vazão), já sem os efeitos das tendências da vazão e da dependência parâmetrovazão. A curva "PAV x tempo" mostra visualmente, novamente através do auxílio da regressão RLWRS, a existência de possíveis tendências.

4. Teste de sazonalidade: Os testes estatísticos a serem empregados dependem da existência ou não de sazonalidade na série final obtida (PAV). Com essa finalidade são empregadas duas técnicas: gráficos Box-Whisker (Tukey, 1997; Hipel \& McLeod, 1994) e teste de Kruskall-Wallis (Krusckal \& Wallis, 1952; Hipel \& McLeod, 1994).

5. Série sem sazonalidade: $O$ teste estatístico empregado para a verificação se a tendência é estatisticamente significativa ou não é o teste de Mann-Kendall (Hipel \& McLeod, 1994). Este é um teste não paramétrico baseado num processo de hierarquização ("rank") dos dados (Moraes et al., 1998) .

6. Série com sazonalidade: Neste caso é empregado o teste Sazonal de Mann-Kendall (Hirsch, 1991). Trata-se de um teste não paramétrico no qual os dados são agrupados dentro de blocos sazonais, e então testados quanto à tendência dentro de cada bloco, utilizando um procedimento de hierarquia (Evans \& Jenkins, 2000).

As regressões RLWRS, a curva residual e os testes estatísticos são aplicados às séries utilizando-se as ferramentas do programa MHTS ("The McLeod-Hipel Time Series Package", Hipel \& McLeod, 1994).

Os postos de monitoramento de vazão, precipitação e qualidade de água são apresentados nas tabelas 2, 3 e 4, respectivamente. É importante ressaltar que o período de estudo utilizado foi de 1979 a 2001. 
Tabela 2. Relação dos postos de vazão das bacias do projeto BIOTASP

\begin{tabular}{ccccc}
\hline Postos & Latitude & Longitude & Bacia & Rio \\
\hline 4D-007 & $22^{\circ} 40^{\prime}$ & $47^{\circ} 46^{\prime}$ & Piracicaba & Piracicaba \\
4D-001 & $22^{\circ} 39^{\prime}$ & $47^{\circ} 12^{\prime}$ & Piracicaba & Jaguari \\
3D-006 & $22^{\circ} 58^{\prime}$ & $46^{\circ} 49^{\prime}$ & Piracicaba & Atibaia \\
4C-007 & $21^{\circ} 41^{\prime}$ & $47^{\circ} 48^{\prime}$ & Mogi-Guaçu & Mogi-Guaçu \\
5B-004 & $20^{\circ} 51^{\prime}$ & $48^{\circ} 58^{\prime}$ & Turvo Grande & Turvo \\
6C-008 & $21^{\circ} 03^{\prime}$ & $49^{\circ} 03^{\prime}$ & Turvo Grande & Turvo \\
7D-010 & $22^{\circ} 18^{\prime}$ & $50^{\circ} 01^{\prime}$ & Peixe & Peixe \\
8C-004 & $21^{\circ} 25^{\prime}$ & $51^{\circ} 00^{\prime}$ & Aguapeí & Aguapé \\
7B-007 & $20^{\circ} 31^{\prime}$ & $50^{\circ} 35^{\prime}$ & São José dos Dourados & São José dos Dourados \\
5E-002 & $23^{\circ} 57^{\prime}$ & $48^{\circ} 56^{\prime}$ & Alto do Paranapanema & Taquari \\
5E-003 & $23^{\circ} 56^{\prime}$ & $48^{\circ} 12^{\prime}$ & Alto do Paranapanema & Paranapanema \\
\hline
\end{tabular}

Tabela 3. Relação dos postos de precipitação das bacias do projeto BIOTASP

\begin{tabular}{ccccc}
\hline Postos & Latitude & Longitude & Bacia & Município \\
\hline D4-036 & $22^{\circ} 18^{\prime}$ & $47^{\circ} 45^{\prime}$ & Piracicaba & Itirapina \\
D4-043 & $22^{\circ} 13^{\prime}$ & $47^{\circ} 45^{\prime}$ & Piracicaba & Corumbataí \\
D4-059 & $22^{\circ} 29^{\prime}$ & $47^{\circ} 31^{\prime}$ & Piracicaba & Sta. Gertrudes \\
D4-029 & $22^{\circ} 15^{\prime}$ & $47^{\circ} 23^{\prime}$ & Mogi-Guaçu & Araras \\
D4-034 & $22^{\circ} 16^{\prime}$ & $47^{\circ} 19^{\prime}$ & Mogi-Guaçu & Araras \\
B5-035 & $20^{\circ} 51^{\prime}$ & $48^{\circ} 48^{\prime}$ & Turvo Grande & Cajobi \\
C4-092 & $21^{\circ} 52^{\prime}$ & $47^{\circ} 48^{\prime}$ & Turvo Grande & São Carlos \\
D6-025 & $22^{\circ} 12^{\prime}$ & $49^{\circ} 56^{\prime}$ & Peixe & Marília \\
D7-074 & $22^{\circ} 16^{\prime}$ & $50^{\circ} 06^{\prime}$ & Peixe & Marília \\
C7-006 & $21^{\circ} 44^{\prime}$ & $50^{\circ} 07^{\prime}$ & Aguapeí & Getulina \\
C7-064 & $21^{\circ} 42^{\prime}$ & $50^{\circ} 18^{\prime}$ & Aguapeí & Luisiania \\
C7-075 & $21^{\circ} 37^{\prime}$ & $50^{\circ} 55^{\prime}$ & Aguapeí & Salmorão \\
B6-038 & $28^{\circ} 26^{\prime}$ & $50^{\circ} 32^{\prime}$ & São José dos Dourados & Ponta Linda \\
B6-048 & $20^{\circ} 37^{\prime}$ & $49^{\circ} 57^{\prime}$ & São José dos Dourados & Sebastianópolis do Sul \\
B7-011 & $20^{\circ} 26^{\prime}$ & $50^{\circ} 03^{\prime}$ & São José dos Dourados & Valentim Gentil \\
E5-015 & $23^{\circ} 35^{\prime}$ & $48^{\circ} 03^{\prime}$ & Alto Paranapanema & Itapetininga \\
E5-066 & $23^{\circ} 47^{\prime}$ & $48^{\circ} 21^{\prime}$ & Alto Paranapanema & Itapetininga \\
E5-071 & $23^{\circ} 57^{\prime}$ & $48^{\circ} 25^{\prime}$ & Alto Paranapanema & Capão Bonito \\
\hline
\end{tabular}


Tabela 4. Relação dos postos de qualidade de água das bacias do projeto BIOTASP

\begin{tabular}{cccccc}
\hline Mapa & Postos & Latitude & Longitude & Bacia & Rio \\
\hline 1 & PI2800 (PI) & $22^{\circ} 40^{\prime}$ & $47^{\circ} 46^{\prime}$ & Piracicaba & Piracicaba \\
2 & JA2800 (JA) & $22^{\circ} 39^{\prime}$ & $47^{\circ} 16^{\prime}$ & Piracicaba & Jaguari \\
3 & AT2065 (AT) & $22^{\circ} 54^{\prime}$ & $48^{\circ} 58^{\prime}$ & Piracicaba & Atibaia \\
4 & MG2200 (MG1) & $22^{\circ} 31^{\prime}$ & $47^{\circ} 16^{\prime}$ & Mogi-Guaçu & Mogi-Guaçu \\
5 & MG2900 (MG2) & $21^{\circ} 02^{\prime}$ & $48^{\circ} 18^{\prime}$ & Mogi-Guaçu & Mogi-Guaçu \\
6 & TU2250 (TU1) & $20^{\circ} 45^{\prime}$ & $49^{\circ} 06^{\prime}$ & Turvo Grande & Turvo \\
7 & TU2500 (TU2) & $20^{\circ} 25^{\prime}$ & $49^{\circ} 16^{\prime}$ & Turvo Grande & Turvo \\
8 & PX2100 (PX1) & $22^{\circ} 18^{\prime}$ & $50^{\circ} 03^{\prime}$ & Peixe & Peixe \\
9 & PX2800 (PX2) & $21^{\circ} 36^{\prime}$ & $51^{\circ} 14^{\prime}$ & Peixe & Peixe \\
10 & AG2100 (AG1) & $21^{\circ} 40^{\prime}$ & $50^{\circ} 35^{\prime}$ & Aguapeí & Aguapeí \\
11 & AG2800 (AG2) & $21^{\circ} 13^{\prime}$ & $51^{\circ} 30^{\prime}$ & Aguapeí & Aguapeí \\
12 & JD2500 (JD) & $20^{\circ} 30^{\prime}$ & $50^{\circ} 31^{\prime}$ & São José dos Dourados & São José dos Dourados \\
13 & TQ2400 (TQ) & $23^{\circ} 58^{\prime}$ & $48^{\circ} 54^{\prime}$ & Alto do Paranapanema & Taquari \\
14 & PR2100 (PR) & $23^{\circ} 36^{\prime}$ & $48^{\circ} 29^{\prime}$ & Alto do Paranapanema & Paranapanema \\
\hline
\end{tabular}

\subsection{Descrição da metodologia estatística empregada}

Os métodos estatísticos utilizados relacionados acima serão descritos sucintamente abaixo.

\subsubsection{Teste de normalidade}

A normalidade da distribuição é verificada pelo ajuste das variáveis estudadas com a linha reta. Se os dados $X_{1}, \ldots, X_{n}$ são normalmente distribuídos com uma média de $\mu$ e variância de $\sigma^{2}$, então os valores aparecem em uma linha reta com inclinação $\sigma^{-1} \mathrm{e} x$ é intercepto de $\mu$, uma linha com $\mathrm{x}$ igual $\bar{X}={ }^{1} / \mathrm{n} \sum \mathrm{X}_{\mathrm{i}}$ e inclinação igual $\sigma^{\text {,-1 }}$, onde $\sigma^{,-1}=1 / n-1 \sum\left(X_{i}-\bar{X}\right)^{2}$.

Essa metodologia, no programa MHTS ("The McLeod-Hipel Time Series Package", Hipel \& McLeod, 1994), é completada pela realização de outros testes estatísticos que comprovam a normalidade da distribuição. Esses testes são: 
A. Teste de assimetria da distribuição $\left(\mathrm{g}_{1}\right)$, que é dado pela equação abaixo:

$$
g_{1}=\frac{\frac{1}{n} \sum_{i=1}^{n}\left(X_{i}-\bar{X}\right)^{3}}{\left(\frac{1}{n} \sum_{i=1}^{n}\left(X_{i}-\bar{X}\right)^{2}\right)^{\frac{3}{2}}}
$$

Se $g_{1}>0$, a distribuição apresenta deslocamento positivo (à direita) com relação à média, se $\mathrm{g}_{1}<0$, a distribuição apresenta deslocamento negativo (à esquerda).

B. Teste de aderência através da estatística de Michael (Dsp), considerada por Hipel e McLeod (1994) como mais robusta do que o teste de Kolmogoroff-Smirnoff. Essa estatística é obtida aplicando-se a transformação da variância estabilizada para o método de Kolmogoroff-Smirnoff. Seja $\mathrm{p}_{\mathrm{i}}=(\mathrm{i}-0,5) / \mathrm{n}, \mathrm{i}=1, \ldots, \mathrm{n}$. Dsp é calculada pela equação:

$$
\operatorname{Dsp}=\operatorname{Max}\left|g\left(f_{i}\right)-g\left(p_{i}\right)\right|
$$

onde:

$$
\begin{aligned}
& g(x)=(2 / \pi) \sin ^{-1}(\sqrt{x}) \\
& f_{i}=\phi\left(\left(X_{(i)}-\bar{X}\right) / \sqrt{v}\right) \\
& v=\sum\left(X_{i}-\bar{X}\right)^{2} / n
\end{aligned}
$$

onde: $\Phi$ função da distribuição normal padrão.

Royston (1993) fornece um algoritmo para determinar o nível de significância de um valor de Dsp sob a hipótese de que os dados são independentes com constante variância e também discute o nível de significância no gráfico de probabilidade normal. 
O gráfico produzido pelo MHTS mostra o limite de significância de $0,5 \%$. O valor da estatística Dsp e o nível de significância são também apresentados.

C. Teste de Wilk-Shapiro para a aderência à linha reta, é similar ao coeficiente de determinação na regressão $\mathrm{R}^{2}$ com os valores de $\mathrm{W}$ no intervalo entre 0 e 1 .

$$
W=b^{2} / \sum_{t=1}^{n} \hat{a}_{t}^{2}
$$

onde $\mathrm{b}^{2}$ é proporcional à melhor estimativa linear da inclinação da regressão de $\hat{\mathrm{a}}_{(\mathrm{i})}$ no valor esperado do $i_{\text {ésimo }}$ ordem estatística normal.

Quanto mais próximo de 1, melhor o ajuste. Segundo McLeod \& Hipel (1994) esse teste é o mais robusto na verificação da normalidade de uma série de dados.

\subsubsection{Regressão RLWRS}

A regressão RLWRS é um ajuste ponderado de mínimos quadrados (Helsel e Hirsch, 1995). Para todo $\mathrm{X}_{0}$, um $\hat{Y}$ é calculado através de uma regressão ponderada (WLS - “Weighted Least Squares"), cujos pesos são uma função da distância de $\mathrm{X}_{\mathrm{o}}$ e da magnitude do residual da regressão precedente (procedimento interativo). A regressão robusta de pesos $w_{i}$ é calculada por:

$$
w_{i}=w x_{i}^{*} w r_{i}
$$

onde $w x_{i}$, é o peso relacionado à distância, que é uma função da distância entre o centro das distâncias entre $\mathrm{X}_{\mathrm{i}}$ e todos outros $\mathrm{X}$. O peso do residual $w r_{i}$, é uma função de $\mid \mathrm{Y}_{\mathrm{i}}$ $\hat{Y}_{\mathrm{i}} \mid$, da distância na direção $\mathrm{Y}$ entre o $\mathrm{Y}_{\mathrm{i}}$ observado e o valor predito previamente pela regressão WLS. Um ponto receberá um peso menor, e conseqüentemente terá pouca influência no $\hat{Y}$ (valor alisado), se a distância na direção $\mathrm{X}$ ou ainda se o residual na direção $\mathrm{Y}$ for grande. Para um ponto $\left(\mathrm{X}_{\mathrm{i}}, \mathrm{Y}_{\mathrm{i}}\right)$, o peso biquadrado é determinado como: 


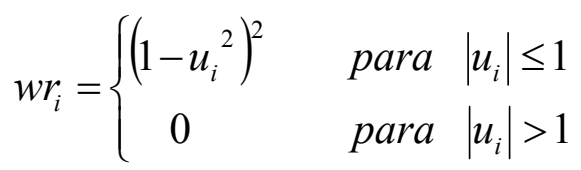

onde $u_{i}=\frac{Y_{i}-\hat{Y}_{i}}{6^{*} \text { mediana de }\left|Y_{i}-\hat{Y}_{i}\right|}$

e $\quad w x_{i}=\left\{\begin{array}{cc}\left(1-v_{i}^{2}\right)^{2} & \text { para }\left|v_{i}\right| \leq 1 \\ 0 & \text { para }\left|v_{i}\right|>1\end{array}\right.$

onde $v_{i}=\frac{X_{i}-X}{d_{x}}$

onde $d_{x}=$ metade da largura da janela de distribuição dos pesos $=m_{\text {ésimo }}$ maior $\left|X_{i}-X\right|$

$\mathrm{m}=\mathrm{N} * \mathrm{f}$

$\mathrm{N}=$ número de observações

$\mathrm{f}=$ fator de alisamento

O grau de alisamento do RLWRS pode ser variado alterando-se a largura da distribuição dos pesos que é controlada por um fator de alisamento f. Com o aumento de f, aumenta-se o número de pontos que influenciam na magnitude do valor alisado $\hat{Y}$. A seleção de um $\mathrm{f}$ apropriado é determinada subjetivamente de acordo com a finalidade do alisamento (Helsel \& Hirch, 1995). Segundo Hipel \& McLeod (1994), frequentemente o valor $\mathrm{f}=0.5$ produz resultados razoáveis de alisamento. Esse foi o valor adotado no presente estudo. 


\subsubsection{Teste de sazonalidade de Kruskal-Wallis}

Nesse teste diversos grupos de dados são comparados, para determinar se as medianas são significativamente diferentes.

Todas as observações são ordenadas de 1 a $\mathrm{N}$, do menor para o maior. $\mathrm{O}$ posto de um valor em um conjunto de $\mathrm{N}$ valores é um número que indica sua posição no conjunto ordenado. Os postos $\mathrm{R}_{\mathrm{ij}}$ são então usados para o cálculo do teste estatístico, ou seja, dentro de cada grupo, a média dos postos de cada grupo $\overline{\mathrm{R}}_{\mathrm{j}}$ é calculada pela equação:

$$
\bar{R}_{j}=\frac{\sum_{i=1}^{n_{j}} R_{i j}}{n_{j}}
$$

Quando as observações são iguais, atribuir a média do seu posto para cada.

$\mathrm{O}$ teste estatístico K de Kruskal-Wallis é:

$$
K=\frac{12}{N(N+1)} \sum_{j=1}^{k} n_{j}\left[\bar{R}_{j}-\frac{N+1}{2}\right]^{2}
$$

$\mathrm{H}_{\mathrm{o}}$ : todos os grupos tem distribuição idêntica, contra

$\mathrm{H}_{1}$ : ao menos uma distribuição é diferente.

Rejeitamos $\mathrm{H}_{\mathrm{o}}$ se $\mathrm{K} \geq \mathrm{K}_{\text {crit }}$, onde $\mathrm{K}_{\text {crit }}$ é tal que $\mathrm{P}_{\mathrm{Ho}}\left(\mathrm{K} \geq \mathrm{K}_{\text {crit }}\right)=\alpha, \alpha=$ nível de significância do teste. 


\subsubsection{Testes de tendência não sazonal e sazonal}

O teste estatístico empregado para verificar-se se a tendência é estatisticamente significativa ou não é o teste não paramétrico de Mann-Kendall (Hipel \& McLeod, 1994). Seja uma série temporal de observações, $x_{1}, x_{2}, \ldots, x_{n}$, Mann (1945) propôs para hipótese nula, $\mathrm{H}_{\mathrm{o}}$, que o dado vindo de uma população onde as variáveis aleatórias são independentes e igualmente distribuídas. A hipótese alternativa, $\mathrm{H}_{1}$, é que os dados seguem uma tendência monotônica no tempo. Sob $\mathrm{H}_{0}$, o teste estatístico de MannKendall é:

$$
S=\sum_{k=1}^{n_{i}-1} \sum_{j=k+1}^{n} \operatorname{sgn}\left(x_{j}-x_{k}\right)
$$

onde

$$
\operatorname{sgn}(x)=\left\{\begin{array}{cc}
+1 & x>0 \\
0 & x=0 \\
-1 & x<0
\end{array}\right.
$$

Kendall (1975) mostra que S é normalmente distribuída, e a média e a variância de S, para uma situação na qual pode haver valores iguais nos valores de $\mathrm{x}$, são calculadas pelas equações abaixo:

$$
\begin{aligned}
& E\left[S_{i}\right]=0 \\
& \operatorname{Var}[S]=\frac{n(n-1)(2 n+5)-\sum_{j=1}^{p} t_{j}\left(t_{j}-1\right)\left(2 t_{j}+5\right)}{18}
\end{aligned}
$$

onde $\mathrm{p}$ é o número de grupos contendo valores iguais na série de dados e $\mathrm{t}_{\mathrm{j}}$ é o número de dados com valores iguais num certo grupo $\mathrm{j}$. 
Usando a equação (12), um valor positivo de $S$ indica tendência positiva na qual os dados crescem com o tempo. Por outro lado, um valor negativo de $\mathrm{S}$ indica uma tendência negativa. Sabendo-se que S é normalmente distribuído e tem média zero e variância dada pela equação (13), pode-se checar se a tendência positiva ou negativa é significantemente diferente de zero. Se $\mathrm{S}$ é significantemente diferente de zero, $\mathrm{H}_{\mathrm{o}}$ pode ser rejeitada para certo nível de significância apontando para a existência de tendência ( $\mathrm{H}_{1}$ é aceita).

Mann (1945) e Kendall (1975) mostraram que mesmo para valores pequenos de $\mathrm{n}$, pode-se assumir uma distribuição normal desde que o valor da estatística $\mathrm{Z}$ seja dado por:

$$
Z=\left\{\begin{array}{ccc}
\frac{S-1}{(\operatorname{Var}(S))^{1 / 2}} & \text { se } & S>0 \\
0 & \text { se } & S=0 \\
\frac{S+1}{(\operatorname{Var}(S))^{1 / 2}} & \text { se } & S<0
\end{array}\right.
$$

Num teste bilateral para tendência, Ho deve ser aceito se $|Z| \leq Z_{\alpha / 2}$, onde $F_{N}\left(Z_{\alpha / 2}\right)=\alpha / 2$, sendo $F_{N}$ o valor de distribuição normal cumulativa e a o nível de significância do teste.

O teste Sazonal de Kendall avalia sazonalmente o teste de Mann-Kendall separadamente em cada estação, e então combina os resultados. Assim para "estações" mensais, dados de janeiro são comparados somente com janeiro, fevereiro só com fevereiro, e assim por diante. As estatísticas $\mathrm{S}_{\mathrm{i}}$ de Kendall para cada estação são somadas para formar a estatística geral $\mathrm{S}_{\mathrm{k}}$. 


$$
S_{k}=\sum_{i=1}^{m} S_{i}
$$

Quando o produto do número de estações pelo número de anos é maior que 25, a distribuição do $S_{k}$ pode ser aproximada de uma distribuição normal. $S_{k}$ é padronizado pela subtração da esperança $\mu_{\mathrm{k}}=0$ dividindo-se pelo desvio padrão $\sigma_{\mathrm{Sk}}$. O resultado é avaliado através de uma tabela padrão de distribuição normal.

$$
Z_{S k}=\left\{\begin{array}{lll}
\frac{S_{k}-1}{\sigma_{S k}} & \text { se } & S_{k}>0 \\
0 & \text { se } & S_{k}=0 \\
\frac{S_{k}+1}{\sigma_{S k}} & \text { se } & S_{k}<0
\end{array}\right.
$$

onde

$$
\begin{aligned}
& \mu_{S k}=0 \\
& \sigma_{S k}=\sqrt{\sum_{i=1}^{m}\left(n_{i} / 18\right) *\left(n_{i}-1\right) *\left(2 n_{i}+5\right)} \\
& n_{i}=\text { número de dados em ith estações }
\end{aligned}
$$

A hipótese nula é rejeitada com o nível de significância $\alpha$ se $\left|Z_{S k}\right|>Z_{\text {crit }}$, onde $Z_{\text {crit }}$ é o valor padrão da distribuição normal com uma probabilidade $\alpha / 2$. Caso a hipótese nula seja rejeitada, significará a existência significativa de tendência, sendo que o sinal da estatística $S_{k}$ indica que a tendência é positiva $\left(S_{k}>0\right)$ ou negativa $\left(S_{k}<0\right)$. 


\subsection{Metodologia para determinação da magnitude}

A magnitude das tendências foi obtida através do coeficiente de regressão "Sen's slope" (Sen, 1968), utilizando-se valores médios anuais. Pois, como observado por Hirsch et al. (1982), o valor do coeficiente angular obtido pela regressão linear é muito mais sensível a valores extremos que o valor do estimador sazonal de inclinação de Kendall ("Seazonal Kendall Slope Estimator"). Esse estimador, desenvolvido por Hirsch et al. (1982), é utilizado para séries temporais com sazonalidade e vem sendo utilizado na quantificação de tendências em diversos estudos (Burn, 1994; Osburn et. al., 2002; Langrand et al., 1998).

\subsection{Metodologia de análise estatística de mudança brusca em séries temporais}

O teste de Pettitt (Pettitt,1979), também não paramétrico, utiliza uma versão do teste de Mann-Whitney na qual se verifica se duas amostras $\mathrm{Y}_{1}, \ldots, \mathrm{Y}_{\mathrm{t}}$ e $\mathrm{Y}_{\mathrm{t}+1}, \ldots, \mathrm{Y}_{\mathrm{T}}$ são da mesma população. A estatística $U_{t, T}$ faz uma contagem do número de vezes que um membro da primeira amostra é maior que um membro da segunda, e pode ser escrita:

$$
U_{t, T}=U_{t-1, T}+\sum_{j=1}^{T} \operatorname{sgn}\left(Y_{t}-Y_{j}\right)
$$

para $\mathrm{t}=2, \ldots, \mathrm{T}$

onde : $\operatorname{sgn}(x)=1$ para $x>0$;

$\operatorname{sgn}(x)=0$ para $x=0$;

$\operatorname{sgn}(x)=-1$ para $x<0$.

A estatística $U_{t, T}$ é então calculada para os valores de $1 \leq \mathrm{t} \leq \mathrm{T}$ e a estatística $\mathrm{k}(\mathrm{t})$ do teste de Pettitt é o máximo valor absoluto de $\mathrm{U}_{\mathrm{t}, \mathrm{T}}$. Esta estatística localiza o ponto onde houve uma ruptura ("changing point") de uma série temporal e a sua significância pode ser calculada aproximadamente pela equação :

$$
\mathrm{p} \cong 2 \exp \left\{-6 \mathrm{k}(\mathrm{t})^{2} /\left(\mathrm{T}^{3}+\mathrm{T}^{2}\right\}\right.
$$




\subsection{Metodologia de Análise de Agrupamento}

A técnica classificatória multivariada da análise de agrupamento ("Cluster Analysis") é utilizada quando se deseja explorar as similaridades entre indivíduos ou entre variáveis, definindo-os em grupos (Johnson \& Wichern, 1982). Para tal finalidade consideram-se simultaneamente, no primeiro caso, todas as variáveis medidas em cada indivíduo e, no segundo, todos os indivíduos nos quais foram feitas as mesmas medidas. Essa análise agrupa um conjunto de $\mathrm{n}$ amostras com $\mathrm{m}$ variáveis, de acordo com as suas similaridades, utilizando conceitos geométricos (Martins, 1994).

Partindo-se do espaço de $\mathrm{N}$ dimensões (variáveis ou amostras), são calculadas as distâncias entre os pontos (objetos) desse espaço. A partir daí, agrupam-se os objetos com distâncias menores. Sobre esses grupos, são calculadas novamente distâncias entre eles, formando um segundo nível de agrupamento, e assim sucessivamente. O método de agrupamento escolhido para ser aplicado foi o de Ward's ou variância mínima (Johnson \& Wichern, 1982; Yung et al., 1999; Hannappel \& Piepho, 1996), uma das melhores e mais utilizadas estratégias de agrupamento hierárquico. Nesse método o enfoque é sobre a variabilidade que existe dentro de cada caso, e os agrupamentos são efetuados ao se determinar que pares de casos, quando tomados em conjunto, apresentam o menor acréscimo de variabilidade (Landim, 2000).

O coeficiente de similaridade a ser utilizado é a distância euclidiana dos dados, provavelmente o tipo de distância mais comumente escolhida. Esse coeficiente é simplesmente a distância geométrica no espaço multidimensional.

$$
\operatorname{distância}(\mathrm{x}, \mathrm{y})=\left\{\Sigma_{\mathrm{i}}\left(\mathrm{x}_{\mathrm{i}}-\mathrm{y}_{\mathrm{i}}\right)^{2}\right\}^{1 / 2}
$$

A distância euclidiana é geralmente computada com dados brutos. Este método tem certas vantagens (a distância entre dois objetos não é afetada pela adição de novos parâmetros para analisar, que possam ser anômalos “outlier”). Contudo, a distância pode ser altamente afetada pela diferença na escala entre os parâmetros, e, conseqüentemente, 
o resultado da análise de Cluster pode ser muito diferente. O programa estatístico Statitistica (1999) foi utilizado para essa finalidade.

A proposta para a utilização dessa técnica é agrupar regiões com comportamento similar (Yung et al. 1999; Momem et al., 1996), no intuito de selecionar regiões de comportamento homogêneo e comparar tendências com a metodologia anteriormente descrita.

Esses resultados serão confrontados com a caracterização sócio-econômica das bacias estudadas (população, porcentagem de urbanização, atividades agro-industriais, descarga de poluentes) ao longo dos anos.

\subsection{Preparação dos dados}

A agência responsável pelos dados de qualidade de água é a CETESB. Até 1984 esse monitoramento era realizado mensalmente, passando a ser bimestral a partir de 1985. Neste estudo, foram escolhidas 7 bacias hidrográficas dentro do Estado de São Paulo, com diferentes graus de intervenção, sendo utilizados 14 postos de monitoramento.

Optou-se pela utilização de séries bimestrais, ao invés de completar a série transformando-a em dados mensais através de interpolações. Essa opção pode ser explicada pela não introdução de novas incertezas na análise devido aos métodos de interpolação e pelo problema suplementar de estimar o valor correspondente de vazão no dia dos dados falhos.

Nas séries temporais de qualidade de água podem ocorrer falhas ou valores discrepantes (“outliers"). Estes dados discrepantes podem freqüentemente indicar problemas específicos de medições, descargas pontuais de algum poluente ou ainda valores que representam a variabilidade devido a outras intervenções ocorridas na bacia. Portanto, é necessário identificá-los, classificá-los e removê-los no caso de um valor anômalo esporádico. Transformações Box-Cox foram utilizadas antes de avaliar esses dados discrepantes para que as séries de qualidade da água passem a ter distribuição normal. Essas transformações são também necessárias em algumas análises estatísticas 
propostas por McLeod et al. (1991). Segundo McLeod (comunicação pessoal) a transformação dos dados faz com que eles sejam distribuídos mais simetricamente havendo, portanto, duas vantagens: (a) alguns métodos não paramétricos, tais como a regressão RLWRS assumem que os dados são distribuídos simetricamente e (b) para dados simetricamente distribuídos é mais fácil localizar o centro da distribuição.

Existe a conveniência em análises comparativas entre bacias, como é o caso do presente trabalho, de que as séries para cada parâmetro tenham certa uniformidade, ou seja, quando um parâmetro necessita de transformação na maioria das bacias, é interessante que a mesma seja feita para todas as bacias a serem comparadas com esse parâmetro. Isso uniformiza os procedimentos de análise de valores discrepantes (“outliers") e também a análise da magnitude da tendência.

A decisão sobre a utilização de transformações quando da comparação de diversas áreas não é trivial, uma vez que um mesmo parâmetro pode apresentar características diferentes entre elas (Helsel \& Hirsch, 1995). Foram testados os valores de lambda da transformação Box-Cox iguais a $-2,-1,-1 / 2,0,1 / 2,1$ e 2 . Os valores obtidos nos testes estatísticos de normalidade mostram que uma dada transformação para cada parâmetro, nas diversas bacias, nunca deixa todas as séries normais. Diante desta dificuldade, houve a necessidade da criação de um critério para a escolha da transformação mais adequada. Considerou-se que um valor de $\mathrm{W}$ do teste de WilkShapiro próximo de 1 apontava para um bom ajuste, mesmo que às vezes a normalidade se apresentasse como sendo não significativa. Essa premissa foi assumida, já que W mede a qualidade do ajuste entre os dados e a distribuição normal, sendo que ele varia entre 0 e 1 , similar ao $\mathrm{R}^{2}$ de uma regressão, sendo que valores próximos de 1 mostram um bom ajuste. Segundo McLeod \& Hipel (1994) esse teste é o mais robusto na verificação da normalidade de uma série de dados.

Esse critério levou à transformação dos dados com Log (lambda=0) para os parâmetros DBO, nitrogênio amoniacal, fósforo total, cloreto, coliformes fecais e a vazão. Para os outros parâmetros não foi utilizada nenhuma transformação. Os valores de W e sua significância são apresentados no anexo A. 
Mesmo depois das transformações Box-Cox, alguns valores discrepantes necessitaram ser removidos. O critério para identificação desses dados discrepantes é subjetivo, entretanto, no presente trabalho, foi adotado como sendo as observações abaixo ou acima de 3 desvios padrões da média ( $\bar{X} \pm 3 \mathrm{~s}$ ), similar ao adotado por Forester (2000). Entretanto, se o parâmetro for encontrado com valores anteriores e posteriores da mesma ordem de grandeza, indicando a persistência da anomalia, análises complementares para verificar a coerência das medidas devem ser realizadas. No caso da anomalia confirmada, optou-se pela substituição do valor anômalo pelo valor médio da série, uma vez que a presente análise necessita de séries contínuas. A Figura 2 mostra um exemplo da serie temporal de OD antes (a) e após (b) a substituição de um valor discrepante. 
Piracicaba - OD

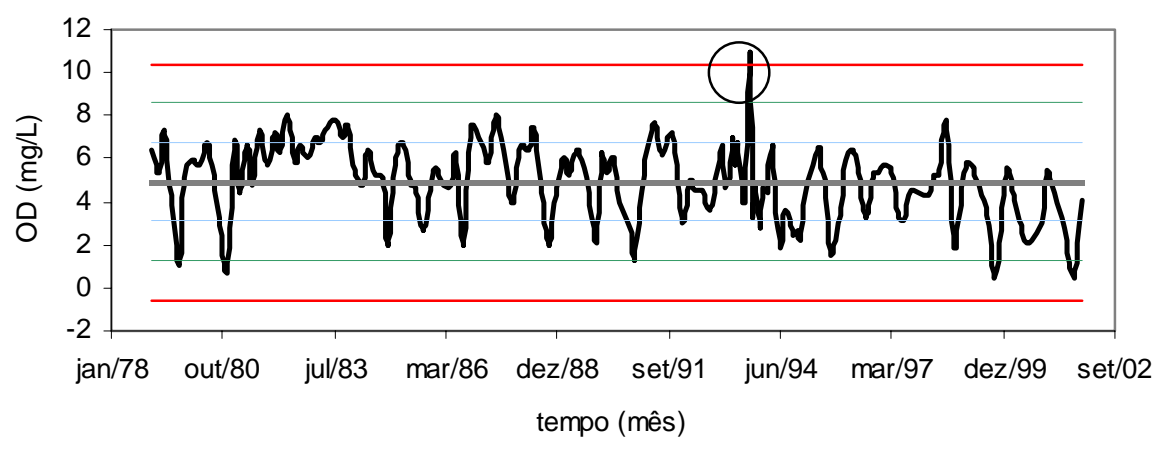

a)

$\longrightarrow$ OD 1 stdev 2 stdev $-3 \operatorname{stdev} \longleftarrow$ média

Piracicaba - OD

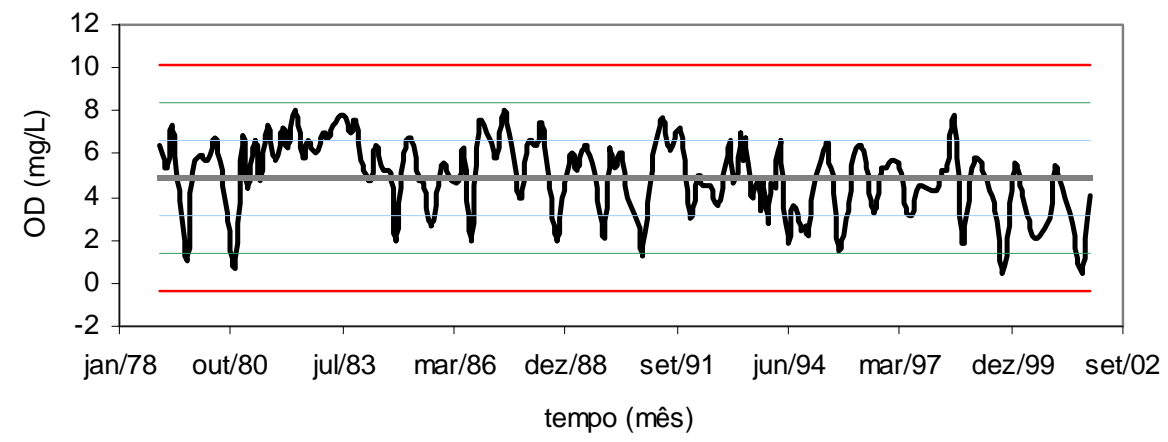

b)

\begin{tabular}{|c|c|}
\hline$\longrightarrow \mathrm{OD}$ & $1 \mathrm{stdev} \quad 2 \mathrm{stdev}-3 \mathrm{stdev}=$ média \\
\hline
\end{tabular}

Figura 2 - Verificação de anomalias nas series temporais de OD na bacia do rio Piracicaba mostrando a série original (a) e a corrigida (b). Os número de desvios padrão (stdev) apresentados são 1, 2, e 3 


\section{RESULTADOS E DISCUSSÕES}

\subsection{Análise de tendências}

Para ilustrar a metodologia utilizada será demonstrado o caso do OD para a bacia do rio Piracicaba.

Como descrito na metodologia, primeiramente foi testada a normalidade das séries. O teste de normalidade para o caso do OD é mostrado na Figura 3, onde a distribuição normal é verificada pela qualidade do ajuste das variáveis com a linha reta. Esse teste ainda é completado pela realização de outros testes estatísticos que comprovam a normalidade da distribuição. Esses testes são: o teste de assimetria da distribuição (g1), o teste de aderência através da estatística de Michael (DSP), considerada por Hipel e McLeod (1994) como mais robusta que o teste de KolmogoroffSmirnoff, e ainda o teste de Wilk-Shapiro para a aderência à linha reta. Os testes mostram que o nível de significância foram inferiores a 0,05 , evidenciando que a série testada apresenta distribuição normal. Portanto, para o caso do OD na bacia do rio Piracicaba, não foi necessária a transformação Box-Cox. 


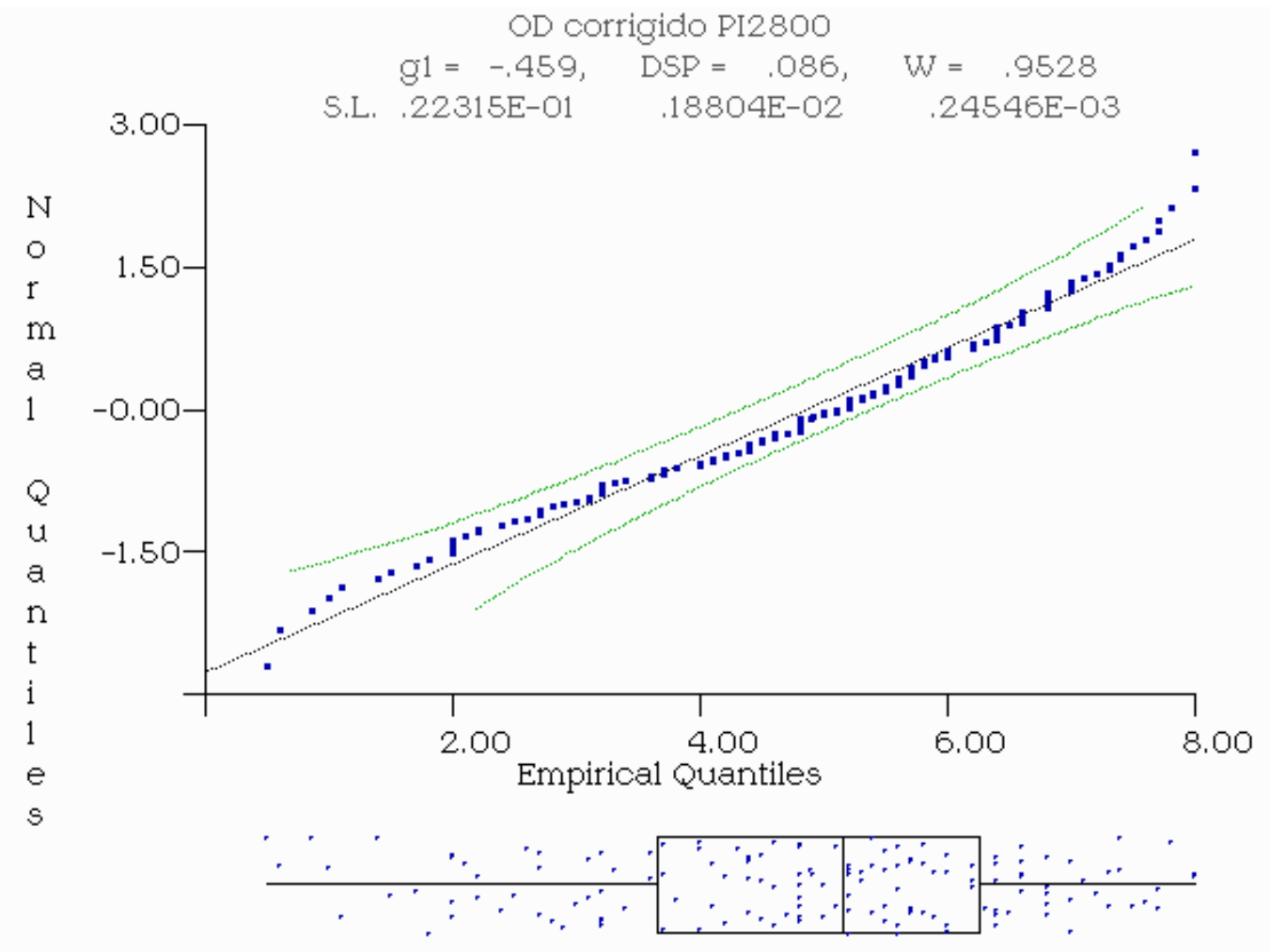

$\# 148$

Figura 3 - Teste de normalidade para Oxigênio Dissolvido

A metodologia empregada necessita da entrada da vazão sem tendências. A regressão RLWRS mostra na Figura 4 que a vazão (Posto 4D-007, no período 1979 a 2001) apresentou uma tendência negativa. A remoção dessa tendência, como descrito anteriormente, é realizada obtendo-se o residual da vazão chamado de VST (vazão sem tendência).

Posteriormente essa vazão é associada ao parâmetro (VST x parâmetro), como mostrado na Figura 5. Pode-se observar que existe uma dependência entre os dois parâmetros, com uma tendência negativa demonstrando que esse parâmetro é influenciado pela vazão do rio. A remoção dessa correlação é realizada novamente com o auxilio da regressão RLWRS, e o residual chamado PAV. 


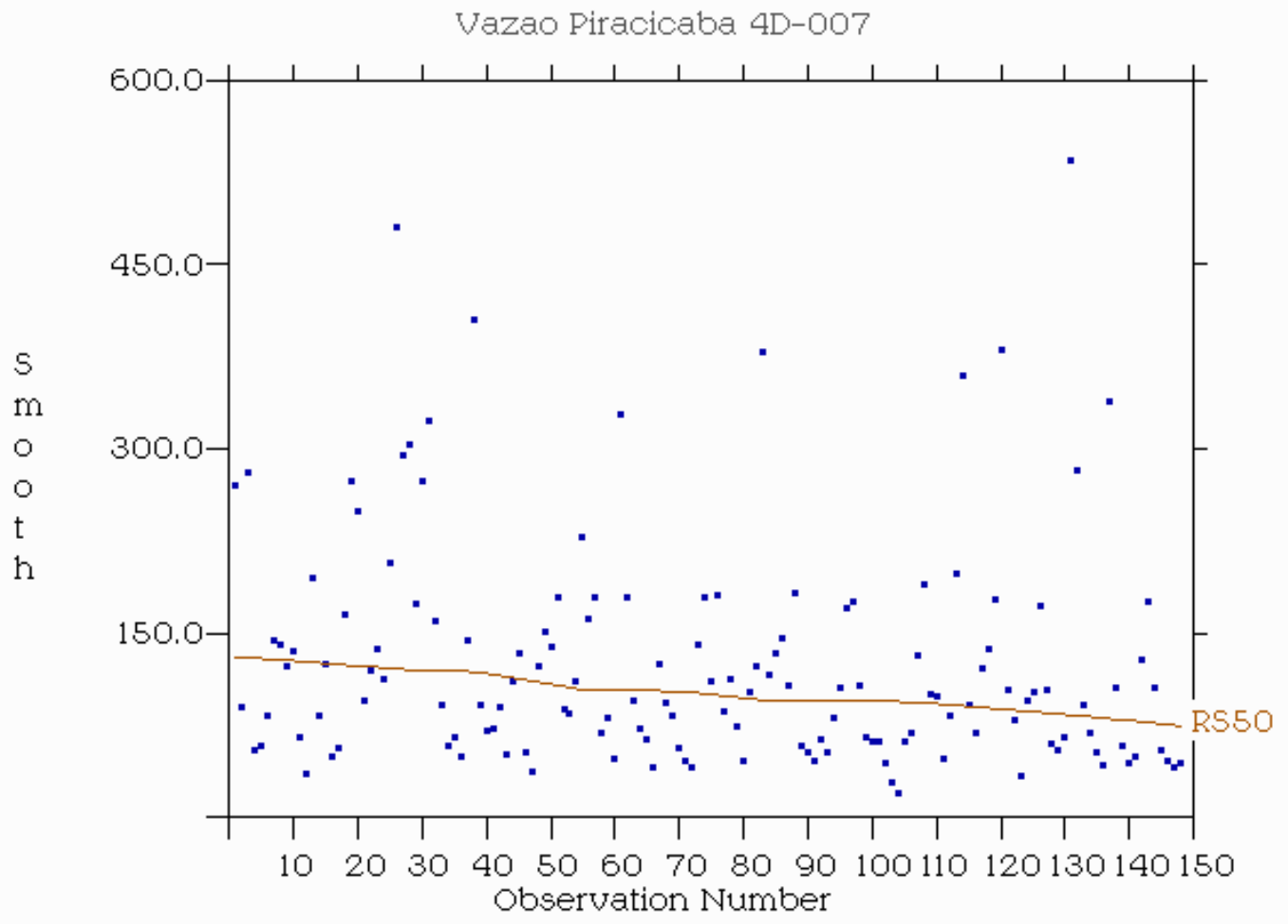

Figura 4 - Regressão RLWRS para o posto de vazão do rio Piracicaba 4D-007, (19792001) 


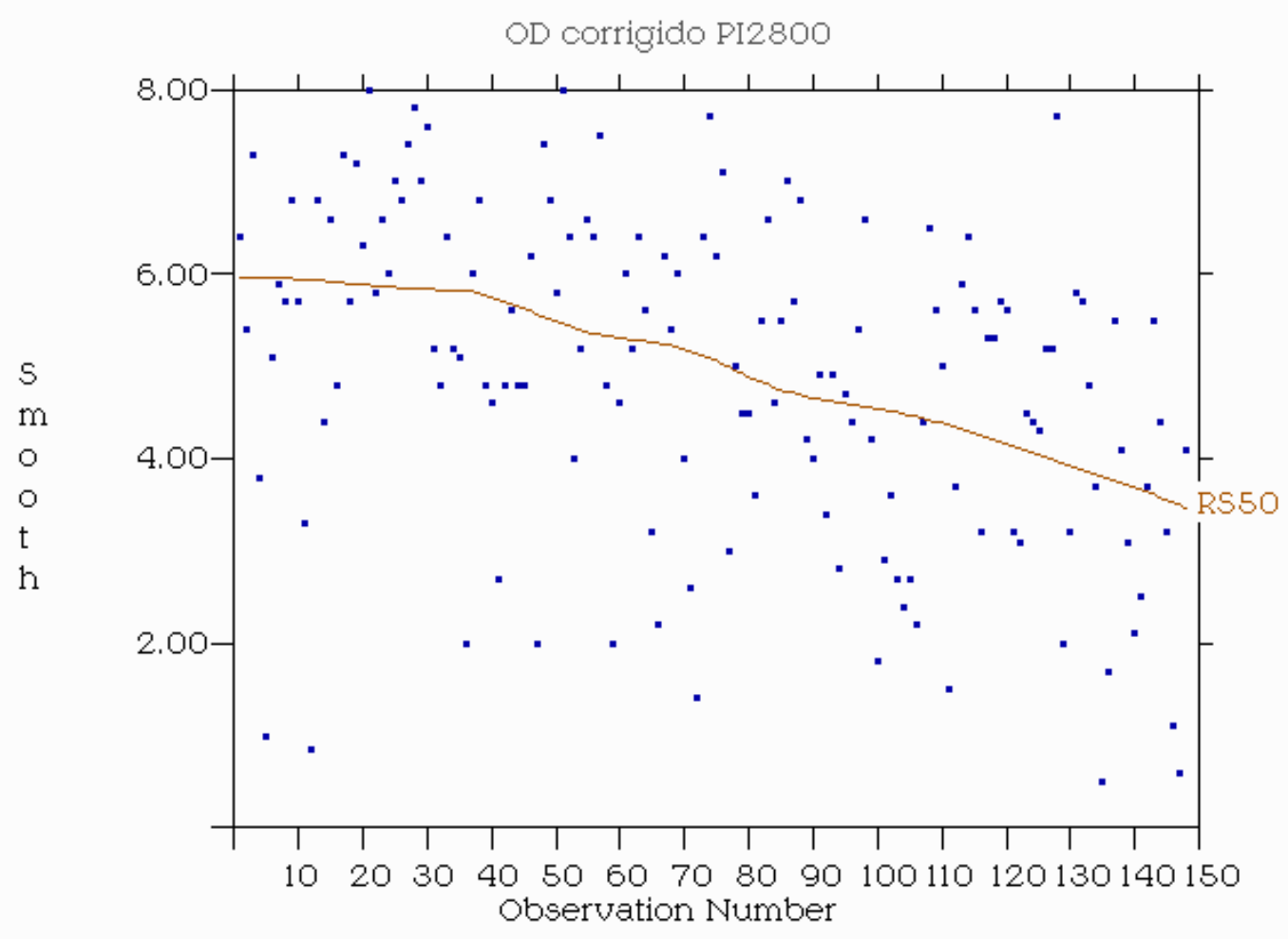

Figura 5 - Regressão RLWRS para OD, posto do rio Piracicaba (PI)

O passo seguinte é a verificação da sazonalidade, necessária para a aplicação adequada dos testes de tendência série PAV. Para tal finalidade foram traçados gráficos do tipo "Box-Plot", que mostram a variabilidade dos parâmetros ao longo do ano (Figura 6). Em adição foi utilizado o método estatístico de Kruskall-Wallis para testar a sazonalidade da série. Pode-se observar para o OD que a série pode ser considerada sazonal. 


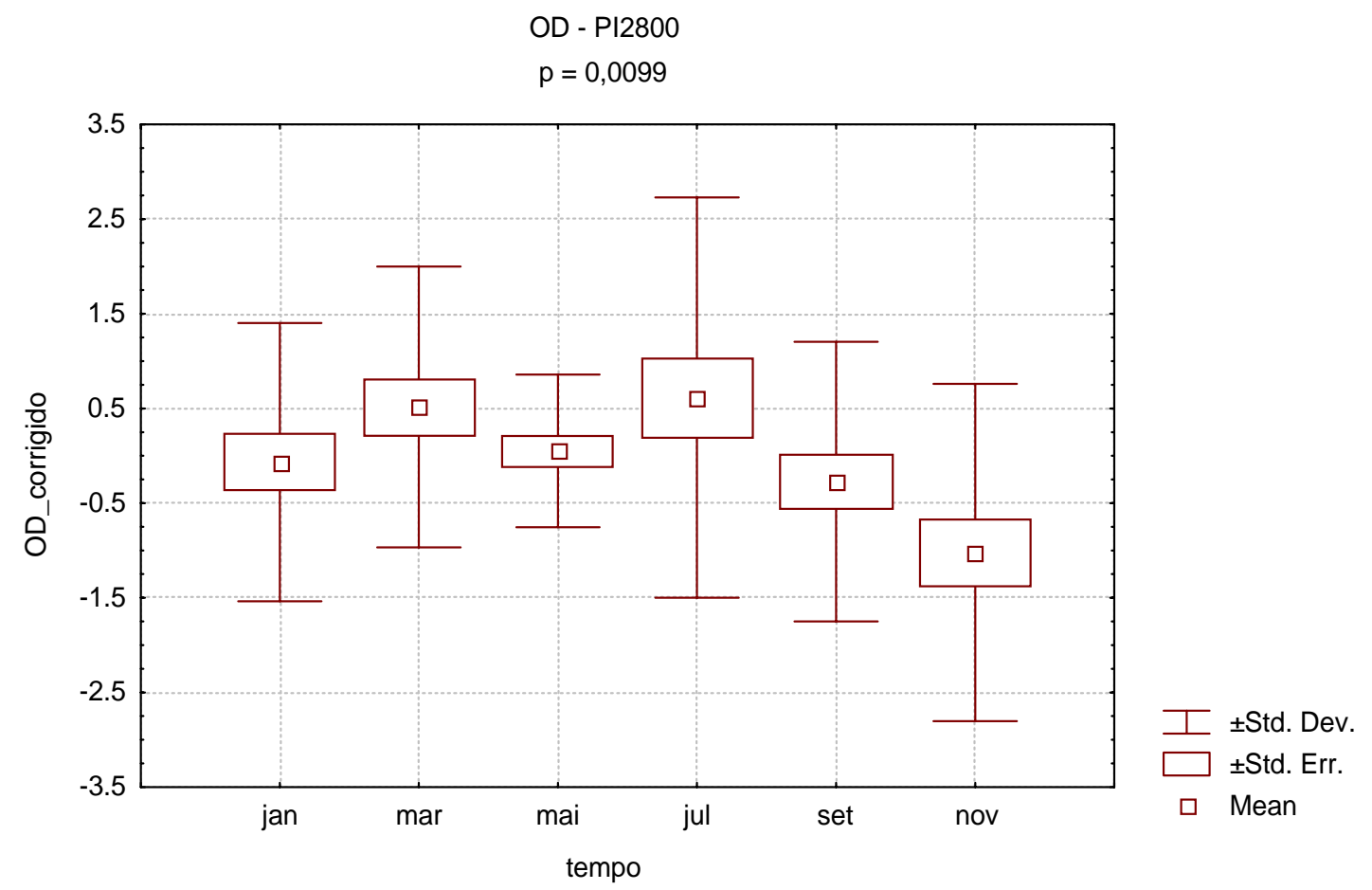

Figura 6 - Gráfico "Box-Plot", com a finalidade de mostrar a variabilidade do OD ao longo do ano

Finalmente, a tendência temporal da série foi testada pelo método de MannKendall, em suas versões sazonal ou não sazonal, dependendo dos resultados dos testes de sazonalidade.

Os resultados da análise de tendência são apresentados na Tabela 5, e as análises dos resultados foram realizados por bacia hidrográfica. 
Tabela 5. Sumário dos resultados das análises de tendências, nível de significância de 5\%, no período de 1979 e 2001 . Sendo que + representa tendência positiva, - tendência negativa, $\mathbf{s}$ tendência significativa, ns tendência não significativa e st não apresenta tendência

\begin{tabular}{|c|c|c|c|c|c|c|c|c|c|c|c|c|c|c|}
\hline \multirow[t]{2}{*}{ Bacias } & \multicolumn{3}{|c|}{ Piracicaba } & \multicolumn{2}{|c|}{ Mogi } & \multicolumn{2}{|c|}{ Turvo } & \multicolumn{2}{|c|}{ Peixe } & \multicolumn{2}{|c|}{ Aguapeí } & \multirow{2}{*}{$\begin{array}{c}S J D \\
\text { JD } \\
\text { JD2500 }\end{array}$} & \multicolumn{2}{|c|}{ Paranapan. } \\
\hline & $\underset{\text { PI2800 }}{\text { PI }}$ & $\begin{array}{c}\text { JA } \\
\text { JA2800 }\end{array}$ & $\begin{array}{c}\text { AT } \\
\text { AT2065 }\end{array}$ & $\begin{array}{c}\text { MG1 } \\
\text { MG2200 }\end{array}$ & $\begin{array}{c}\text { MG2 } \\
\text { MG2900 }\end{array}$ & $\begin{array}{c}\text { TU1 } \\
\text { TU2250 }\end{array}$ & $\begin{array}{c}\text { TU2 } \\
\text { TU2500 } \\
\end{array}$ & $\begin{array}{c}\text { PX1 } \\
\text { PX2100 }\end{array}$ & $\begin{array}{c}\text { PX2 } \\
\text { PX2800 }\end{array}$ & $\begin{array}{c}\text { AG1 } \\
\text { AG2100 }\end{array}$ & $\begin{array}{c}\text { AG2 } \\
\text { AG2800 }\end{array}$ & & $\begin{array}{c}\text { PR } \\
\text { PR2100 }\end{array}$ & $\begin{array}{c}\text { TQ } \\
\text { TQ2400 }\end{array}$ \\
\hline$\underset{\left(m g \cdot L^{-1}\right)}{O D}$ & $-\mathbf{S}$ & ns & ns & $-\mathbf{S}$ & ns & ns & ns & $-\mathbf{S}$ & $-\mathbf{s}$ & $-\mathbf{S}$ & $-\mathbf{S}$ & $-\mathbf{S}$ & ns & $+\mathrm{s}$ \\
\hline$\underset{\left(m g \cdot L^{-1}\right)}{D B O}$ & $+\mathrm{s}$ & ns & $+\mathrm{s}$ & $+s$ & $+\mathrm{s}$ & $+\mathrm{s}$ & $+\mathrm{s}$ & ns & $+\mathrm{s}$ & $+s$ & ns & $+s$ & $+\mathrm{s}$ & $-s$ \\
\hline $\begin{array}{l}\text { Nitrogênio } \\
\left(m g \cdot L^{-1}\right)\end{array}$ & ns & $-s$ & & $-s$ & ns & $+\mathrm{s}$ & ns & $-s$ & $-s$ & $-s$ & $-\mathbf{S}$ & ns & ns & ns \\
\hline $\begin{array}{c}\text { Nitrato } \\
\left.\left(m g . L^{-1}\right)\right)\end{array}$ & $+\mathrm{s}$ & $+\mathrm{s}$ & $+\mathrm{s}$ & $+\mathrm{s}$ & $+s$ & $+\mathrm{s}$ & $+\mathrm{s}$ & ns & $-\mathrm{s}$ & ns & ns & $+s$ & $+\mathrm{s}$ & $+s$ \\
\hline$\underset{\left(m g . L^{-I}\right)}{\operatorname{Amônio}}$ & $+\mathrm{s}$ & $+\mathrm{s}$ & $+\mathrm{s}$ & $+\mathrm{s}$ & $+\mathrm{s}$ & $+\mathrm{s}$ & $+\mathrm{s}$ & ns & $+s$ & ns & ns & ns & ns & $-\mathbf{s}$ \\
\hline $\begin{array}{c}\text { Fósfororo } \\
\left(m g . L^{-1}\right)\end{array}$ & $+\mathrm{s}$ & $+\mathrm{s}$ & $+s$ & ns & $+s$ & $+s$ & $+s$ & $+s$ & ns & ns & ns & $+s$ & $+s$ & $+s$ \\
\hline $\begin{array}{c}\text { Cloreto } \\
\left(m g . L^{-1}\right)\end{array}$ & ns & $+s$ & ns & ns & $+s$ & $+s$ & $+s$ & $+s$ & $+s$ & $+\mathrm{s}$ & $+s$ & $+s$ & ns & $-s$ \\
\hline $\begin{array}{l}\text { Vazãao } \\
\left(\mathrm{m}^{3} \cdot \mathrm{s}^{-1}\right)\end{array}$ & ns & st & ns & ns & ns & ns & ns & ns & ns & ns & ns & ns & ns & ns \\
\hline$\underset{(m m)}{\text { Precipitação }}$ & ns & ns & ns & ns & ns & ns & ns & ns & ns & ns & ns & ns & ns & ns \\
\hline$I Q A$ & $-S$ & $+s$ & ns & $+s$ & ns & ns & ns & $-s$ & $-s$ & $-s$ & $-s$ & $-s$ & $+s$ & ns \\
\hline
\end{tabular}




\section{- Bacia do rio Piracicaba:}

A análise dos resultados de tendência, tanto do rio Piracicaba quanto dos seus formadores, ou seja, Atibaia e Jaguari, mostrou tendências positivas significativas na maior parte dos parâmetros de qualidade estudados, com exceção do OD e coliformes fecais, cujas tendências são negativas. Desses resultados, a maior parte apresenta características negativas relativas à qualidade de água, com exceção do resultado surpreendente de tendência negativa dos coliformes fecais. Nesse caso, o presente resultado contraria os apresentados por Krusche et al. (1997) que analisou os dados no período de 1978 a 1993, com uma tendência positiva nesse parâmetro.

A bacia do rio Piracicaba é a mais impactada das estudadas, sendo a porcentagem de esgoto tratado muito baixa, aliado ao elevado número de habitantes (aproximadamente 3,9 milhões de habitantes) e o elevado número de indústrias. Esse fato faz com que a carga domiciliar potencial seja próxima da remanescente.

Os resultados de vazão e precipitação não apresentaram tendências significativas. Cabe salientar que o período estudado se inicia próximo ao das operações do Sistema Cantareira (1975 no Atibaia e 1981 no Jaguari), portanto praticamente toda a série histórica das vazões está sobre sob a influência do mesmo. Groppo (2002) mostrou, entretanto, que no período 1947 a 1997 as tendências foram negativas para a vazão e positivas para precipitação.

\section{- Bacia do rio Mogi-Guaçu:}

Os resultados mostraram um comportamento similar ao do rio Piracicaba em termos de tendências, apresentando tendências positivas nos parâmetros DBO, nitrogênios, fósforo total, cloreto e coliformes fecais, e negativa no parâmetro OD. Quanto aos coliformes fecais, existe uma tendência negativa significativa no posto mais à montante do rio (MG1), enquanto no posto mais à jusante (MG2) não apresentam tendência significativa, o que seria mais coerente que o resultado obtido para a bacia do rio Piracicaba. Quanto aos parâmetros fósforo total e cloreto, observou-se uma 
tendência positiva significativa no $\mathrm{MG} 2$ e não significativa no $\mathrm{MG1}$, o que possivelmente indicaria a existência de entrada desses elementos via dejetos urbanos e industriais ao longo do rio, entre os dois postos. Não foram observadas tendências nem na vazão nem na precipitação.

A bacia do rio Mogi-Guaçu possui uma população de aproximadamente 1,3 milhões de habitantes, contando com um número considerável de indústrias, o que faz dessa bacia uma das mais impactadas das estudadas.

\section{- Bacia do rio Turvo Grande:}

Os resultados dessa bacia também acusam tendências que indicam uma diminuição na qualidade da água. De uma maneira geral, os dois postos analisados tiveram praticamente o mesmo comportamento dos anteriores. Tanto a vazão quanto a precipitação não apresentaram tendências estatisticamente significativas.

\section{- Bacia do rio Peixe:}

Os resultados apontam também para uma diminuição na qualidade de água. Diferentemente do rio Turvo, ocorreram tendências negativas significativas para os parâmetros OD e nitrogênio. $O$ nitrato apresentou tendência negativa significativa somente para o posto PX2, e o parâmetro coliformes fecais apresenta uma tendência positiva estatisticamente significativa em ambos os postos. Tanto a vazão quanto a precipitação não apresentaram tendências estatisticamente significativas.

A bacia do rio Peixe, juntamente com as bacias dos rios Piracicaba, Mogi-Guaçu e Turvo Grande, possui uma taxa de urbanização acima de 90\%, similar à do Estado de São Paulo (Martinelli et al, 2002). 


\section{- Bacia do rio Aguapeí:}

Os dois postos analisados dessa bacia tiveram comportamento similar, com tendências negativas significativas para os parâmetros OD e nitrogênio, e positivas para o cloreto e o coliformes fecais. Tanto a vazão quanto a precipitação não apresentaram tendências estatisticamente significativas.

\section{- Bacia do São José dos Dourados:}

Para essa bacia foi estudado apenas um posto, que também apresentou uma diminuição da qualidade de água, com tendência negativa significativa para o parâmetro $\mathrm{OD}$, e positivas a $\mathrm{DBO}$, nitrato, fósforo, cloreto e coliformes fecais. Tanto a vazão quanto a precipitação não apresentaram tendências estatisticamente significativas.

\section{- Bacia do Alto Paranapanema:}

Essa é a bacia menos impactada das bacias estudadas. Foram estudados dois rios nessa bacia, o rio Paranapanema (PR) e o rio Taquari (TQ). O rio Taquari foi o único que apresentou tendência positiva significativa no OD e tendências negativas na DBO e no cloreto; essas tendências apontam para uma diminuição de despejos industriais ou esgoto doméstico. O posto do rio Paranapanema apresentou tendências positivas significativas na DBO, no nitrato e no fósforo, que indicam um aumento de despejos domésticos e industriais. Tanto a vazão quanto a precipitação em ambos os rios não apresentaram tendências estatisticamente significativas.

Alguns resultados, como o índice de qualidade de agua (IQA) e coliformes fecais, necessitaram de uma análise suplementar, e são apresentados nos itens 5.2.1. e 5.2 .2 , respectivamente. 


\subsubsection{Indice de Qualidade de Água (IQA)}

Os resultados da tendência do IQA nos postos dos rios Piracicaba, Atibaia, Mogi-Guaçu 2, Turvo 2, Peixe, Aguapeí e São José dos Dourados confirmaram a degradação da qualidade das águas, apresentando tendências negativas. Entretanto, os rios Jaguari, Mogi-Guaçu 1 e Paranapanema apresentaram tendências positivas significativas, e o Turvo 1 e o Taquari apresentaram tendências positivas não significativas.

O IQA é calculado pelo produtório ponderado dos seguintes parâmetros, que caracterizam a qualidade de água: temperatura da amostra, $\mathrm{pH}$, oxigênio dissolvido, demanda bioquímica de oxigênio $\left(5\right.$ dias, $\left.20^{\circ} \mathrm{C}\right)$, coliformes termotolerantes, nitrogênio total, fósforo total, resíduo total e turbidez. A partir do cálculo efetuado, pode-se determinar a qualidade das águas brutas, e classificá-la numa escala de 0 a 100, conforme apresentada na Tabela 6 .

\begin{tabular}{lc}
\multicolumn{2}{c}{ Tabela 6. Escala do IQA } \\
\hline & IQA \\
\hline ÓTIMA & 80 a 100 \\
BOA & 52 a 79 \\
ACEITÁVEL & 37 a 51 \\
RUIM & 20 a 36 \\
PÉSSIMA & 0 a 19 \\
\hline
\end{tabular}

Muitos dos parâmetros utilizados no cálculo do IQA não foram aqui analisados, entretanto, resultados apontando melhoria de qualidade desses rios são incoerentes com as tendências detectadas nos parâmetros biogeoquímicos do presente trabalho.

Uma análise dos dados médios das séries temporais apresentados para seis meses do ano (Tabela 7), mostra valores de IQA indicando qualidade aceitável e boa ao longo do ano, além de uma melhor qualidade da água no período seco (maio e julho). Esses resultados são incoerentes com as observações e medidas realizadas por vários trabalhos que enquadram a água do rio Piracicaba como pior que classe 4 (Plano de Bacia Hidrográfica 2000-2003; Martinelli et al.,2003). 
Tabela 7. Distribuição bimestral dos resultados do IQA

\begin{tabular}{|c|c|c|c|c|c|c|c|}
\hline BACIA & POSTO & janeiro & março & maio & julho & setembro & dezembro \\
\hline \multirow[t]{3}{*}{ Piracicaba } & PI & 43 & 50 & 53 & 51 & 47 & 42 \\
\hline & JA & 53 & 58 & 59 & 61 & 59 & 53 \\
\hline & $\mathrm{AT}$ & 51 & 52 & 51 & 50 & 53 & 48 \\
\hline \multirow[t]{2}{*}{ Mogi-Guaçu } & MG1 & 48 & 52 & 56 & 58 & 56 & 50 \\
\hline & MG2 & 61 & 60 & 64 & 63 & 66 & 61 \\
\hline \multirow[t]{2}{*}{ Turvo Grande } & TU1 & 55 & 57 & 64 & 65 & 60 & 60 \\
\hline & TU2 & 61 & 60 & 64 & 70 & 67 & 62 \\
\hline \multirow[t]{2}{*}{ Peixe } & PX1 & 44 & 49 & 56 & 59 & 55 & 49 \\
\hline & PX2 & 55 & 52 & 59 & 62 & 67 & 55 \\
\hline \multirow[t]{2}{*}{ Aguapeí } & AG1 & 59 & 57 & 63 & 66 & 65 & 61 \\
\hline & AG2 & 60 & 61 & 64 & 68 & 69 & 61 \\
\hline SJD & JD & 64 & 67 & 70 & 73 & 71 & 62 \\
\hline Alto & TQ & 51 & 50 & 52 & 58 & 58 & 52 \\
\hline Paranapanema & PR & 57 & 57 & 66 & 72 & 68 & 59 \\
\hline
\end{tabular}

A análise da real representatividade do IQA como índice da qualidade de água, assim como a influência de cada parâmetro incluído no cálculo desse índice, necessitariam de uma análise de sensibilidade de todas as variáveis envolvidas. Esse estudo não está incluído nos objetivos do presente trabalho.

\subsubsection{Coliformes fecais}

Algumas questões quanto ao comportamento do parâmetro coliformes fecais, apresentaram tendências negativas para algumas bacias com qualidade de água reconhecidamente deteriorada. Foram testadas diversas transformações "Box-Cox", mas essas não tiveram influência sobre o resultado dos testes estatísticos.

Segundo Martinelli (CENA-USP) e Tavares (Escola de Engenharia de Piracicaba) e Ribeiro (Semae-Piracicaba), através de comunicações pessoais, os resultados podem ser explicados das seguintes maneiras: (1) a metodologia utilizada pela CETESB ("Coliformes termotolerantes" Método de análise baseado na 20.a edição do "Standard Methods for the Examination of Water and Wastewater") que expressa os resultados em número mais provável (NMP.100 $\mathrm{ml}^{-1}$ ), é subjetiva e pode apresentar uma variabilidade muito grande; a melhor metodologia a ser empregada nesse caso seria Contagem Padrão em Placa de Petri, onde a unidade dos resultados seria em unidade 
formadora de colônia (UFC.ml ${ }^{-1}$ ); (2) o dia da semana em que as coletas foram realizadas pode influenciar os resultados; (3) a diminuição da colimetria talvez possa estar associada aos interceptores que alguns municípios estão implantando, afastando o ponto de lançamento dos pontos de coleta da CETESB; (4) particularmente na bacia do rio Piracicaba algumas hipóteses foram questionadas para a contradição dos resultados obtidos: (A) a porcentagem de tratamento de esgoto passou de $2 \%$ do volume gerado na bacia em 1989 a aproximadamente 18\%. Talvez o número de coliformes fecais, por ser um parâmetro biológico, seja o primeiro a responder ao maior volume de esgoto tratado, enquanto parâmetros químicos, como $\mathrm{OD}$, demorem mais; (B) valores altos nos primeiros anos da série (Figura 7) provavelmente forçam a existência de uma tendência negativa.

Piracicaba - Coliformes Fecais

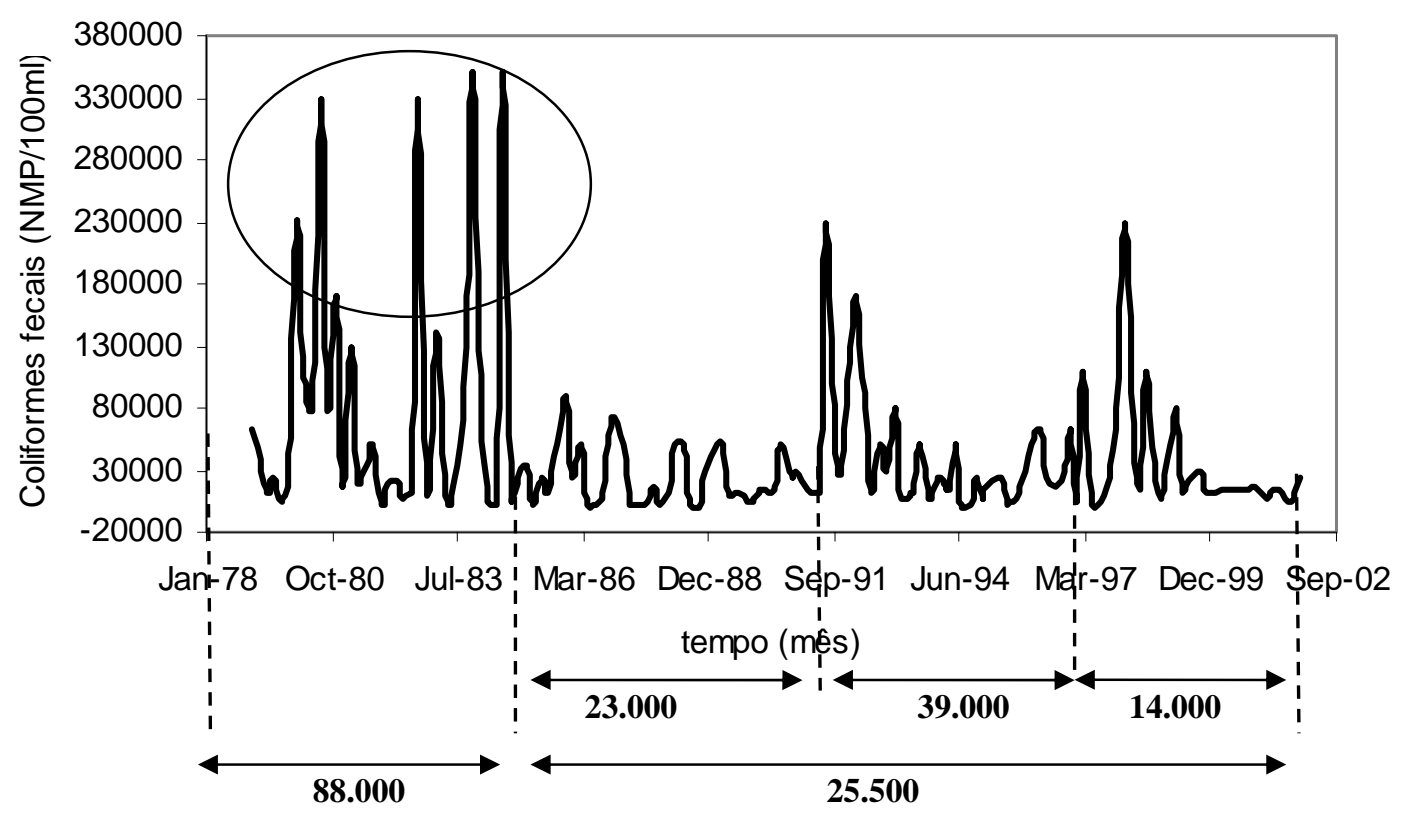

Figura 7 - Valores de coliformes fecais em relação ao tempo. Os valores apresentados nos intervalos abaixo da figura representam a média do período 


\subsection{Análise da magnitude da tendência}

Os resultados do coeficiente de regressão "Sen's slope" (Sen), acompanhado dos valores médios (VM), representados aqui pela mediana dos parâmetros são apresentados na Tabela 8. É importante deixar claro que esses resultados representam a variação no período de estudo, ou seja, se o rio já era poluído quando do início da análise, não necessariamente vai apresentar um alto valor de Sen.

Tabela 8. Resultados do coeficiente "Sen's slope" (Sen) e valores médios (VM) dos parâmetros estudados, no período de 1979 a 2001

\begin{tabular}{|c|c|c|c|c|c|c|c|c|c|c|}
\hline & & $\begin{array}{c}\text { OD } \\
m g^{*} \mathrm{~L}^{-1}\end{array}$ & $\begin{array}{c}\text { DBO } \\
m g * L^{-1}\end{array}$ & $\begin{array}{c}\boldsymbol{N}_{\text {total }} \\
\mathrm{mg}^{*} \mathrm{~L}^{-1}\end{array}$ & $\begin{array}{c}\mathrm{NO}_{3} \\
m \mathrm{~m}^{*} \mathrm{~L}^{-1}\end{array}$ & $\begin{array}{c}\mathrm{NH}_{4} \\
\mathrm{mg}^{*} \mathrm{~L}^{-1}\end{array}$ & $\begin{array}{c}\text { Fósf. } \\
m g^{*} \mathrm{~L}^{-1}\end{array}$ & $\begin{array}{c}C \boldsymbol{C l} \\
\mathrm{mg} * \mathrm{~L}^{-1}\end{array}$ & $\begin{array}{c}\text { Colif. } \\
\mathrm{NMP}^{*} 100 \mathrm{ml}^{-1}\end{array}$ & $I Q A$ \\
\hline \multirow[t]{2}{*}{ PI } & Sen & $-0,095$ & 0,152 & 0,010 & 0,013 & 0,028 & 0,009 & 0,493 & $-1385,7$ & $-0,447$ \\
\hline & $V M$ & 4,78 & 5,00 & 1,728 & 0,385 & 0,405 & 0,236 & 13,02 & 33801,0 & 45,66 \\
\hline \multirow[t]{2}{*}{ JA } & Sen & $-0,017$ & 0,014 & $-0,013$ & 0,035 & 0,003 & 0,002 & 0,141 & $-985,5$ & 0,417 \\
\hline & $V M$ & 7,27 & 1,67 & 0,815 & 0,442 & 0,118 & 0,125 & 4,67 & 15550,0 & 59,67 \\
\hline \multirow[t]{2}{*}{$\mathbf{A T}$} & Sen & $-0,033$ & 0,073 & - & 0,007 & 0,023 & 0,004 & 0,032 & $-8708,3$ & 0,0 \\
\hline & $V M$ & 6,97 & 3,17 & - & 0,282 & 0,433 & 0,161 & 5,83 & 132833,3 & 51,33 \\
\hline \multirow[t]{2}{*}{ MG1 } & Sen & $-0,03$ & 0,03 & $-0,02$ & 0,003 & 0,003 & $-0,001$ & 0,004 & -4587 & 0,311 \\
\hline & $V M$ & 6,63 & 2,33 & 0,997 & 0,250 & 0,150 & 0,130 & 10,67 & 38716,7 & 54,16 \\
\hline \multirow[t]{2}{*}{ MG2 } & Sen & 0 & 0,04 & 0,008 & 0,008 & 0,002 & 0,002 & 0,04 & 121,05 & $-0,064$ \\
\hline & $V M$ & 6,13 & 1,67 & 0,635 & 0,172 & 0,047 & 0,058 & 5,92 & 6200,0 & 63,00 \\
\hline \multirow[t]{2}{*}{ TU1 } & Sen & 0,008 & 0,05 & 0,01 & 0,009 & 0,01 & 0,002 & 0,05 & $-202,7$ & 0,083 \\
\hline & $V M$ & 6,15 & 2,17 & 0,792 & 0,197 & 0,143 & 0,063 & 4,17 & 4521,7 & 63,33 \\
\hline \multirow[t]{2}{*}{ TU2 } & Sen & 0,02 & 0,03 & 0,008 & 0,01 & 0,003 & 0,003 & 0,06 & $-78,8$ & $-0,033$ \\
\hline & $V M$ & 6,00 & 1,83 & 0,660 & 0,233 & 0,077 & 0,055 & 4,08 & 2410,0 & 64,66 \\
\hline \multirow[t]{2}{*}{ PX1 } & Sen & $-0,08$ & 0,06 & $-0,04$ & 0 & 0,001 & 0,003 & 0,05 & 4545,5 & $-0,403$ \\
\hline & $V M$ & 7,20 & 4,00 & 1,27 & 0,470 & 0,140 & 0,090 & 3,80 & 87333,3 & 52,83 \\
\hline \multirow[t]{2}{*}{ PX2 } & Sen & $-0,07$ & 0,07 & $-0,03$ & $-0,008$ & 0 & 0 & 0,04 & 156,3 & $-0,333$ \\
\hline & $V M$ & 7,89 & 3,00 & 1,18 & 0,510 & 0,120 & 0,100 & 3,24 & 8233,3 & 59,16 \\
\hline \multirow[t]{2}{*}{ AG1 } & Sen & $-0,05$ & 0,04 & $-0,02$ & $-0,001$ & 0 & $-0,001$ & 0,04 & 152,4 & $-0,241$ \\
\hline & $V M$ & 7,42 & 2,50 & 0,905 & 0,422 & 0,107 & 0,080 & 3,22 & 4021,6 & 61,33 \\
\hline \multirow[t]{2}{*}{ AG2 } & Sen & $-0,06$ & 0,04 & $-0,02$ & 0,001 & $-0,002$ & 0 & 0,04 & 22,8 & $-0,154$ \\
\hline & $V M$ & 7,55 & 2,50 & 0,805 & 0,366 & 0,095 & 0,079 & 3,37 & 1333,3 & 64,50 \\
\hline \multirow[t]{2}{*}{ JD } & Sen & $-0,05$ & 0,05 & $-0,001$ & 0,01 & 0 & 0,001 & 0,1 & 79 & $-0,298$ \\
\hline & $V M$ & 7,78 & 2,00 & 0,623 & 0,189 & 0,097 & 0,065 & 3,53 & 2333,3 & 66,83 \\
\hline \multirow[t]{2}{*}{ PR } & Sen & 0,02 & 0,05 & $-0,01$ & 0,007 & $-0,001$ & 0,002 & 0 & $-82,5$ & 0,417 \\
\hline & $V M$ & 7,08 & 2,16 & 0,733 & 0,287 & 0,066 & 0,070 & 3,00 & 2553,6 & 66,16 \\
\hline \multirow[t]{2}{*}{$\mathbf{T Q}$} & Sen & 0,12 & $-0,15$ & 0,003 & 0,01 & $-0,002$ & 0,003 & $-0,04$ & 196,4 & 0,0 \\
\hline & $V M$ & 6,88 & 3,66 & 0,832 & 0,218 & 0,104 & 0,095 & 2,46 & 28283,3 & 55,83 \\
\hline
\end{tabular}


Para auxiliar a interpretação dos resultados, gráficos "Box-Plot" dos parâmetros estudados são apresentados no anexo B. Esses gráficos mostram o valor da mediana e a variabilidade de cada parâmetro nas diversas bacias estudadas, através dos limites inferior e superior dos retângulos (percentis $25 \%$ e $75 \%$ ) com a extremidade das linhas perpendiculares representando os valores máximos e mínimos. As séries empregadas foram as das médias anuais dos parâmetros estudados.

Os resultados apontam para variações mais acentuadas, representada pela grandeza de Sen, na bacia do rio Piracicaba, em praticamente todos os parâmetros analisados. Em termos de OD, o rio Peixe também apresentou resultados altos, mostrando que no período estudado houve um decréscimo acentuado desse parâmetro; nesse mesmo rio observou-se também a maior variação de DBO.

Para a bacia do rio Piracicaba o posto de Piracicaba (PI), apresentou os maiores valores médios (ver também Anexo 2) e coeficiente angular em praticamente todos os parâmetros, confirmando ser o rio mais impactado dos postos estudados. O posto avaliado nesse rio situa-se no trecho final do mesmo, antes da formação da barragem de Barra Bonita e recebe efluentes das cidades mais populosas e industrializadas da bacia, ou seja, Campinas, Americana, Limeira e Piracicaba. Em termos de degradação da qualidade da água segue-se o posto do rio Atibaia (AT) localizado na captação $n^{0} 3$ de água para abastecimento da região metropolitana de Campinas, e que por esse motivo não recebe o esgoto dessa cidade, mas por sua vez recebe grande parte dos esgotos domésticos de Valinhos e Vinhedo. Já o posto do rio Jaguari (JA), localizado próximo à sua foz, na captação da cidade de Limeira, apesar de assimilar o esgoto da cidade de Bragança Paulista, localizada no trecho inicial do rio, tem sua qualidade de água deteriorada após receber esgoto doméstico da cidade de Cosmópolis.

Nos rios onde foram estudados dois postos, como é o caso dos rios Mogi-Guaçu, Turvo Grande, Peixe e Aguapeí, de uma maneira geral os postos mais à montante, representados pelo número 1, apresentaram pior qualidade de água do que os postos mais à jusante (representados pelo número 2). Nesses rios os postos 1 são próximos às maiores cidades das bacias, cidades do porte de Araras, Mogi-Guaçu, Mogi-Mirim (na bacia Mogi-Guaçu), Catanduva (na bacia Turvo Grande), Marília (na bacia Peixe), Tupã, 
Pompéia (na bacia Aguapeí), portanto recebendo efluentes de origem doméstica e industrial; provavelmente esse decréscimo é devido aos efeitos de auto-depuração.

No posto do rio São José dos Dourados (JD), apesar de apresentar tendências que indicam diminuição na qualidade de água, seus valores médios são os melhores observados, mostrando possuir águas com a melhor qualidade dentre os locais estudados. Em termos de valores médios, os postos da bacia do Alto Paranapanema também apresentam boa qualidade da água, além de alguns parâmetros (OD, cloreto e amônio) apresentarem tendências que indicam melhoria na qualidade de água.

\subsection{Análise estatística de mudanças bruscas}

É importante ressaltar que as mudanças bruscas nas médias das séries utilizadas são relativas ao período em que as análises foram realizadas. As séries empregadas foram as das médias anuais dos parâmetros estudados e a influência da vazão não foi retirada.

A análise exploratória dos dados e as médias antes e depois da mudança brusca são sumarizados nas Tabelas 9 e 10, respectivamente. 
Tabela 9. Sumário das análises estatísticas de mudança brusca: $\mathrm{CP}=$ ano de ocorrência;

\begin{tabular}{|c|c|c|c|c|c|c|c|c|}
\hline & $O D$ & $D B O$ & $N_{\text {total }}$ & $\mathrm{NO}_{3}$ & $\mathrm{NH}_{4}$ & Fósforo & $\mathrm{Cl}$ & Colif. \\
\hline \multirow[t]{2}{*}{ PI } & CP 1988 & CP 1987 & $\mathrm{CP}$ ns & CP 1987 & CP 1991 & $\mathrm{CP}$ ns & CP 1988 & $\mathrm{CP}$ ns \\
\hline & SL 0,02 & SL 0,01 & SL ns & SL 0,001 & SL 0,02 & SL ns & SL 0,01 & SL ns \\
\hline \multirow[t]{2}{*}{ JA } & $\mathrm{CP}$ ns & $\mathrm{CP}$ ns & СР 1988 & CP 1991 & CP 1995 & CP ns & $\mathrm{CP}$ ns & $\mathrm{CP}$ ns \\
\hline & SL ns & SL ns & SL 0,01 & SL 0,002 & SL 0,04 & SL ns & SL ns & SL ns \\
\hline \multirow[t]{2}{*}{ AT } & $\mathrm{CP}$ ns & $\mathrm{CP}$ ns & - & CP ns & CP 1989 & $\mathrm{CP}$ ns & $\mathrm{CP}$ ns & $\mathrm{CP}$ ns \\
\hline & SL ns & SL ns & & SL ns & SL 0,002 & SL ns & SL ns & SL ns \\
\hline \multirow[t]{2}{*}{ MG1 } & СР 1987 & $\mathrm{CP}$ ns & СР 1988 & $\mathrm{CP}$ ns & $\mathrm{CP}$ ns & $\mathrm{CP}$ ns & $\mathrm{CP}$ ns & СР 1991 \\
\hline & SL 0,03 & SL ns & SL 0,02 & SL ns & SL ns & SL ns & SL ns & SL 0,002 \\
\hline \multirow[t]{2}{*}{ MG2 } & $\mathrm{CP}$ ns & $\mathrm{CP}$ ns & $\mathrm{CP}$ ns & CP 1985 & $\mathrm{CP}$ ns & СР 1984 & $\mathrm{CP}$ ns & $\mathrm{CP}$ ns \\
\hline & SL ns & SL ns & SL ns & SL 0,03 & SL ns & SL 0,03 & SL ns & SL ns \\
\hline \multirow[t]{2}{*}{ TU1 } & $\mathrm{CP}$ ns & $\mathrm{CP}$ ns & СР 1983 & CP 1983 & CP 1993 & CP 1983 & $\mathrm{CP}$ ns & $\mathrm{CP}$ ns \\
\hline & SL ns & SL ns & SL 0,04 & SL 0,04 & SL 0,02 & SL 0,04 & SL ns & SL ns \\
\hline \multirow[t]{2}{*}{ TU2 } & $\mathrm{CP}$ ns & $\mathrm{CP}$ ns & $\mathrm{CP}$ ns & СР 1992 & СР 1993 & СР 1984 & СР 1990 & $\mathrm{CP}$ ns \\
\hline & SL ns & SL ns & SL ns & SL 0,006 & SL 0,03 & SL 0,02 & SL 0,04 & SL ns \\
\hline \multirow[t]{2}{*}{ PX1 } & СР 1989 & $\mathrm{CP}$ ns & СР 1988 & $\mathrm{CP}$ ns & $\mathrm{CP}$ ns & $\mathrm{CP}$ ns & $\mathrm{CP}$ ns & СР 1985 \\
\hline & SL 0,004 & SL ns & SL 0,003 & SL ns & SL ns & SL ns & SL ns & SL 0,02 \\
\hline \multirow[t]{2}{*}{ PX2 } & СР 1989 & CP 1988 & СР 1990 & CP 1985 & $\mathrm{CP}$ ns & $\mathrm{CP}$ ns & $\mathrm{CP}$ ns & $\mathrm{CP}$ ns \\
\hline & SL 0,002 & SL 0,03 & SL 0,004 & SL 0,01 & SL ns & SL ns & SL ns & SL ns \\
\hline \multirow[t]{2}{*}{ AG1 } & СР 1989 & $\mathrm{CP}$ ns & СР 1989 & $\mathrm{CP}$ ns & $\mathrm{CP}$ ns & $\mathrm{CP}$ ns & $\mathrm{CP}$ ns & СР 1983 \\
\hline & SL 0,008 & SL ns & SL 0,003 & SL ns & SL ns & SL ns & SL ns & SL 0,04 \\
\hline \multirow[t]{2}{*}{ AG2 } & CP 1988 & $\mathrm{CP}$ ns & СР 1989 & $\mathrm{CP}$ ns & CP ns & $\mathrm{CP}$ ns & $\mathrm{CP}$ ns & $\mathrm{CP}$ ns \\
\hline & SL 0,003 & SL ns & SL 0,001 & SL ns & SL ns & SL ns & SL ns & SL ns \\
\hline \multirow[t]{2}{*}{ JD } & СР 1989 & $\mathrm{CP}$ ns & $\mathrm{CP}$ ns & СР 1992 & $\mathrm{CP}$ ns & $\mathrm{CP}$ ns & CP 1989 & CP 1983 \\
\hline & SL 0,001 & SL ns & SL ns & SL 0,02 & SL ns & SL ns & SL 0,01 & SL 0,04 \\
\hline \multirow[t]{2}{*}{ PR } & $\mathrm{CP}$ ns & СР 1985 & $\mathrm{CP}$ ns & $\mathrm{CP}$ ns & $\mathrm{CP}$ ns & CP ns & $\mathrm{CP}$ ns & CP ns \\
\hline & SL ns & SL 0,03 & SL ns & SL ns & SL ns & SL ns & SL ns & SL ns \\
\hline \multirow[t]{2}{*}{ TQ } & СР 1989 & $\mathrm{CP}$ ns & $\mathrm{CP}$ ns & СР 1989 & $\mathrm{CP}$ ns & CP 1984 & $\mathrm{CP}$ ns & $\mathrm{CP}$ ns \\
\hline & SL 0,002 & SL ns & SL ns & SL 0,001 & SL ns & SL 0,04 & SL ns & SL ns \\
\hline
\end{tabular}


Tabela 10. Média dos parâmetros antes e depois da mudança brusca

\begin{tabular}{|c|c|c|c|c|c|c|c|c|}
\hline & $\begin{array}{c}O D \\
\left(m g^{*} L^{-1}\right)\end{array}$ & $\begin{array}{c}D B O \\
\left(m g^{*} L^{-1}\right)\end{array}$ & $\begin{array}{c}N_{\text {total }} \\
\left(m g^{*} L^{-1}\right)\end{array}$ & $\begin{array}{c}\mathrm{NO}_{3} \\
\left(m g^{*} L^{-1}\right)\end{array}$ & $\begin{array}{c}N H_{4} \\
\left(m g^{*} L^{-1}\right)\end{array}$ & $\begin{array}{l}\text { Fósforo } \\
\left(m g^{*} L^{-I}\right)\end{array}$ & $\begin{array}{c}C l \\
\left(m g * L^{-1}\right)\end{array}$ & $\begin{array}{c}\text { Coliformes } \\
\left(N M P * 100 m l^{l}\right)\end{array}$ \\
\hline \multirow[t]{2}{*}{ PI } & $\begin{array}{l}(79-88) \\
5,56\end{array}$ & $\begin{array}{l}(79-87) 3,70 \\
\end{array}$ & & $\begin{array}{l}(79-87) \\
0,24\end{array}$ & $\begin{array}{l}(79-91) \\
0,35\end{array}$ & & $\begin{array}{l}(79-88) \\
9,47\end{array}$ & \\
\hline & (89-01) 4,42 & (88-01) 5,80 & & (88-01) 0,44 & (92-01) 0,72 & & (89-01) 15,49 & \\
\hline \multirow[t]{2}{*}{ JA } & & & (79-88) 1,03 & (79-91) 0,29 & (79-95) 0,11 & & & \\
\hline & & & (89-01) 0,73 & (92-01) 0,68 & (96-01) 0,26 & & & \\
\hline \multirow[t]{2}{*}{ AT } & & & & & (79-89) 0,26 & & & \\
\hline & & & & & (90-01) 0,63 & & & \\
\hline \multirow[t]{2}{*}{ MG1 } & (79-87) 6,85 & & (79-88) 1,20 & & & & & (79-91) 112763 \\
\hline & (88-01) 6,37 & & (89-01) 0,89 & & & & & (92-01) 17390 \\
\hline \multirow[t]{2}{*}{ MG2 } & & & & (79-85) 0,11 & & (79-84) 0,02 & & \\
\hline & & & & (86-01) 0,20 & & (85-01) 0,07 & & \\
\hline \multirow[t]{2}{*}{ TU1 } & & & (79-83) 0,42 & (79-83) 0,08 & (79-93) 0,10 & (79-83) 0,02 & & \\
\hline & & & (84-01) 0,87 & (84-01) 0,22 & (94-01) 0,23 & (84-01) 0,07 & & \\
\hline \multirow[t]{2}{*}{ TU2 } & & & & (79-92) 0,16 & (79-93) 0,06 & (79-84) 0,02 & (79-90) 3,70 & \\
\hline & & & & (93-01) 0,35 & (94-01) 0,10 & (85-01) 0,07 & (91-01) 4,46 & \\
\hline \multirow[t]{2}{*}{ PX1 } & (79-89) 8,00 & & (79-88) 1,60 & & & & & (79-85) 18015 \\
\hline & (90-01) 6,92 & & (89-01) 1,07 & & & & & (86-01) 134752 \\
\hline \multirow[t]{2}{*}{ PX2 } & (79-89) 8,37 & (79-88) 2,63 & (79-90) 1,42 & (79-85) 0,56 & & & & \\
\hline & $(90-01) 7,36$ & (89-01) 3,71 & (91-01) 0,89 & (86-01) 0,44 & & & & \\
\hline \multirow[t]{2}{*}{ AG1 } & (79-89) 7,84 & & (79-89) 1,06 & & & & & $(79-83) 618$ \\
\hline & $(90-01) 7,11$ & & (90-01) 0,75 & & & & & $(84-01) 6649$ \\
\hline \multirow[t]{2}{*}{ AG2 } & (79-88) 8,13 & & (79-89) 1,06 & & & & & \\
\hline & (89-01) 7,26 & & (90-01) 0,66 & & & & & \\
\hline \multirow[t]{2}{*}{ JD } & (79-89) 8,23 & & & (79-92) 0,15 & & & (79-89) 2,78) & (79-83) 274 \\
\hline & $(90-01) 7,36$ & & & (93-01) 0,27 & & & (90-01) 4,33 & (84-01) 4030 \\
\hline \multirow[t]{2}{*}{ PR } & & (79-85) 1,64 & & & & & & \\
\hline & & (86-01) 2,73 & & & & & & \\
\hline \multirow[t]{2}{*}{ TQ } & (79-89) 5,55 & & & (79-89) 0,12 & & (79-84) 0,05) & & \\
\hline & $(90-01) 7,23$ & & & (90-01) 0,31 & & (85-01) 0,13 & & \\
\hline
\end{tabular}

Piracicaba: mesmo com o aumento do tratamento de esgoto dessa bacia a partir de 1989 de 3\% para 12\% do total de esgoto gerado (Consórcio PCJ, comunicação pessoal), nessa bacia ocorreram mudanças bruscas com deterioração da qualidade da água a partir do final dos anos 80 em alguns parâmetros. Cabe lembrar que o Sistema Cantareira começou a interferir no funcionamento desse rio a partir do início dos anos 80 (Moraes et al., 1997). A retirada de $31 \mathrm{~m}^{3} / \mathrm{s}$ de água dos formadores do rio Piracicaba para o abastecimento da grande São Paulo ocasionou uma diminuição significativa na vazão desses rios (Pellegrino et al., 1995, Moraes et. al., 1997 e Groppo et al., 2001). Essa 
diminuição de vazão, além do crescimento populacional, que passou de aproximadamente 1,5 milhões de habitantes nos anos 70 para aproximadamente 2,5 milhões de habitantes nos anos 80 , são as mais prováveis causas dessa deterioração em todos os rios estudados nessa bacia. Pode-se observar que essas mudanças bruscas foram detectadas principalmente no rio Jaguari, onde a vazão diminuiu em torno de $50 \%$, e também no rio Piracicaba, que além da diminuição de vazão recebe efluentes urbanos e industriais das principais cidades da bacia.

Mogi-Guaçu: ocorreram mudanças bruscas em torno do final dos anos 80 para o posto mais à montante (MG 1) e em torno do início dos anos 80 no posto mais à jusante (MG 2); as mudanças ocorridas no posto MG 1 indicam melhoria na qualidade da água, enquanto no posto MG 2 a deterioração com o aumento do nitrato e fósforo indica uma provável contaminação por esgoto humano e animal.

Turvo Grande: ocorreram mudanças bruscas nos anos 80 e início dos anos 90, nos parâmetros nitrogênio, nitrato, amônio, fósforo e cloreto, sendo o nitrogênio só em TU1 e o cloreto só no TU2, indicando deterioração da qualidade de água, sendo que esses parâmetros são ligados à contaminação por esgoto sanitário ou por alguns efluentes industriais.

Peixe: ocorreram mudanças bruscas a partir da metade dos anos 80 e início dos anos 90 . No posto à montante (PX1) os parâmetros $\mathrm{OD}$ e coliformes fecais indicam deterioração da qualidade da água e no nitrogênio, enquanto para o posto mais à jusante (PX2) ocorreram no OD e DBO, e melhora no nitrogênio e no nitrato. A diminuição de despejos de efluentes industriais, com influência na diminuição do nitrato, é a mais provável causa da melhora da qualidade, enquanto as prováveis causas pela deterioração são o aumento de despejos de esgoto de origem orgânica, com influência no OD e DBO. 
Aguapeí: as mudanças bruscas ocorridas nessa bacia foram semelhantes às ocorridas na bacia do Peixe, com exceção dos parâmetros DBO e nitrato que não ocorreram nessa bacia.

São José dos Dourados: nessa bacia também ocorrem mudanças bruscas nos anos 80 e início dos anos 90, os parâmetros OD, nitrato, cloreto e coliformes apresentaram mudanças indicando deterioração da qualidade de água, sendo as causas mais prováveis despejos industriais e sanitários.

Alto Paranapanema: para o rio Paranapanema (PR) ocorreu mudança brusca somente na DBO, indicando deterioração da qualidade da água por efluentes de origem orgânica. Já para o rio Taquari ocorreram mudanças bruscas indicando somente melhoria da qualidade da água, para os parâmetros OD, nitrato e fósforo total; a diminuição de despejos sanitários é a causa mais provável dessa melhora.

\subsection{Análise de agrupamento}

Para realizar a análise de agrupamento utilizou-se o programa estatístico Estatística 5.5, sendo que o método de agrupamento escolhido e aplicado foi o de Ward's ou variância mínima, e o coeficiente de similaridade utilizado foi a distância Euclidiana dos dados. A forma gráfica usada para representar os resultados dos diversos agrupamentos é o dendrograma.

Os resultados do agrupamento entre regiões com comportamentos similares, foram apresentados para cada parâmetro entre as Figuras 8 e 9, seguida da análise dos dendrogramas. 

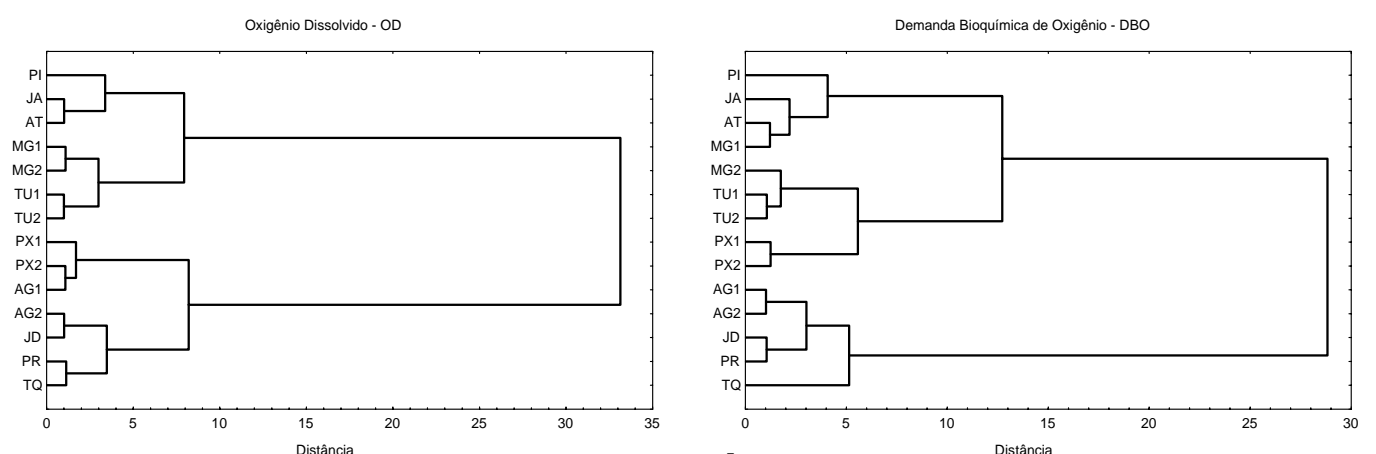

b.
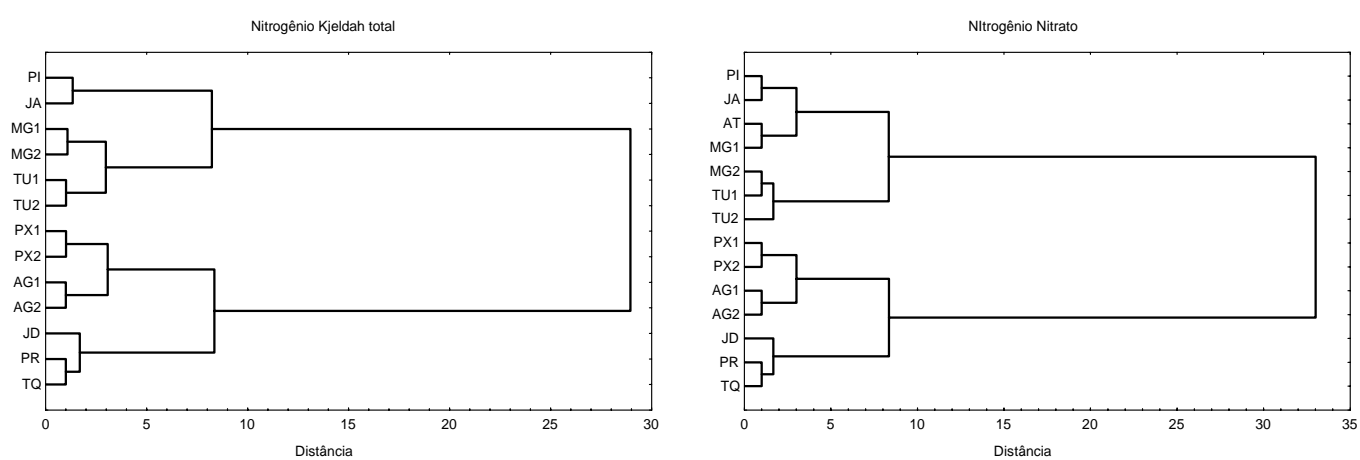

d.

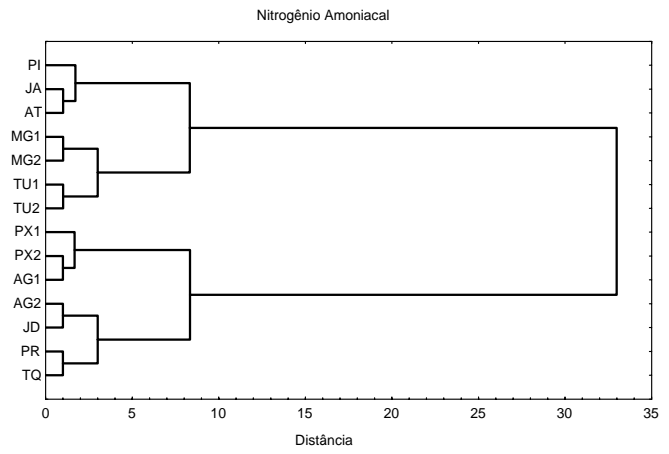

e.

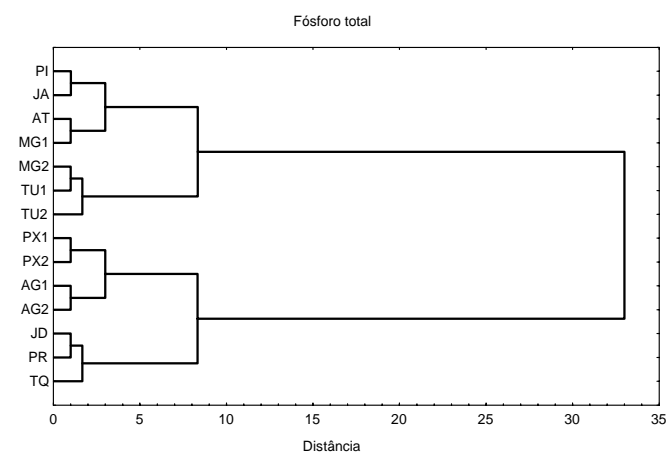

f.

Figura 8 - Dendrogramas resultantes da análise de agrupamento entre as bacias: a) OD; b) DBO; c) nitrogênio; d) nitrato; e) amônio; f) fósforo total 


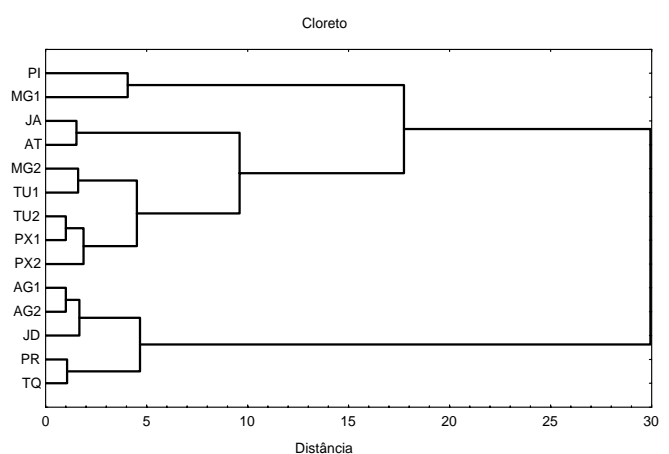

a.

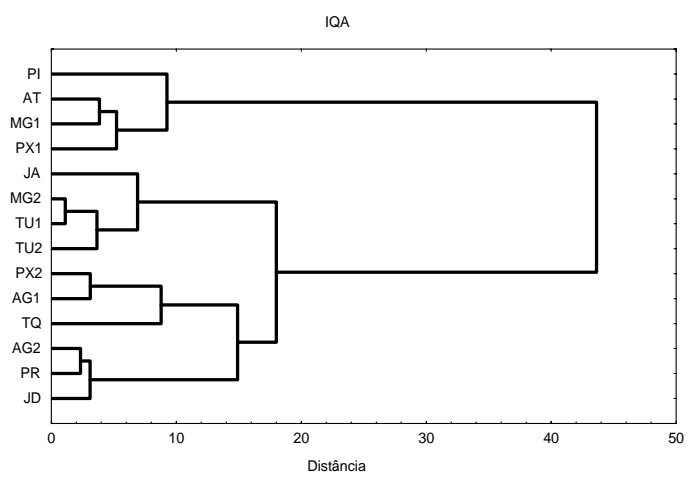

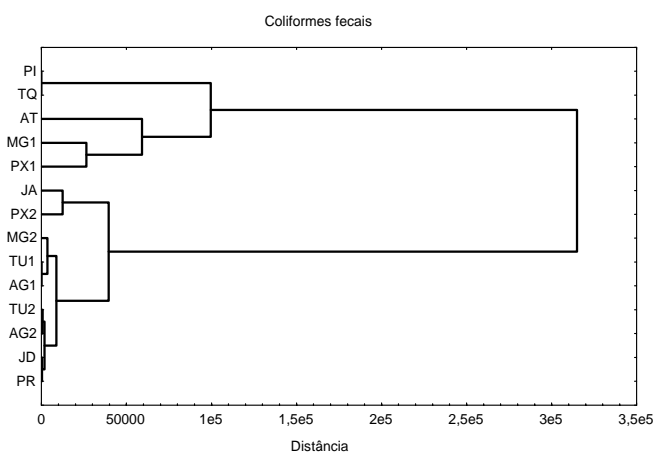

b.

Figura 9 - Dendrogramas resultantes da análise de agrupamento entre as bacias: a) cloreto; b) coliformes fecais; c) IQA

Os dendrogramas resultantes da análise de agrupamento entre regiões com comportamento similares mostram uma nítida distinção entre dois principais grupos, o primeiro podendo ainda ser subdividido em outros dois grupos, um com os postos da bacia do rio Piracicaba e seus formadores Atibaia e Jaguari; e outro com as bacias dos rios Mogi-Guaçu e Turvo Grande. O segundo também pode ser subdividido em outros dois grupos, um composto pelos postos das bacias dos rios Peixe e Aguapeí, e outro com os postos das bacias dos rios São José dos Dourados, Paranapanema e Taquari. Essa distinção pode estar condicionada às regiões mais impactadas, sendo as mais populosas e industrializadas, das regiões menos impactadas. 


\subsection{Análise sócio-econômica}

A análise sócio-econômica das bacias estudadas foi realizada visando apontar as possíveis causas da diminuição na qualidade da água, porém a base de dados existente é dispersa, principalmente na obtenção de dados históricos, e faz com que a maior dificuldade enfrentada seja a elaboração do banco de dados.

Para tal finalidade, várias fontes foram pesquisadas, entres elas IBGE (Instituto Brasileiro de Geografia e Estatística), SEADE (Fundação Sistema Estadual de Análise de Dados), SIGRH (Sistema Integrado de Gerenciamento de Recursos Hídricos de São Paulo), FUNDAP (Fundação do Desenvolvimento Administrativo), CETESB, SEMAE (Serviço Municipal de Água e Esgoto), Consórcio, Comitê CBH-PCJ (Piracicaba, Capivari e Jundiai), etc.

As Tabelas 11 e 12 apresentam dados de características sócio-econômicas obtidas para as bacias estudadas.

Apenas as populações médias das bacias estudadas, obtidas a partir das populações dos municípios inseridos em cada bacia, foram correlacionadas com os parâmetros de qualidade de água (Tabela 13), já que foi o único parâmetro sócioeconômico com dados históricos no mesmo período das séries de qualidade de água, e são apresentadas por bacia entre as Figuras 10 e 11. A população é um dos fatores sócioeconômicos que mais interferem na qualidade da água, uma vez que a relação do crescimento populacional com o baixo nível de tratamento de esgoto faz com que o aporte de esgotos domésticos para os corpos hídricos seja alto, deteriorando a qualidade da água.

Levando-se em consideração somente as bacias estudadas, a população total é de cerca de 8,5 milhões de pessoas, sendo aproximadamente 3,8 milhões na bacia do rio Piracicaba, 1,3 milhões na bacia do rio Mogi-Guaçu, 870 mil na bacia do rio Turvo Grande, 790 mil na bacia do rio Peixe, 590 mil na bacia do rio Aguapeí, 206 mil na bacia do rio São José dos Dourados e 680 mil na bacia do Alto Paranapanema.

Para a análise de correlação entre a população das bacias e os parâmetros estudados foram utilizadas médias anuais dos parâmetros de qualidade de água. Para a 
transformação da população média de 1970, 1980, 1990 e 2000 em séries anuais foram testadas diversas regressões, ou seja, lineares, exponenciais, potenciais e polinomiais, sendo retida a que apresentou maior coeficiente de correlação. O método de Spearman foi utilizado para verificar se população e parâmetro de qualidade de água apresentam correlação estatísticamente significativa. 
Tabela 11. Área e histórico de atributos sócio-econômicos das bacias estudadas

\begin{tabular}{|c|c|c|c|c|c|c|c|c|}
\hline & & Piracicaba & Mogi & Turvo & Peixe & Aguapeí & SJD & Alto Par. \\
\hline & Area $(\mathrm{km} 2)$ & 11.540 & 13.310 & 11.500 & 12.980 & 12.240 & 5.800 & 20.640 \\
\hline \multirow[t]{2}{*}{1970} & $\begin{array}{l}\text { Habitantes (x1000) } \\
\text { Taxa urb. (\%) }\end{array}$ & 1.500 & 600 & 470 & 570 & 500 & 160 & 410 \\
\hline & $\begin{array}{l}\text { Dens. dem. }\left(\mathrm{hab}^{\mathrm{km}} \mathrm{km}^{-2}\right) \\
\text { Trat. esgoto (\%) } \\
\left.\text { DBO remanes. (tDBO.dia }{ }^{-1}\right)\end{array}$ & 130 & 45 & 41 & 44 & 41 & 28 & 20 \\
\hline \multirow[t]{5}{*}{1980} & Habitantes (x1000) & 2.300 & 800 & 560 & 600 & 520 & 140 & 490 \\
\hline & Taxa urb. (\%) & 85 & 80 & 79 & 77 & 68 & 60 & 53 \\
\hline & Dens. dem. $\left(h a b . \mathrm{km}^{-2}\right)$ & 202 & 60 & 49 & 47 & 43 & 24 & 22 \\
\hline & Trat. esgoto (\%) & & & & & & & \\
\hline & DBO remanes. (tDBO.dia $\left.{ }^{-1}\right) 84$ & 156 & 89 & 46 & 10 & 20 & 3 & 24 \\
\hline \multirow[t]{5}{*}{1990} & Habitantes (x1000) & 3.150 & 1.050 & 720 & 674 & 540 & 150 & 600 \\
\hline & Taxa urb. (\%) & 91 & 87 & 88 & 87 & 82 & 74 & 66 \\
\hline & Dens. dem. $\left(h a b . \mathrm{km}^{-2}\right)$ & 272 & 79 & 63 & 52 & 45 & 26 & 26 \\
\hline & Trat. esgoto (\%) & & & & & & & \\
\hline & $\begin{array}{l}\text { DBO remanes. }(\text { tDBO.dia } \\
95\end{array}$ & 15 & 104 & 43 & 10 & 22 & 5 & 28 \\
\hline \multirow[t]{5}{*}{2000} & Habitantes (x1000) & 3.800 & 1.300 & 870 & 790 & 590 & 206 & 680 \\
\hline & Taxa urb. (\%) & 93 & 91 & 92 & 92 & 89 & 85 & 75 \\
\hline & Dens. dem. $\left(\right.$ hab. $\left.\mathrm{km}^{-2}\right)$ & 329 & 95 & 76 & 61 & 48 & 36 & 33 \\
\hline & Trat. esgoto (\%) & 12 & 20 & 18 & 29 & 36 & 63 & 48 \\
\hline & $\begin{array}{l}\text { DBO remanes. }\left(\text { (DBO.dia }{ }^{-1}\right) \\
\text { valores diferentes }(95-00)\end{array}$ & 122 & 50 & 34 & 16 & 11 & 3 & 11 \\
\hline
\end{tabular}

\footnotetext{
Fonte: SEADE e IBGE
} 
Tabela 12. Uso do solo das bacias estudadas referente ao ano de 1997 (Silva et al, submetido)

\begin{tabular}{|c|c|c|c|c|c|c|c|c|c|c|}
\hline \multirow{3}{*}{ Bacias } & \multirow{3}{*}{ sub-bacias } & \multirow{3}{*}{$\begin{array}{c}\text { pastagem } \\
\\
\\
\%\end{array}$} & \multirow{3}{*}{$\begin{array}{c}\text { Cultura } \\
\text { perene } \\
\text { \% }\end{array}$} & \multirow{3}{*}{$\begin{array}{c}\text { Floresta } \\
\\
\%\end{array}$} & \multirow{3}{*}{$\begin{array}{c}\text { Cana } \\
\text { açúcar } \\
\text { \% }\end{array}$} & \multirow{3}{*}{$\begin{array}{c}\text { silvicultura } \\
\\
\%\end{array}$} & \multirow{3}{*}{$\begin{array}{c}\text { água } \\
\text { \% }\end{array}$} & \multirow{3}{*}{$\begin{array}{c}\text { culturas } \\
\text { temporárias } \\
\%\end{array}$} & \multirow{3}{*}{$\begin{array}{c}\text { solo } \\
\text { exposto } \\
\% \\
\end{array}$} & \multirow{3}{*}{$\begin{array}{c}\text { urbaniz. } \\
\\
\%\end{array}$} \\
\hline & & & & & & & & & & \\
\hline & & & & & & & & & & \\
\hline \multirow[t]{2}{*}{ PARANAPANEMA } & TQ & 25,6 & 3,5 & 47,3 & 0,4 & 17,3 & 0,2 & 3,2 & 2,4 & 0,0 \\
\hline & PR & 49,8 & 4,2 & 23,7 & 0,3 & 11,5 & 3,4 & 4,5 & 2,2 & 0,3 \\
\hline \multirow[t]{2}{*}{ PEIXE } & PX1 & 47,5 & 10,4 & 35,4 & 5,0 & 0,6 & 0,0 & 0,0 & 1,0 & 0,0 \\
\hline & PX2 & 62,8 & 10,5 & 18,6 & 3,8 & 0,2 & 0,0 & 0,2 & 2,8 & 1,1 \\
\hline \multirow[t]{2}{*}{ AGUAPEÍ } & AG1 & 70,9 & 5,7 & 16,1 & 2,2 & 0,4 & 0,0 & 2,6 & 1,3 & 0,9 \\
\hline & AG2 & 72,6 & 4,4 & 13,4 & 3,4 & 0,2 & 0,0 & 3,1 & 2,0 & 0,8 \\
\hline SJDOURADOS & JD & 75,6 & 5,6 & 9,9 & 3,1 & 0,0 & 0,0 & 0,3 & 4,8 & 0,7 \\
\hline TURVO & TU & 44,4 & 3,6 & 25,7 & 12,6 & 0,2 & 0,1 & 0,8 & 11,0 & 1,6 \\
\hline MOGI-GUAÇU & MG & 19,6 & 1,5 & 9,6 & 38,9 & 4,3 & 0,6 & 0,7 & 21,5 & 1,7 \\
\hline PIRACICABA & PI & 43,2 & 0,1 & 10,1 & 33,7 & 4,2 & 1,7 & 1,1 & 0,3 & 5,7 \\
\hline
\end{tabular}


A Tabela 12 mostra que a pastagem é um dos principais usos da terra na maioria das bacias, variando de cerca de 19,6\%, na bacia do rio Mogi-Guaçu, até o caso da bacia do rio Aguapeí, com $73,7 \%$ da área total. Já na bacia do alto Paranapanema a principal cobertura do solo é floresta, e é a que apresenta a maior área relativa coberta por reflorestamento. Outras bacias que apresentam importantes áreas cobertas por vegetação nativa são a do rio do Peixe e a do rio Turvo. Nas bacias dos rios Mogi-Guaçu, Piracicaba e Turvo destacam-se a cultura de cana-de-açucar e a área coberta por urbanização (Silva et al, submetido).

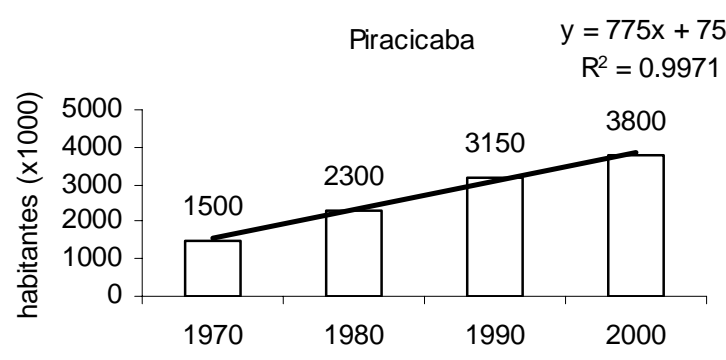

a)

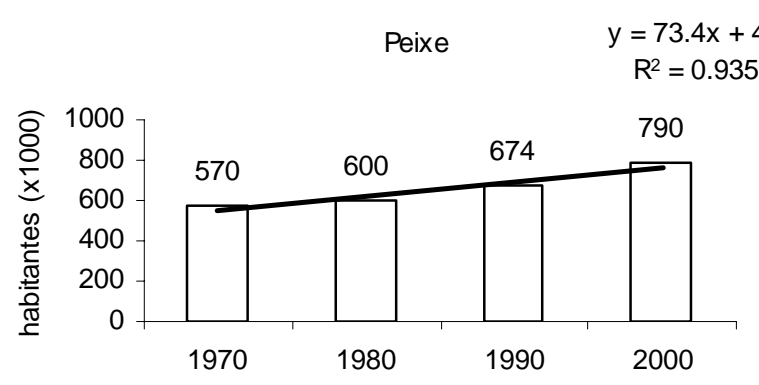

c)

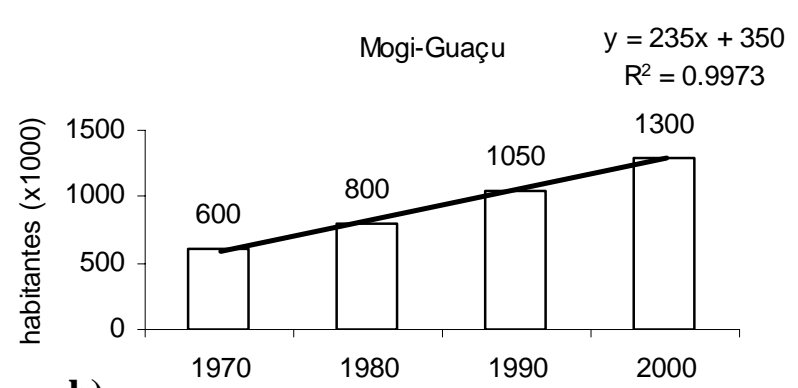

b)

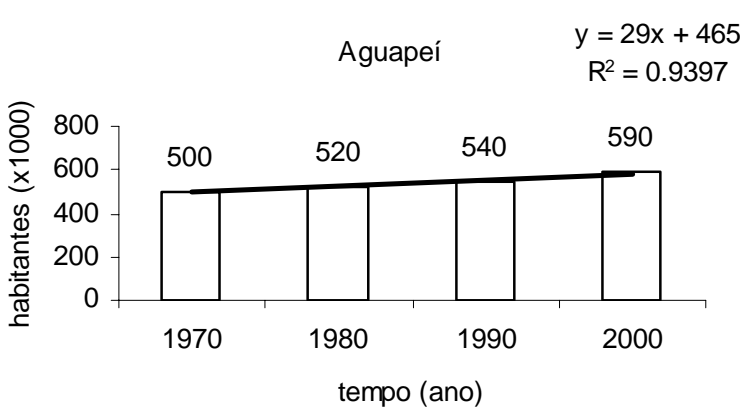

d)

Figura 10 - Evolução da população nas bacias estudadas e suas respectivas equações de regressão: a) Piracicaba; b) Mogi-Guaçu; c) Peixe; d) Aguapeí 


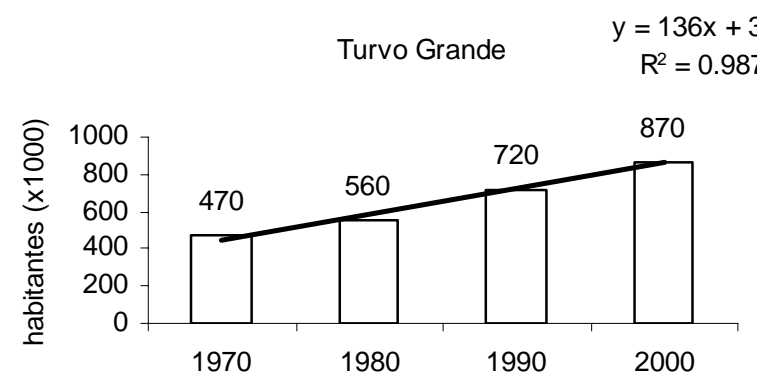

a)

tempo (ano)
São José dos Dourados

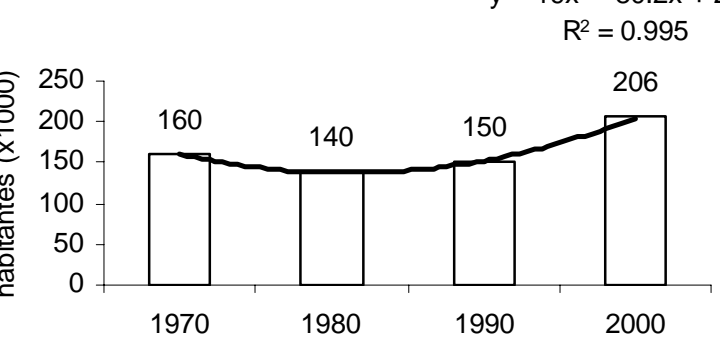

b)

tempo (ano)

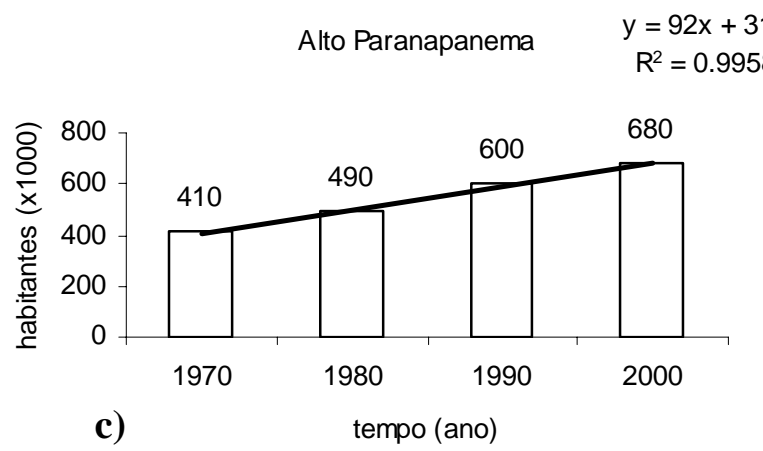

Figura 11 - Evolução da população nas bacias estudadas e suas respectivas equações de regressão: a) Turvo Grande; b) São José dos Dourados; c) Alto Paranapanema 
Tabela 13. Correlação da população com os parâmetros estudados: $r^{2}=$ coeficiente de correlação, $\mathrm{SL}=$ nível de significância; $\mathrm{s}=$ significativo; $\mathrm{ns}=$ não significativo, considerando $\alpha=0,05$

\begin{tabular}{|c|c|c|c|c|c|c|c|c|c|c|c|c|c|c|c|}
\hline & & \multicolumn{3}{|c|}{ Piracicaba } & \multicolumn{2}{|c|}{ Mogi } & \multicolumn{2}{|c|}{ Turvo } & \multicolumn{2}{|c|}{ Peixe } & \multicolumn{2}{|c|}{ Aguapeí } & \multirow{2}{*}{$\begin{array}{c}\boldsymbol{S J D} \\
\text { JD }\end{array}$} & \multicolumn{2}{|c|}{ Paranap } \\
\hline & & PI & JA & $\mathrm{AT}$ & MG1 & MG2 & TU1 & TU2 & PX1 & $\mathrm{PX} 2$ & AG1 & AG2 & & PR & TQ \\
\hline Pop $x$ & $r^{2}$ & $-0,6$ & $-0,2$ & $-0,3$ & $-0,4$ & $-0,02$ & 0,25 & 0,3 & $-0,8$ & $-0,7$ & $-0,6$ & $-0,6$ & $-0,7$ & 0,27 & 0,78 \\
\hline OD & $S L$ & s & ns & ns & s & ns & ns & ns & $\mathbf{s}$ & $\mathbf{s}$ & $\mathbf{s}$ & $\mathbf{s}$ & $\mathbf{s}$ & ns & $\mathbf{s}$ \\
\hline Pop $x$ & $r^{2}$ & 0,74 & 0,14 & 0,39 & 0,18 & 0,36 & 0,71 & 0,40 & 0,35 & 0,66 & 0,32 & 0,46 & 0,48 & 0,28 & $-0,5$ \\
\hline DBO & $S L$ & $\mathbf{s}$ & ns & ns & ns & ns & s & ns & ns & s & ns & s & $\mathbf{s}$ & ns & $\mathbf{s}$ \\
\hline Pop $x$ & $r^{2}$ & 0,17 & $-0,4$ & - & $-0,5$ & 0,2 & 0,38 & 0,2 & $-0,6$ & $-0,6$ & $-0,7$ & $-0,7$ & $-0,02$ & $-0,2$ & 0,17 \\
\hline Nitr & $S L$ & ns & ns & - & $\mathbf{s}$ & ns & ns & ns & s & s & s & s & ns & ns & ns \\
\hline Pop $x$ & $r^{2}$ & 0,71 & 0,91 & 0,32 & 0,39 & 0,59 & 0,73 & 0,79 & 0,10 & $-0,6$ & $-0,01$ & 0,08 & 0,75 & 0,51 & 0,79 \\
\hline Nitrato & $S L$ & $\mathbf{s}$ & $\mathbf{s}$ & ns & ns & $\mathbf{s}$ & s & $\mathbf{s}$ & ns & s & ns & ns & s & s & s \\
\hline Pop $x$ & $r^{2}$ & 0,52 & 0,54 & 0,57 & 0,47 & 0,40 & 0,66 & 0,56 & 0,19 & 0,02 & $-0,1$ & $-0,1$ & $-0,13$ & $-0,3$ & $-0,3$ \\
\hline Amon & $S L$ & s & s & s & s & $\mathrm{s}$ & s & s & ns & ns & ns & ns & ns & ns & ns \\
\hline Pop $x$ & $r^{2}$ & 0,52 & 0,31 & 0,46 & $-0,02$ & 0,42 & 0,52 & 0,57 & 0,8 & 0,04 & $-0,2$ & 0,06 & 0,39 & 0,38 & 0,35 \\
\hline Fósf & $S L$ & $\mathbf{s}$ & ns & $\mathbf{s}$ & ns & $\mathbf{s}$ & s & $\mathbf{s}$ & ns & ns & ns & ns & ns & ns & ns \\
\hline Pop $x$ & $r^{2}$ & 0,75 & 0,46 & 0,25 & 0,04 & 0,21 & 0,43 & 0,61 & 0,28 & 0,35 & 0,25 & 0,29 & 0,67 & $-0,07$ & $-0,4$ \\
\hline Cloret & $S L$ & s & $\mathbf{s}$ & ns & ns & ns & $\mathbf{s}$ & s & ns & ns & ns & ns & $\mathbf{s}$ & ns & ns \\
\hline Pop $x$ & $r^{2}$ & $-0,4$ & $-0,3$ & $-0,3$ & $-0,66$ & 0,26 & $-0,4$ & $-0,2$ & 0,37 & 0,18 & 0,15 & 0,09 & 0,32 & $-0,25$ & 0,11 \\
\hline Colif & $S L$ & $\mathbf{s}$ & ns & ns & s & ns & ns & ns & ns & ns & ns & ns & ns & ns & ns \\
\hline
\end{tabular}

As correlações entre a população das bacias à montante dos pontos de coleta aos longos dos anos e as séries temporais dos parâmetros não apresentaram uma resposta muito clara na interpretação dos resultados. Uma tentativa de interpretação em termos de bacias pode ser realizada separando-se as mais impactadas Piracicaba, Mogi e Turvo das menos impactadas Peixe, Aguapeí, São José dos Dourados e Alto Paranapanema. No primeiro grupo, 50\% apresentaram correlações estatisticamente significativas relativas aos parâmetros estudados, e no segundo grupo apenas 34\% apresentaram correlações estatisticamente significativas. 
Quanto aos resultados relativos aos parâmetros em todas as bacias, apenas o OD e o nitrato apresentaram correlações significativas na maior parte das bacias. Por outro lado, o amônio, o fósforo e o cloreto, que estão ligados a despejos domésticos, apresentaram correlações significativas apenas no grupo das mais impactadas (Piracicaba, Mogi e Turvo). 


\section{CONCLUSÕES}

Os resultados da análise de tendência mostraram que, de uma maneira geral, existe uma degradação da qualidade da água na maior parte das bacias, representada pelas tendências positivas nos parâmetros (DBO, nitrogênios, fósforo total, cloreto e coliformes fecais) e negativo no parâmetro (OD). Das bacias hidrográficas estudadas, a bacia do rio Piracicaba, representada pelosmaiores coeficientes angulares, "Sen's Slope" e valores médios em praticamente todos os parâmetros, é a mais severamente afetada, seguida pelas bacias dos rios Mogi e Turvo, sendo que por outro lado, as bacias Alto Paranapanema e São José dos Dourados são as menos afetadas.

Esses resultados foram confirmados pela análise de agrupamento que mostrou uma nítida distinção entre dois principais grupos, um com os postos da bacia do rio Piracicaba, Mogi-Guaçu e Turvo Grande, e o segundo composto pelos postos das bacias dos rios Peixe, Aguapeí, São José dos Dourados, Paranapanema e Taquari.

A diminuição na qualidade de água nas bacias estudadas afeta cerca de 8,5 milhões de pessoas, e essa diminuição tem como principais causas o crescimento industrial e urbano, e o baixo nível do tratamento de esgoto, sendo que somente $17 \%$ do esgoto gerado no Estado recebe algum tipo de tratamento prévio (Martinelli et al, 2002). Portanto, a carga domiciliar remanescente é extremamente elevada. Esse aporte extra de matéria orgânica causa mudanças profundas nos corpos hídricos receptores. 
ANEXOS 


\section{Anexo A} tendência:

Sumário das análises estatísticas dos testes de normalidade, sazonalidade e

Onde:

* $\lambda$ : transformações Box-Cox $(\lambda=0$ transformação logarítmica; e $\lambda=1$ nenhuma transformação);

* W: teste de Wilk-Shapiro;

* Kruskall: teste de sazonalidade de Kruskall-Wallis;

* SL: nível de significância;

* Sazonal de Mann-Kendall e Mann-Kendall: teste de tendência sazonal ou não sazonal. 


\begin{tabular}{|c|c|c|c|c|c|c|c|c|c|c|c|}
\hline \multirow{2}{*}{ TESTES } & \multicolumn{9}{|c|}{ PI2800 (PI) } & \multirow[b]{2}{*}{ Tendência } & \multirow[b]{2}{*}{$S L$} \\
\hline & \multicolumn{2}{|c|}{ Normalidade } & Kruskall & $\boldsymbol{P}$ & Combined & Variança & $S L$ & tau & $S L$ & & \\
\hline$O D$ & 1 & $\begin{array}{c}0,952 \\
0,24 * 10^{-3}\end{array}$ & Não & 0,514 & & & & $-0,312$ & $1,7 * 10^{-8}$ & - & $\mathrm{S}$ \\
\hline$D B O$ & 0 & $\begin{array}{c}0,95 \\
0,67 * 10^{-3}\end{array}$ & Não & 0,737 & & & & 0,310 & 000 & + & $\mathrm{S}$ \\
\hline Nitrogênio & 1 & $\begin{array}{l}0,77 \\
000\end{array}$ & Não & 0,108 & & & & 0,085 & $1,2^{*} 10^{-1}$ & + & ns \\
\hline Nitrato & 1 & $\begin{array}{c}0,950 \\
0,11^{*} 10^{-3}\end{array}$ & Não & 0,895 & & & & 0,287 & $2,4 * 10^{-7}$ & + & $\mathrm{S}$ \\
\hline Amônio & 0 & $\begin{array}{c}0,969 \\
0,53 * 10^{-1}\end{array}$ & Não & 0,105 & & & & 0,270 & $1,1 * 10^{-6}$ & + & $\mathrm{S}$ \\
\hline Fósforo & 0 & $\begin{array}{c}0,920 \\
0,19^{*} 10^{-9}\end{array}$ & Não & 0,272 & & & & 0,330 & 000 & + & $\mathrm{S}$ \\
\hline Cloreto & 0 & $\begin{array}{l}0,944 \\
0,188\end{array}$ & Não & 0,613 & & & & 0,360 & 000 & + & $\mathrm{S}$ \\
\hline $\begin{array}{l}\text { Coliformes } \\
\text { Fecais }\end{array}$ & 0 & $\begin{array}{l}0,979 \\
0,401\end{array}$ & Não & 0,470 & & & & $-0,115$ & $3,7 * 10^{-2}$ & - & $\mathrm{S}$ \\
\hline$V a z \tilde{a} o$ & 0 & $\begin{array}{l}0,974 \\
0,154\end{array}$ & & & -14 & 10584 & $8,9^{*} 10^{-1}$ & & & - & ns \\
\hline Precipitação & & & & & & IMESTRAL & & & JAL & & \\
\hline D4-034 & 1 & $\begin{array}{l}0,945 \\
0,229\end{array}$ & & & 112 & 8600 & $2,3 * 10^{-1}$ & 0,333 & $2,3 * 10^{-2}(\mathbf{s})$ & + & $\mathrm{ns}$ \\
\hline D4-036 & 1 & $\begin{array}{c}0,87 \\
0,58^{*} 10^{-2}\end{array}$ & & & 76 & 8600 & $4,1 * 10^{-1}$ & $-0,137(-)$ & $3,4 * 10^{-1}$ & + & $\mathrm{ns}$ \\
\hline D4-059 & 1 & $\begin{array}{l}0,950 \\
0,298\end{array}$ & & & 112 & 8600 & $2,2 * 10^{-1}$ & 0,130 & $3,9 * 10^{-1}$ & + & ns \\
\hline & & & & & & Sazonal & & Não & azonal & & \\
\hline
\end{tabular}

\begin{tabular}{|c|c|c|c|c|c|c|c|c|c|c|c|}
\hline \multicolumn{12}{|c|}{ JA2800 (JA) } \\
\hline TESTES & & malidade & Sazonc & dade & Sazon & de Mann-I & ndall & Mann & Kendall & & \\
\hline & $\lambda$ & We $S L$ & Kruskall & $\boldsymbol{P}$ & Combined & Variança & $S L$ & tau & $S L$ & Tendência & $S L$ \\
\hline$O D$ & 1 & $\begin{array}{c}0,939 \\
0,54 * 10^{-5}\end{array}$ & Sim & 0,001 & -175 & 8249 & $5,4 * 10^{-2}$ & & & - & ns \\
\hline DBO & 0 & $\begin{array}{c}0,776 \\
000\end{array}$ & Não & 0,578 & & & & 0,086 & $1,4 * 10^{-1}$ & + & ns \\
\hline Nitrogênio & 1 & $\begin{array}{c}0,947 \\
0,13 * 10^{-4}\end{array}$ & Não & 0,327 & & & & $-0,118$ & $4,1 * 10^{-2}$ & - & S \\
\hline Nitrato & 1 & $\begin{array}{c}0,897 \\
0,13 * 10^{-12}\end{array}$ & Não & 0,158 & & & & 0,481 & 000 & + & $\mathrm{S}$ \\
\hline Amônio & 0 & $\begin{array}{l}0,975 \\
0,222\end{array}$ & Não & 0,901 & & & & 0,190 & $9,9 * 10^{-4}$ & + & $\mathrm{S}$ \\
\hline Fósforo & 0 & $\begin{array}{l}0,974 \\
0,194\end{array}$ & Não & 0,551 & & & & 0,174 & $2,7 * 10^{-3}$ & + & $\mathrm{S}$ \\
\hline Cloreto & 0 & $\begin{array}{l}0,972 \\
0,128\end{array}$ & Não & 0,968 & & & & 0,378 & 000 & + & $\mathrm{S}$ \\
\hline $\begin{array}{l}\text { Coliformes } \\
\text { Fecais }\end{array}$ & 0 & $\begin{array}{c}0,965 \\
0,24 * 10^{-1}\end{array}$ & Não & 0,339 & & & & $-0,313$ & $6,5^{*} 10^{-8}$ & - & $\mathrm{S}$ \\
\hline Vazãa & 0 & $\begin{array}{c}0,961 \\
0,79 * 10^{-2}\end{array}$ & & & 0 & & 1,00 & & & & \\
\hline Precipitação & & & & & & IMESTRAI & & & JAL & & \\
\hline D4-034 & 1 & $\begin{array}{l}0,945 \\
0,229\end{array}$ & & & 112 & 8600 & $2,3 * 10^{-1}$ & 0,333 & $2,3 * 10^{-2}(\mathbf{s})$ & + & ns \\
\hline D4-036 & 1 & $\begin{array}{c}0,87 \\
0,58 * 10^{-2}\end{array}$ & & & 76 & 8600 & $4,1 * 10^{-1}$ & $-0,137(-)$ & $3,4 * 10^{-1}$ & + & ns \\
\hline D4-059 & 1 & $\begin{array}{l}0,950 \\
0,298\end{array}$ & & & 112 & 8600 & $2,2 * 10^{-1}$ & 0,130 & $3,9 * 10^{-1}$ & + & ns \\
\hline
\end{tabular}




\begin{tabular}{|c|c|c|c|c|c|c|c|c|c|c|c|}
\hline \multirow{2}{*}{ TESTES } & \multicolumn{9}{|c|}{ AT2065 (AT) } & \multirow[b]{2}{*}{ Tendência } & \multirow[b]{2}{*}{$S L$} \\
\hline & \multicolumn{2}{|c|}{ Normalidade } & Kruskall & $\boldsymbol{P}$ & Combined & Variança & $S L$ & tau & $S L$ & & \\
\hline$O D$ & 1 & $\begin{array}{c}0,950 \\
0,22 * 10^{-3}\end{array}$ & Não & 0,081 & & & & $-0,112$ & $5,1 * 10^{-2}$ & - & $\mathrm{ns}$ \\
\hline$D B O$ & 0 & $\begin{array}{c}0,929 \\
0,96^{*} 10^{-7}\end{array}$ & Não & 0,481 & & & & 0,194 & $7,6^{*} 10^{-4}$ & + & $\mathrm{S}$ \\
\hline Nitrato & 1 & $\begin{array}{c}0,927 \\
0,34 * 10^{-7}\end{array}$ & Não & 0,155 & & & & 0,231 & $6,1 * 10^{-5}$ & + & $\mathrm{S}$ \\
\hline Amônio & 0 & $\begin{array}{l}0,984 \\
0,729\end{array}$ & Não & 0,294 & & & & 0,353 & 000 & + & $\mathrm{S}$ \\
\hline Fósforo & 0 & $\begin{array}{c}0,921 \\
0,37 * 10^{-8}\end{array}$ & Não & 0,870 & & & & 0,310 & $1,2 * 10^{-7}$ & + & $\mathrm{S}$ \\
\hline Cloreto & 0 & $\begin{array}{l}0,986 \\
0,835\end{array}$ & Sim & 0,014 & 176 & 8426 & $5,5^{*} 10^{-2}$ & & & + & $\mathrm{ns}$ \\
\hline $\begin{array}{l}\text { Coliformes } \\
\text { Fecais }\end{array}$ & 0 & $\begin{array}{c}0,977 \\
0,3203\end{array}$ & Não & 0,346 & & & & $-0,049$ & $3,9 * 10^{-1}$ & - & ns \\
\hline$V a z \tilde{a} o$ & 0 & $\begin{array}{l}0,975 \\
0,225\end{array}$ & & & 8 & 8426 & $9,3^{*} 10^{-1}$ & & & + & ns \\
\hline Precipitação & & & & & & IMESTRAL & & & JAL & & \\
\hline D4-034 & 1 & $\begin{array}{l}0,945 \\
0,229\end{array}$ & & & 112 & 8600 & $2,3 * 10^{-1}$ & 0,333 & $2,3 * 10^{-2}$ (s) & + & ns \\
\hline D4-036 & 1 & $\begin{array}{c}0,87 \\
0,58 * 10^{-2}\end{array}$ & & & 76 & 8600 & $4,1 * 10^{-1}$ & $-0,137(-)$ & $3,4 * 10^{-1}$ & + & $\mathrm{ns}$ \\
\hline D4-059 & 1 & $\begin{array}{l}0,950 \\
0,298\end{array}$ & & & 112 & 8600 & $2,2 * 10^{-1}$ & 0,130 & $3,9^{*} 10^{-1}$ & + & ns \\
\hline & & & & & & Sazonal & & Não & azonal & & \\
\hline
\end{tabular}

\section{MG2070 (MG1)}

\begin{tabular}{|c|c|c|c|c|c|c|c|c|c|c|c|}
\hline \multirow[t]{2}{*}{ TESTES } & \multicolumn{2}{|c|}{ Normalidade } & \multicolumn{2}{|c|}{ Sazonalidade } & \multicolumn{3}{|c|}{ Sazonal de Mann-Kendall } & \multicolumn{2}{|c|}{ Mann-Kendall } & \multirow[b]{2}{*}{ Tendência } & \multirow[b]{2}{*}{$S L$} \\
\hline & $\lambda$ & $W e S L$ & Kruskall & $\boldsymbol{P}$ & Combined & Variança & $S L$ & tau & $S L$ & & \\
\hline$O D$ & 1 & $\begin{array}{c}0,977 \\
0,28\end{array}$ & Sim & 0,002 & -292 & 8602 & $1,6 * 10^{-3}$ & & & s. & $\mathrm{S}$ \\
\hline$D B O$ & 0 & $\begin{array}{c}0,883 \\
0,9^{*} 10^{-16}\end{array}$ & Sim & 0,030 & 218 & 8602 & $1,8 * 10^{-2}$ & & & + & $\mathrm{S}$ \\
\hline Nitrogênio & 1 & $\begin{array}{c}0,745 \\
000\end{array}$ & Sim & 0,023 & -278 & 8602 & $2,7 * 10^{-3}$ & & & - & $\mathrm{S}$ \\
\hline Nitrato & 1 & $\begin{array}{c}0,940 \\
0,52 * 10^{-5}\end{array}$ & Não & 0,446 & & & & 0,222 & $1,1 * 10^{-4}$ & + & $\mathrm{S}$ \\
\hline Amônio & 0 & $\begin{array}{c}0,968 \\
0,41 * 10^{-1}\end{array}$ & Sim & 0,033 & 188 & 8602 & $4,2 * 10^{-2}$ & & & + & $\mathrm{S}$ \\
\hline Fósforo & 0 & $\begin{array}{c}0,927 \\
0,36^{*} 10^{-7}\end{array}$ & Não & 0,656 & & & & 0,034 & $5,5^{*} 10^{-1}$ & + & ns \\
\hline Cloreto & 0 & $\begin{array}{c}0,960 \\
0,51 * 10^{-2}\end{array}$ & Sim & 0,0001 & 76 & 8602 & $4,1 * 10^{-1}$ & & & + & ns \\
\hline $\begin{array}{l}\text { Coliformes } \\
\text { Fecais }\end{array}$ & 0 & $\begin{array}{c}0,967 \\
0,34 * 10^{-1}\end{array}$ & Sim & 0,002 & -500 & 8602 & $7 * 10^{-8}$ & & & - & $\mathrm{S}$ \\
\hline Vazão & 0 & $\begin{array}{c}0,968 \\
0,49 * 10^{-1}\end{array}$ & & & 88 & 8602 & $3,4 * 10^{-1}$ & & & + & ns \\
\hline Precipitação & & & & & & BIMESTRAL & & & JAL & & \\
\hline D4-029 & 1 & $\begin{array}{c}0,866 \\
0,44 * 10^{-2}\end{array}$ & & & 21 & 7219 & $8,1 * 10-1$ & & & + & ns \\
\hline D4-034 & 1 & $\begin{array}{c}0,882 \\
0,99 * 10^{-2}\end{array}$ & & & 45 & 7054 & $5,9 * 10-1$ & & & + & ns \\
\hline & & & & & & Sazonal & & Não & azonal & & \\
\hline
\end{tabular}




\begin{tabular}{|c|c|c|c|c|c|c|c|c|c|c|c|}
\hline \multicolumn{12}{|c|}{ MG2280 (MG2) } \\
\hline \multirow[t]{2}{*}{ TESTES } & \multirow{2}{*}{\multicolumn{2}{|c|}{ Normalidade }} & \multicolumn{2}{|c|}{ Sazonalidade } & \multicolumn{3}{|c|}{ Sazonal de Mann-Kendall } & \multicolumn{2}{|c|}{ Mann-Kendall } & \multirow[b]{2}{*}{ Tendência } & \multirow[b]{2}{*}{$S L$} \\
\hline & & We $S L$ & Kruskall & $P$ & Combined & Variança & $S L$ & tau & $S L$ & & \\
\hline$O D$ & 1 & $\begin{array}{l}0,982 \\
0,628\end{array}$ & Sim & 0,0002 & -102 & 8602 & $2,7 * 10^{-1}$ & & & - & ns \\
\hline DBO & 0 & $\begin{array}{c}0,779 \\
000\end{array}$ & Sim & 0,016 & 206 & 8602 & $2,6^{*} 10^{-2}$ & & & + & S \\
\hline Nitrogênio & 1 & $\begin{array}{c}0,961 \\
0,71 * 10^{-2}\end{array}$ & Não & 0,874 & & & & 0,098 & $8,7 * 10^{-2}$ & + & $\mathrm{ns}$ \\
\hline Nitrato & 1 & $\begin{array}{c}0,915 \\
0,24 * 10^{-8}\end{array}$ & Sim & 0,003 & 392 & 8602 & $2,4 * 10^{-5}$ & & & + & $\mathrm{S}$ \\
\hline Amônio & 0 & $\begin{array}{c}0,927 \\
0,37 * 10^{-7}\end{array}$ & Não & 0,538 & & & & 0,215 & $1,7 * 10^{-4}$ & + & $\mathrm{S}$ \\
\hline Fósforo & 0 & $\begin{array}{c}0,928 \\
0,43^{*} 10^{-7}\end{array}$ & Não & 0,615 & & & & 0,157 & $6,3 * 10^{-3}$ & + & $\mathrm{S}$ \\
\hline Cloreto & 0 & $\begin{array}{c}0,971 \\
0,97 * 10^{-1}\end{array}$ & Sim & 0,0001 & 234 & 8602 & $1,1 * 10^{-2}$ & & & + & $\mathrm{S}$ \\
\hline $\begin{array}{l}\text { Coliformes } \\
\text { Fecais }\end{array}$ & 0 & $\begin{array}{c}0,965 \\
0,24 * 10^{-1}\end{array}$ & Não & 0,292 & & & & 0,075 & $1,9 * 10^{-1}$ & + & $\mathrm{S}$ \\
\hline $\operatorname{Vaz} \tilde{a} o$ & 0 & $\begin{array}{c}0,968 \\
0,49 * 10^{-1}\end{array}$ & & & 88 & 8602 & $3,4 * 10^{-1}$ & & & + & $\mathrm{ns}$ \\
\hline Precipitação & & & & & & 3IMESTRAL & & & JAL & & \\
\hline D4-029 & 1 & $\begin{array}{c}0,866 \\
0,44 * 10^{-2}\end{array}$ & & & 21 & 7219 & $8,1 * 10-1$ & & & + & ns \\
\hline D4-034 & 1 & $\begin{array}{c}0,882 \\
0,99 * 10^{-2}\end{array}$ & & & 45 & 7054 & $5,9 * 10-1$ & & & + & $\mathrm{ns}$ \\
\hline & & & & & & Sazonal & & Nãc & azonal & & \\
\hline
\end{tabular}

\begin{tabular}{|c|c|c|c|c|c|c|c|c|c|c|c|}
\hline \multicolumn{12}{|c|}{ TU2250 (TU1) } \\
\hline TESTES & \multicolumn{2}{|c|}{ Normalidade } & \multicolumn{2}{|c|}{ Sazonalidade } & \multicolumn{3}{|c|}{ Sazonal de Mann-Kendall } & \multicolumn{2}{|c|}{ Mann-Kendall } & \multirow[b]{2}{*}{ Tendência } & \multirow[b]{2}{*}{$S L$} \\
\hline & $\lambda$ & We $S L$ & Kruskall & $\boldsymbol{P}$ & Combined & Variança & $S L$ & tau & $S L$ & & \\
\hline$O D$ & 1 & $\begin{array}{c}0,965 \\
0,23^{*} 10^{-1}\end{array}$ & Sim & 0,0001 & -56 & 8602 & $5,45^{*} 10^{-1}$ & & & - & ns \\
\hline DBO & 0 & $\begin{array}{c}0,851 \\
0,1^{*} 10^{-22}\end{array}$ & Não & 0,133 & & & & 0,215 & $1,74 * 10^{-4}$ & + & $\mathrm{S}$ \\
\hline Nitrogênio & 1 & $\begin{array}{c}0,879 \\
0,1 * 10^{-16}\end{array}$ & Não & 0,086 & & & & 0,221 & $1,15^{*} 10^{-4}$ & + & $\mathrm{S}$ \\
\hline Nitrato & 1 & $\begin{array}{c}0,887 \\
0,6^{*} 10^{-15}\end{array}$ & Não & 0,200 & & & & 0,312 & 000 & + & $\mathrm{S}$ \\
\hline Amônio & 0 & $\begin{array}{c}0,889 \\
0,2^{*} 10^{-14}\end{array}$ & Sim & 0,017 & 514 & 8602 & 000 & & & + & $\mathrm{S}$ \\
\hline Fósforo & 0 & $\begin{array}{c}0,940 \\
0,66 * 10^{-5}\end{array}$ & Não & 0,676 & & & & 0,227 & $7,63 * 10^{-5}$ & + & $\mathrm{S}$ \\
\hline Cloreto & 0 & $\begin{array}{c}0,965 \\
0,22 * 10^{-1}\end{array}$ & Sim & 0,031 & 260 & 8602 & $5,06^{*} 10^{-3}$ & & & + & $\mathrm{S}$ \\
\hline $\begin{array}{l}\text { Coliformes } \\
\text { Fecais }\end{array}$ & 0 & $\begin{array}{c}0,924 \\
0,99 * 10^{-8}\end{array}$ & Não & 0,319 & & & & 0,025 & $6,54 * 10^{-1}$ & + & ns \\
\hline Vazãa & 0 & $\begin{array}{c}0,947 \\
0,84 * 10^{-4}\end{array}$ & & & -12 & 8602 & $8,97 * 10^{-1}$ & & & - & ns \\
\hline \multicolumn{12}{|l|}{ Precipitação } \\
\hline & & & & & \multicolumn{3}{|c|}{ BIMESTRAL } & \multicolumn{2}{|c|}{ ANUAL } & & \\
\hline B5-035 & 1 & $\begin{array}{c}0,904 \\
0,29^{*} 10^{-1}\end{array}$ & & & -150 & 8590 & $2,6^{*} 10^{-1}$ & $-0,079$ & $5,7 * 10^{-1}$ & - & ns \\
\hline C4-092 & 1 & $\begin{array}{c}0,878 \\
0,79 * 10^{-2}\end{array}$ & & & -31 & 8598 & $7,4 * 10^{-1}$ & $-0,094$ & $5,1 * 10^{-1}$ & - & ns \\
\hline & & & & & \multicolumn{3}{|c|}{ Sazonal } & \multicolumn{2}{|c|}{ Não Sazonal } & & \\
\hline
\end{tabular}




\begin{tabular}{|c|c|c|c|c|c|c|c|c|c|c|c|}
\hline \multicolumn{12}{|c|}{ TU2500 (TU2) } \\
\hline \multirow[t]{2}{*}{ TESTES } & \multirow{2}{*}{\multicolumn{2}{|c|}{ Normalidade }} & \multicolumn{2}{|c|}{ Sazonalidade } & \multicolumn{3}{|c|}{ Sazonal de Mann-Kendall } & \multicolumn{2}{|c|}{ Mann-Kendall } & \multirow[b]{2}{*}{ Tendência } & \multirow[b]{2}{*}{$S L$} \\
\hline & & & Kruskall & $P$ & Combined & Variança & $S L$ & tau & $S L$ & & \\
\hline$O D$ & 1 & $\begin{array}{c}0,923 \\
0,69 * 10^{-8}\end{array}$ & Sim & 000 & 28 & 8602 & $7,6^{*} 10^{-1}$ & & & + & $\mathrm{ns}$ \\
\hline DBO & 0 & $\begin{array}{c}0,797 \\
000\end{array}$ & Não & 0,175 & & & & 0,136 & $1,76^{*} 10^{-2}$ & + & $\mathrm{S}$ \\
\hline Nitrogênio & 1 & $\begin{array}{c}0,932 \\
0,2 * 10^{-6}\end{array}$ & Sim & 0,005 & 172 & 8602 & $6,36^{*} 10^{-2}$ & & & + & ns \\
\hline Nitrato & 1 & $\begin{array}{c}0,828 \\
000\end{array}$ & Sim & 0,023 & 612 & 8602 & 000 & & & + & $\mathrm{S}$ \\
\hline Amônio & 0 & $\begin{array}{c}0,745 \\
000\end{array}$ & Não & 0,069 & & & & 0,250 & $1,35 * 10-5$ & + & $\mathrm{S}$ \\
\hline Fósforo & 0 & $\begin{array}{c}0,930 \\
0,13^{*} 10^{-6}\end{array}$ & Não & 0,751 & & & & 0,284 & $7,15 * 10^{-7}$ & + & $\mathrm{S}$ \\
\hline Cloreto & 0 & $\begin{array}{c}0,961 \\
0,81 * 10^{-2}\end{array}$ & Não & 0,082 & & & & 0,227 & $7,62 * 10^{-5}$ & + & $\mathrm{S}$ \\
\hline $\begin{array}{l}\text { Coliformes } \\
\text { Fecais }\end{array}$ & 0 & $\begin{array}{c}0,935 \\
0,85^{*} 10^{-6}\end{array}$ & Não & 0,540 & & & & $-0,074$ & $1,93 * 10^{-1}$ & - & ns \\
\hline$V a z \tilde{a} \tilde{o}$ & & $\begin{array}{c}0,947 \\
0,84 * 10^{-4}\end{array}$ & & & -12 & 8602 & $8,97 * 10^{-1}$ & & & - & $\mathrm{ns}$ \\
\hline \multicolumn{12}{|l|}{ Precipitação } \\
\hline & & & & & \multicolumn{3}{|c|}{ BIMESTRAL } & \multicolumn{2}{|c|}{ ANUAL } & & \\
\hline B5-035 & 1 & $\begin{array}{c}0,904 \\
0,29^{*} 10^{-1}\end{array}$ & & & -150 & 8590 & $2,6^{*} 10^{-1}$ & $-0,079$ & $5,7^{*} 10^{-1}$ & - & $\mathrm{ns}$ \\
\hline \multirow[t]{2}{*}{ C4-092 } & 1 & $\begin{array}{c}0,878 \\
0,79 * 10^{-2}\end{array}$ & & & -31 & 8590 & $7,4^{*} 10^{-1}$ & $-0,094$ & $5,1 * 10^{-1}$ & - & $\mathrm{ns}$ \\
\hline & & & & & \multicolumn{3}{|c|}{ Sazonal } & \multicolumn{2}{|c|}{ Não Sazonal } & & \\
\hline
\end{tabular}

\begin{tabular}{|c|c|c|c|c|c|c|c|c|c|c|c|}
\hline \multicolumn{12}{|c|}{ PX2032 (PX1) } \\
\hline \multirow[t]{2}{*}{ TESTES } & \multicolumn{2}{|c|}{ Normalidade } & \multicolumn{2}{|c|}{ Sazonalidade } & \multicolumn{3}{|c|}{ Sazonal de Mann-Kendall } & \multicolumn{2}{|c|}{ Mann-Kendall } & \multirow[b]{2}{*}{ Tendência } & \multirow[b]{2}{*}{$S L$} \\
\hline & $\lambda$ & We $S L$ & Kruskall & $\boldsymbol{P}$ & Combined & Variança & $S L$ & tau & $S L$ & & \\
\hline$O D$ & 1 & $\begin{array}{l}0,981 \\
0,509\end{array}$ & Sim & 0,0002 & -484 & 8426 & $1,4 * 10^{-7}$ & & & - & $\mathrm{S}$ \\
\hline DBO & 0 & $\begin{array}{c}0,910 \\
0,3 * 10^{-10}\end{array}$ & Não & 0,230 & & & & 0,032 & $5,7^{*} 10^{-1}$ & + & $\mathrm{ns}$ \\
\hline Nitrogênio & 1 & $\begin{array}{c}0,833 \\
000\end{array}$ & Não & 0,339 & & & & $-0,296$ & $2,7^{*} 10^{-1}$ & - & $\mathrm{S}$ \\
\hline Nitrato & 1 & $\begin{array}{c}0,942 \\
0,11 * 10^{-4}\end{array}$ & Não & 0,068 & & & & $-0,035$ & $5,4 * 10^{-1}$ & - & ns \\
\hline Amônio & 0 & $\begin{array}{c}0,961 \\
0,75^{*} 10^{-2}\end{array}$ & Não & 0,235 & & & & 0,063 & $2,7^{*} 10^{-1}$ & + & ns \\
\hline Fósforo & 0 & $\begin{array}{c}0,962 \\
0,1 * 10^{-1}\end{array}$ & Não & 0,260 & & & & 0,166 & $3,9 * 10^{-3}$ & + & $\mathrm{S}$ \\
\hline Cloreto & 0 & $\begin{array}{l}0,982 \\
0,598\end{array}$ & Não & 0,541 & & & & 0,170 & $3,1 * 10^{-3}$ & + & $\mathrm{S}$ \\
\hline $\begin{array}{l}\text { Coliformes } \\
\text { Fecais }\end{array}$ & 0 & $\begin{array}{c}0,941 \\
0,93 * 10^{-5}\end{array}$ & Não & 0,051 & & & & 0,195 & $7,1 * 10^{-4}$ & + & $\mathrm{S}$ \\
\hline $\operatorname{Vaz} \tilde{a} \boldsymbol{O}$ & 0 & $\begin{array}{c}0,952 \\
0,45^{*} 10^{-3}\end{array}$ & & & -112 & 8426 & $2,2^{*} 10^{-1}$ & & & - & ns \\
\hline Precipitação & & & & & & IMESTRAI & & AN & & & \\
\hline D6-094 & 1 & $\begin{array}{c}0,863 \\
0,38 * 10^{-2}\end{array}$ & & & -33 & 8600 & $7,2^{*} 10^{-1}$ & 0,152 & $3,1 * 10^{-1}$ & - & ns \\
\hline$D 7-074$ & 1 & $\begin{array}{c}0,883 \\
0,10^{*} 10^{-1}\end{array}$ & & & -99 & 8600 & $2,8^{*} 10^{-1}$ & $-0,181(-)$ & $2,1 * 10^{-1}$ & - & ns \\
\hline & & & & & & Sazonal & & Não & onal & & \\
\hline
\end{tabular}




\begin{tabular}{|c|c|c|c|c|c|c|c|c|c|c|c|}
\hline \multicolumn{12}{|c|}{ PX2400 (PX2) } \\
\hline \multirow[t]{2}{*}{ TESTES } & \multicolumn{2}{|c|}{ Normalidade } & \multicolumn{2}{|c|}{ Sazonalidade } & \multicolumn{3}{|c|}{ Sazonal de Mann-Kendall } & \multicolumn{2}{|c|}{ Mann-Kendall } & \multirow[b]{2}{*}{ Tendência } & \multirow[b]{2}{*}{$S L$} \\
\hline & $\lambda$ & We SL & Kruskall & $P$ & Combined & Variança & $S L$ & tau & $S L$ & & \\
\hline$O D$ & 1 & $\begin{array}{l}0,980 \\
0,456\end{array}$ & Sim & 0,0001 & -428 & 8426 & $3,1 * 10^{-6}$ & & & - & $\mathrm{S}$ \\
\hline$D B O$ & 0 & $\begin{array}{c}0,903 \\
0,1 * 10^{-11}\end{array}$ & Sim & 0,014 & 410 & 8426 & $7,9 * 10^{-6}$ & & & + & $\mathrm{S}$ \\
\hline Nitrogênio & 1 & $\begin{array}{c}0,854 \\
0,7^{*} 10^{-19}\end{array}$ & Não & 0,098 & & & & $-0,229$ & $7,1 * 10^{-5}$ & - & $\mathrm{S}$ \\
\hline Nitrato & 1 & $\begin{array}{r}0,975 \\
0,228\end{array}$ & Sim & 0,001 & -270 & 8426 & $3,2 * 10^{-3}$ & & & - & $\mathrm{S}$ \\
\hline Amônio & 0 & $\begin{array}{c}0,871 \\
0,5^{*} 10^{-18}\end{array}$ & Não & 0,890 & & & & 0,145 & $1,1 * 10^{-2}$ & + & $\mathrm{S}$ \\
\hline Fósforo & 0 & $\begin{array}{c}0,952 \\
0,47 * 10^{-3}\end{array}$ & Não & 0,556 & & & & 0,064 & $2,6^{*} 10^{-1}$ & + & ns \\
\hline Cloreto & 0 & $\begin{array}{c}0,971 \\
0,94 * 10^{-1}\end{array}$ & Não & 0,897 & & & & 0,194 & $7,8^{*} 10^{-4}$ & + & $\mathrm{S}$ \\
\hline $\begin{array}{l}\text { Coliformes } \\
\text { Fecais }\end{array}$ & 0 & $\begin{array}{l}0,973 \\
0,156\end{array}$ & Não & 0,577 & & & & 0,120 & $2,7 * 10^{-2}$ & + & $\mathrm{S}$ \\
\hline $\operatorname{Vaz} \tilde{a} o$ & 0 & $\begin{array}{c}0,952 \\
0,45^{*} 10^{-3}\end{array}$ & & & -112 & 8426 & $2,2 * 10^{-1}$ & & & - & $\mathrm{ns}$ \\
\hline Precipitação & & & & & & IMESTRAI & & ANl & & & \\
\hline D6-094 & 1 & $\begin{array}{c}0,863 \\
0,38^{*} 10^{-2}\end{array}$ & & & -33 & 8600 & $7,2^{*} 10^{-1}$ & 0,152 & $3,1^{*} 10^{-1}$ & - & $\mathrm{ns}$ \\
\hline D7-074 & 1 & $\begin{array}{c}0,883 \\
0,10^{*} 10^{-1}\end{array}$ & & & -99 & 8600 & $2,8^{*} 10^{-1}$ & $-0,181(-)$ & $2,1 * 10^{-1}$ & - & ns \\
\hline & & & & & & Sazonal & & Não S & zonal & & \\
\hline
\end{tabular}

\begin{tabular}{|c|c|c|c|c|c|c|c|c|c|c|c|}
\hline \multirow{3}{*}{ TESTES } & \multicolumn{9}{|c|}{ AG2100 (AG1) } & \multirow[b]{3}{*}{ Tendência } & \multirow[b]{3}{*}{$S L$} \\
\hline & \multicolumn{2}{|c|}{ Normalidade } & \multicolumn{2}{|c|}{ Sazonalidade } & \multicolumn{3}{|c|}{ Sazonal de Mann-Kendall } & \multicolumn{2}{|c|}{ Mann-Kendall } & & \\
\hline & $\lambda$ & We $S L$ & Kruskall & $\boldsymbol{P}$ & Combined & Variança & $S L$ & tau & $S L$ & & \\
\hline$O D$ & 1 & $\begin{array}{l}0,982 \\
0,559\end{array}$ & Sim & 0000 & -320 & 8426 & $4,9^{*} 10^{-4}$ & & & - & $\mathrm{S}$ \\
\hline DBO & 0 & $\begin{array}{c}0,867 \\
0,5^{*} 10^{-19}\end{array}$ & Não & 0,453 & & & & 0,162 & $4,7 * 10^{-3}$ & + & $\mathrm{S}$ \\
\hline Nitrogênio & 1 & $\begin{array}{c}0,970 \\
0,82 * 10^{-1}\end{array}$ & Sim & 0,013 & -378 & 8426 & $3,8 * 10^{-5}$ & & & - & $\mathrm{S}$ \\
\hline Nitrato & 1 & $\begin{array}{c}0,945 \\
0,46^{*} 10^{-4}\end{array}$ & Sim & 0,001 & 6 & 8426 & $9,5^{*} 10^{-1}$ & & & + & ns \\
\hline Amônio & 0 & $\begin{array}{c}0,867 \\
0,2 * 10^{-16}\end{array}$ & Não & 0,555 & & & & 0,084 & $1,4 * 10^{-1}$ & + & ns \\
\hline Fósforo & 0 & $\begin{array}{c}0,943 \\
0,19^{*} 10^{-4}\end{array}$ & Sim & 0,001 & -124 & 8426 & $1,8^{*} 10^{-1}$ & & & - & ns \\
\hline Cloreto & 0 & $\begin{array}{c}0,969 \\
0,57 * 10^{-1}\end{array}$ & Não & 0,461 & & & & 0,144 & $1,2 * 10^{-2}$ & + & S \\
\hline $\begin{array}{l}\text { Coliformes } \\
\text { Fecais }\end{array}$ & 0 & $\begin{array}{c}0,947 \\
0,82 * 10^{-4}\end{array}$ & Não & 0,672 & & & & 0,257 & $8,1 * 10^{-6}$ & + & $\mathrm{S}$ \\
\hline Vazão & 0 & $\begin{array}{c}0,957 \\
0,24 * 10^{-2}\end{array}$ & & & -46 & 8426 & $6,1 * 10^{-1}$ & & & - & ns \\
\hline Precipitação & & & & & & IMESTRAI & & & & & \\
\hline$C 7-006$ & 1 & $\begin{array}{l}0,938 \\
0,169\end{array}$ & & & 6 & 8600 & $9,5^{*} 10^{-1}$ & 0,079 & $6,1 * 10^{-1}$ & + & ns \\
\hline$C 7-064$ & 1 & $\begin{array}{l}0,985 \\
0,962\end{array}$ & & & -21 & 8600 & $8,2 * 10^{-1}$ & $-0,021$ & $8,6^{*} 10^{-1}$ & - & ns \\
\hline$C 7-075$ & 1 & $\begin{array}{l}0,951 \\
0,312\end{array}$ & & & 19 & 8600 & $8,4 * 10^{-1}$ & 0,079 & $6,1 * 10^{-1}$ & + & ns \\
\hline & & & & & & Sazonal & & Não & zonal & & \\
\hline
\end{tabular}




\begin{tabular}{|c|c|c|c|c|c|c|c|c|c|c|c|}
\hline \multicolumn{12}{|c|}{ AG2350 (AG2) } \\
\hline \multirow[t]{2}{*}{ TESTES } & \multicolumn{2}{|c|}{ Normalidade } & \multicolumn{2}{|c|}{ Sazonalidade } & \multicolumn{3}{|c|}{ Sazonal de Mann-Kendall } & \multicolumn{2}{|c|}{ Mann-Kendall } & \multirow[b]{2}{*}{ Tendência } & \multirow[b]{2}{*}{$S L$} \\
\hline & $\lambda$ & $W e S L$ & Kruskall & $\boldsymbol{P}$ & Combined & Variança & $S L$ & tau & $S L$ & & \\
\hline$O D$ & 1 & $\begin{array}{c}0,986 \\
0,83\end{array}$ & Sim & 000 & -332 & 8426 & $2,9 * 10^{-4}$ & & & - & $\mathrm{S}$ \\
\hline$D B O$ & 0 & $\begin{array}{c}0,865 \\
0,23^{*} 10^{-19}\end{array}$ & $\operatorname{Sim}$ & 0,012 & 170 & 8426 & $6,4 * 10^{-2}$ & & & + & ns \\
\hline Nitrogênio & 1 & $\begin{array}{c}0,953 \\
0,66^{*} 10^{-3}\end{array}$ & Não & 0,201 & & & & $-0,287$ & $6,5^{*} 10^{-7}$ & - & $\mathrm{S}$ \\
\hline Nitrato & 1 & $\begin{array}{c}0,894 \\
0,9 * 10-12\end{array}$ & $\operatorname{Sim}$ & 0,001 & 36 & 8426 & $6,9 * 10^{-1}$ & & & + & ns \\
\hline Amônio & 0 & $\begin{array}{c}0,865 \\
0,5^{*} 10^{-17}\end{array}$ & Não & 0,888 & & & & 0,029 & $6,1 * 10^{-1}$ & + & ns \\
\hline Fósforo & 0 & $\begin{array}{c}0,926 \\
0,29 * 10^{-7}\end{array}$ & Não & 0,136 & & & & $-0,002$ & $9,6^{*} 10^{-1}$ & - & ns \\
\hline Cloreto & 0 & $\begin{array}{c}0,960 \\
0,52 * 10^{-2}\end{array}$ & Não & 0,560 & & & & 0,131 & $2,3 * 10^{-2}$ & + & $\mathrm{S}$ \\
\hline $\begin{array}{l}\text { Coliformes } \\
\text { Fecais }\end{array}$ & 0 & $\begin{array}{c}0,930 \\
0,29 * 10^{-5}\end{array}$ & Não & 0,816 & & & & 0,138 & $1,6 * 10^{-2}$ & + & $\mathrm{S}$ \\
\hline Vazão & 0 & $\begin{array}{c}0,957 \\
0,24 * 10^{-2}\end{array}$ & & & -46 & 8426 & $6,1 * 10^{-1}$ & & & - & ns \\
\hline Precipitação & & & & & & IMESTRAL & & & $\mathrm{AL}$ & & \\
\hline C7-006 & 1 & $\begin{array}{l}0,938 \\
0,169\end{array}$ & & & 6 & 8600 & $9,5^{*} 10^{-1}$ & 0,079 & $6,1 * 10^{-1}$ & + & ns \\
\hline C7-064 & 1 & $\begin{array}{l}0,985 \\
0,962\end{array}$ & & & -21 & 8600 & $8,2 * 10^{-1}$ & $-0,021$ & $8,6^{*} 10^{-1}$ & - & ns \\
\hline C7-075 & 1 & $\begin{array}{l}0,951 \\
0,312\end{array}$ & & & 19 & 8600 & $8,4^{*} 10^{-1}$ & 0,079 & $6,1 * 10^{-1}$ & + & ns \\
\hline & & & & & & Sazonal & & Nãc & zonal & & \\
\hline
\end{tabular}

\begin{tabular}{|c|c|c|c|c|c|c|c|c|c|c|c|}
\hline \multicolumn{12}{|c|}{ JD2300 (JD) } \\
\hline \multirow[t]{2}{*}{ TESTES } & \multicolumn{2}{|c|}{ Normalidade } & \multicolumn{2}{|c|}{ Sazonalidade } & \multicolumn{3}{|c|}{ Sazonal de Mann-Kendall } & \multicolumn{2}{|c|}{ Mann-Kendall } & \multirow[b]{2}{*}{ Tendência } & \multirow[b]{2}{*}{$S L$} \\
\hline & $\lambda$ & We $S L$ & Kruskall & $\boldsymbol{P}$ & Combined & Variança & $S L$ & tau & $S L$ & & \\
\hline$O D$ & 1 & $\begin{array}{l}0,987 \\
0843\end{array}$ & Sim & 0,0001 & -447 & 9560 & $4,8 * 10^{-6}$ & & & - & $\mathrm{S}$ \\
\hline$D B O$ & 0 & $\begin{array}{c}0,846 \\
000\end{array}$ & Sim & 0,0291 & 379 & 9560 & $1,0 * 10^{-4}$ & & & + & $\mathrm{S}$ \\
\hline Nitrogênio & 1 & $\begin{array}{c}0,923 \\
0,74 * 10^{-8}\end{array}$ & Sim & 0,0430 & -107 & 9560 & $2,7 * 10^{-1}$ & & & - & ns \\
\hline Nitrato & 1 & $\begin{array}{c}0,848 \\
000\end{array}$ & Sim & 0,0131 & 613 & 9560 & 000 & & & + & $\mathrm{S}$ \\
\hline Amônio & 0 & $\begin{array}{c}0,887 \\
0,2 * 10^{-16}\end{array}$ & Não & 0,2438 & & & & 0,044 & $4,3 * 10^{-1}$ & + & ns \\
\hline Fósforo & 0 & $\begin{array}{c}0,957 \\
0,16^{*} 10^{-3}\end{array}$ & Sim & 0,0110 & 253 & 9560 & $9,6^{*} 10^{-3}$ & & & + & $\mathrm{S}$ \\
\hline Cloreto & 0 & $\begin{array}{l}0,977 \\
0,299\end{array}$ & Não & 0,4525 & & & & 0,331 & 000 & + & $\mathrm{S}$ \\
\hline $\begin{array}{l}\text { Coliformes } \\
\text { Fecais }\end{array}$ & 0 & $\begin{array}{c}0,864 \\
0,15^{*} 10^{-1}\end{array}$ & Não & 0,4682 & & & & 0,164 & $3,5^{*} 10^{-3}$ & + & $\mathrm{S}$ \\
\hline$V a z \tilde{a} \tilde{o}$ & 0 & $\begin{array}{c}0,955 \\
0,57 * 10^{-3}\end{array}$ & & & -79 & 9560 & $4,2 * 10^{-1}$ & & & - & ns \\
\hline Precipitação & & & & & & BIMESTRAI & & & JAL & & \\
\hline B6-038 & 1 & $\begin{array}{l}0,955 \\
0,376\end{array}$ & & & -64 & 8600 & $4,9 * 10^{-1}$ & $-0,108$ & $4,4^{*} 10^{-1}$ & - & ns \\
\hline B6-048 & 1 & $\begin{array}{l}0,967 \\
0,611\end{array}$ & & & -79 & 8600 & $3,9 * 10^{-1}$ & $-0,206$ & $1,6^{*} 10^{-1}$ & - & ns \\
\hline B7-011 & 1 & $\begin{array}{c}0,804 \\
0,3 * 10^{-3}\end{array}$ & & & -128 & 8600 & $1,6^{*} 10^{-1}$ & $-0,260$ & $6,9 * 10^{-2}$ & - & ns \\
\hline & & & & & & Sazonal & & Não & zonal & & \\
\hline
\end{tabular}




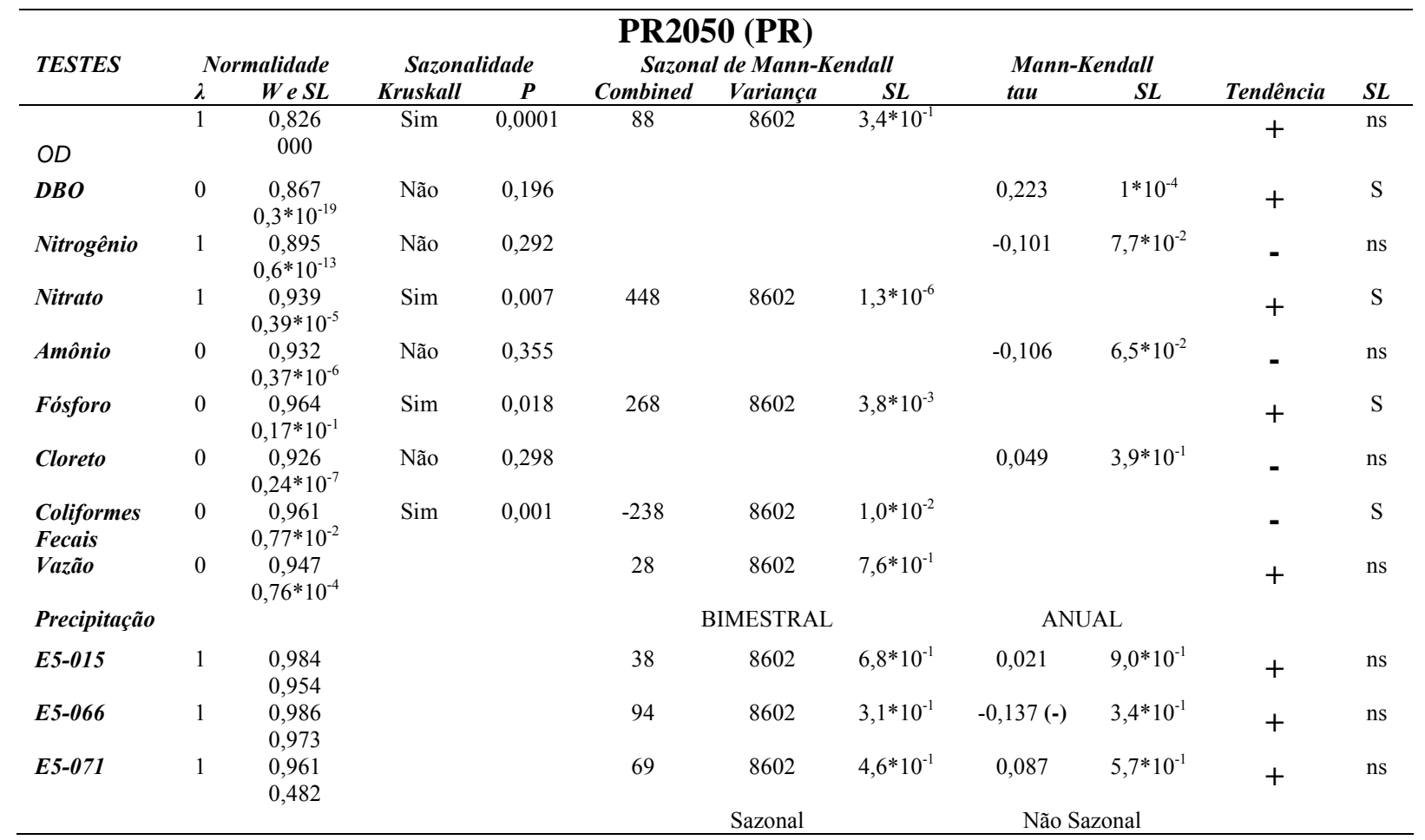

\begin{tabular}{|c|c|c|c|c|c|c|c|c|c|c|c|}
\hline \multicolumn{12}{|c|}{ TQ2012 (TQ) } \\
\hline \multirow[t]{2}{*}{ TESTES } & \multicolumn{2}{|c|}{ Normalidade } & \multicolumn{2}{|c|}{ Sazonalidade } & \multicolumn{3}{|c|}{ Sazonal de Mann-Kendall } & \multicolumn{2}{|c|}{ Mann-Kendall } & \multirow[b]{2}{*}{ Tendência } & \multirow[b]{2}{*}{$S L$} \\
\hline & $\lambda$ & We $S L$ & Kruskall & $\boldsymbol{P}$ & Combined & Variança & $S L$ & tau & $S L$ & & \\
\hline$O D$ & 1 & $\begin{array}{c}0,824 \\
000\end{array}$ & Sim & 0,0001 & 454 & 8602 & $9,5^{*} 10^{-7}$ & & & + & $\mathrm{S}$ \\
\hline$D B O$ & 0 & $\begin{array}{c}0,904 \\
0,2 * 10^{-11}\end{array}$ & Não & 0,782 & & & & $-0,120$ & $3,6 * 10^{-2}$ & - & $\mathrm{S}$ \\
\hline Nitrogênio & 1 & $\begin{array}{c}0,702 \\
000\end{array}$ & Não & 0,784 & & & & $-0,037$ & $5,1 * 10^{-1}$ & - & ns \\
\hline Nitrato & 1 & $\begin{array}{c}0,886 \\
0,3 * 10^{-19}\end{array}$ & Não & 0,304 & & & & 0,430 & 000 & + & $\mathrm{S}$ \\
\hline Amônio & 0 & $\begin{array}{c}0,939 \\
0,59 * 10^{-5}\end{array}$ & Não & 0,853 & & & & $-0,117$ & $4,0 * 10^{-2}$ & - & $\mathrm{S}$ \\
\hline Fósforo & 0 & $\begin{array}{c}0,958 \\
0,26 * 10^{-2}\end{array}$ & Não & 0,966 & & & & 0,166 & $3,7 * 10^{-3}$ & + & $\mathrm{S}$ \\
\hline Cloreto & 0 & $\begin{array}{c}0,946 \\
0,63 * 10^{-4}\end{array}$ & Não & 0,883 & & & & $-0,143$ & $1,2 * 10^{-2}$ & - & $\mathrm{S}$ \\
\hline $\begin{array}{l}\text { Coliformes } \\
\text { Fecais }\end{array}$ & 0 & $\begin{array}{l}0,979 \\
0,425\end{array}$ & Não & 0,242 & & & & 0,108 & $5,9 * 10^{-2}$ & + & ns \\
\hline $\operatorname{Vaz} \tilde{a} o$ & 0 & $\begin{array}{c}0,956 \\
0,17^{*} 10^{-2}\end{array}$ & & & -2 & 8602 & $9,8^{*} 10^{-1}$ & & & - & ns \\
\hline Precipitação & & & & & & BIMESTRAI & & AN & & & \\
\hline E5-015 & 1 & $\begin{array}{l}0,984 \\
0,954\end{array}$ & & & 38 & 8602 & $6,8^{*} 10^{-1}$ & 0,021 & $9,0^{*} 10^{-1}$ & + & ns \\
\hline$E 5-066$ & 1 & $\begin{array}{l}0,986 \\
0,973\end{array}$ & & & 94 & 8602 & $3,1 * 10^{-1}$ & $-0,137(-)$ & $3,4 * 10^{-1}$ & + & ns \\
\hline E5-071 & 1 & $\begin{array}{l}0,961 \\
0,482\end{array}$ & & & 69 & 8602 & $4,6^{*} 10^{-1}$ & 0,087 & $5,7 * 10^{-1}$ & + & ns \\
\hline & & & & & & Sazonal & & Não & zonal & & \\
\hline
\end{tabular}


Anexo B

Curvas "Box-Plot" 

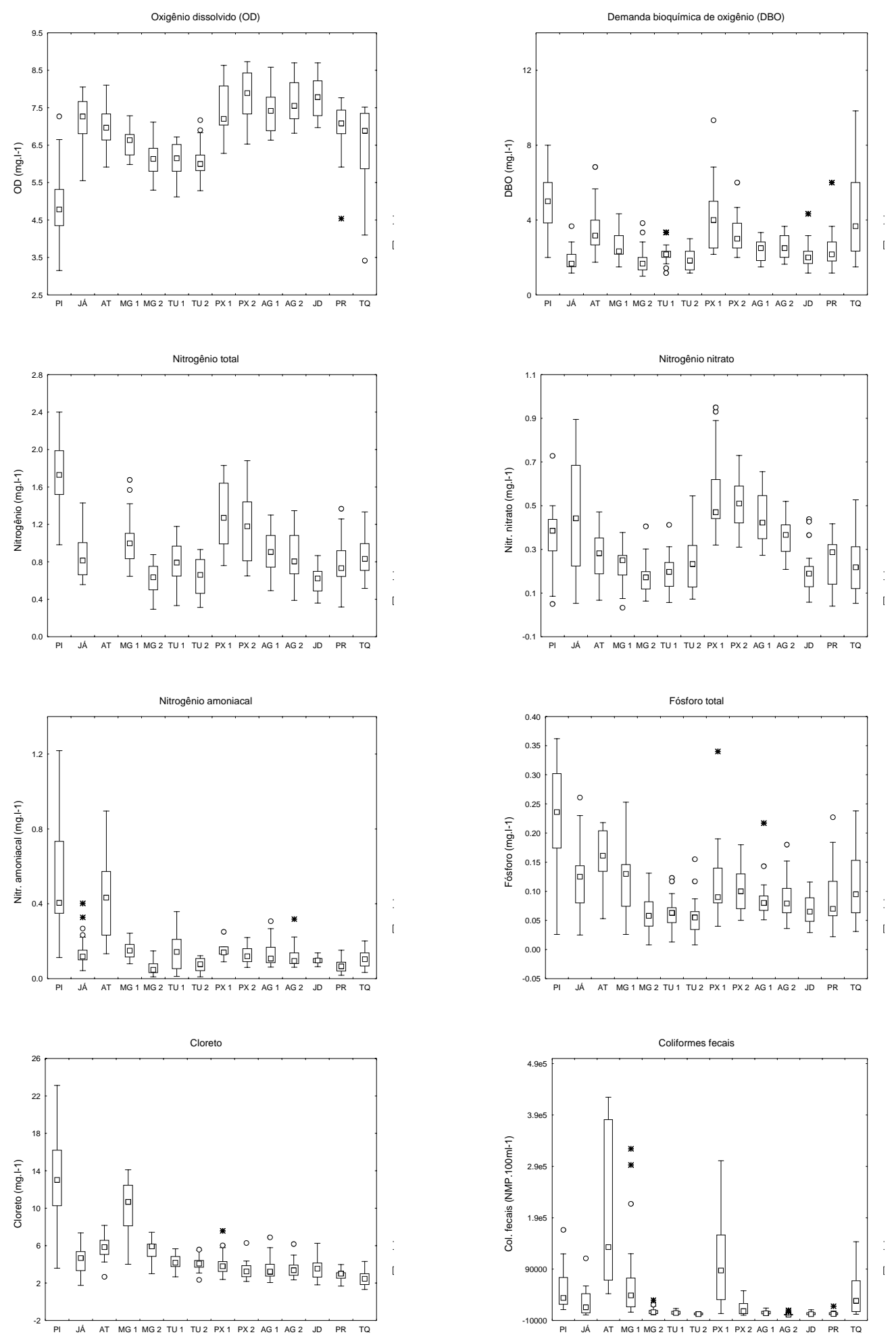


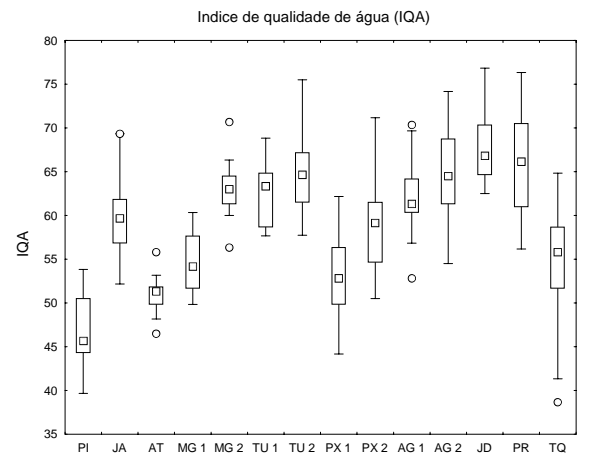




\section{REFERÊNCIAS BIBLIOGRÁFICAS}

BALLESTER, M. V. R.; MARTINELli, L. A.; KRUSCHE, A. V.; VICTORIA, R. L.; BERNARDES, M.; CAMARGO, P. B. Effects of increasing organic matter loading on the dissolved $\mathrm{O} 2$, free dissolved $\mathrm{CO} 2$ and respiration rates in the Piracicaba river basin, southeast Brazil. Water Research, v. 33, n. 9, p 2119-2129, 1999.

BERNARDES, M. C.; MARTINELli, L. A.; CAMARGO, P. B.; VICTÓRIA, R. L; KRUSCHE, A. V.; OMETTO, J. P. H. B.; WAKEHAM, S. G.; HEDGES, J. I. Sterol and fatty acid distributions in sewage-contaminated rivers of the Piracicaba River Basin, southeast Brazil. Organic Biochemistry, (2002).

BURN, D.H. Hydrologic effects of climatic change in west-central Canada. Journal of Hydrology, n. 160, p. 53-70, 1994.

COMPANHIA DE TECNOLOGIA DE SANEAMENTO AMBIENTAL, SÃO PAULO. RELATÓRIO DE QUALIDADE DE ÁGUAS INTERIORES DO ESTADO DE SÃO PAULO 1994. São Paulo: CETESB 1995. 1v.

CETESB - Companhia de Tecnologia de Saneamento Ambiental, site, 2002.

CHRISTOFOLETTI, A.L.H. Estudo sobre a sazonalidade da precipitação na bacia do Piracicaba São Paulo, 1991. Dissertação de (Mestrado) - Instituto de Geografia Universidade de São Paulo.

CLARKE, R. T.; BRUSA,L. C.- O método bootstrap para detectar tendências em séries de vazão, In: SIMPÓSIO BRASILEIRO DE RECURSOS HÍDRICOS, 12, Vitória, ES.1997. Anais, Vitória: Sociedade Brasileira de Recursos Hídricos, 1997. p. 621628. 
CLEVELAND, W. S. Robust locally weighted regression and smoothing scatterplots. Journal of the American Statistical Association, v. 74, n. 368, p. 829-836, 1979.

COMBER, S.; GARDNER, M. An assessment of trends in European environmental data for mercury and chlorinated organic compounds in water and biota. The Science of the Total Environment, v. 243/244, p. 193-201, 1999.

CONSELHO ESTADUAL DE RECURSOS HÍDRICOS, CRH - Sistema Integrado de Gerenciamento de Recursos Hídricos do Estado de São Paulo, Relatório Zero da bacia de São José dos Dourados, Relatório no. 40675, http:www.sigrh.sp.gov.br, 2001a.

CUN, C.; VILAGINES, R. Time series analysis on chlorides, nitrates, ammonium and dissolved oxygen concentrations in the Seine river near Paris. The Science of the Total Environment, v. 208, p. 59-69, 1997.

EVANS, C. D.; JENKINS, A. Surface water acidification in the South Pennines II. Temporal trends. Environment Pollution, v. 109, p. 21-34, 2000.

FORESTER, D.L. Water quality in the credit river 1964-1998, Canadá Institute for Environmental Studies, University of Toronto, 2000.

GOLDSTEIN, E.G. Testes de toxicidade de efluentes industriais. Ambiente, v. 2, n. 1, p. 33-38, 1988.

GOOSSENS,C.; BERGER,A. Annual and seasonal climatic variations over the northern hemisphere and Europe during the last century,. Annales Geophysicae, v. 4, n. 4, p.385-400, 1986.

GROPPO, J. D.; MILDE, L, C; MORAES, J. M.; GUANDIQUE, E. M.; MARTINELLI, L. A. Análise da vazão e da precipitação na bacia do rio Piracicaba: Detecção de sinais devido a intervenções antrópicas. Revista de Ciência e Tecnologia, v. 9, n. 18, p. 109-117, 2001.

HANNAPPEL, S.; PIEPHO, B. Cluster analysis of environmental data which is not interval scaled but categorical. Chemosphere, v. 33, n. 2, p. 335-342, 1996.

HELSEL D. R., HIRSCH, R. M. Statistical methods in water resources, Studies in Environmental Science, v. 49, ed. Elsevier, 1995, 529p. 
HIPEL, K. W., McLEOD, A. D. Times series modelling of water resources and enviromental systems, Developments in Water Science, v. 45, ed. Elsevier, 1994, $1010 \mathrm{p}$.

HIRSCH, R. M.; ALEXANDER, R. B.; SMITH, R. A. Selection of methods for the detection and estimation of trends in water quality. Water Resources Research, $v$. 27, n. 5, p. 803-813, 1991.

HIRSCH, R. M.; SLACK, R. J.; SMITH, R. Techniques of trend analysis for monthly water quality data. Water Resources Research, v. 18, n. 1, p. 107-121, 1982.

JOHNSON, R.; WICHERN, D. Applied multivariate statistical analysis. 3ed. New Jersey: Englewood Cliffs, 1982.

KENDALL, M. G. Rank correlation methods, 2 ed, New York: Hafner, 1970.

KRUSCHE, A. V.; CARVAlhO, F. P.; MORAES, J. M.; BALlESTER, M. V. R.; HORNINK, S.; MARTINELLI, L. A.; VICTORIA, R. L. Spatial and temporal water quality variability in the Piracicaba river basin, Brazil. Journal of the American Water Resources Association, v. 33, n. 5, p. 1117-1123, 1997.

KRUSKALL, W. H.; WALLIS. W. A. Use of ranks on one-criterion variance analysis. Journal of the American Statistical Association, v. 47, p.583-621, 1952.

LANDIM, P.M.B. Análise estatística de dados geológicos multivariados, Rio Claro, 2000. Universidade Federal de São Carlos. Texto didático.

LANGLAND, M.J.; EDWARDS, R.E.; DARRELL, L.C. Status yields and trends of nutrients and sediment and methods of analysis for the nontidal data-collection programs, Chesapeake Bay Basin, 1985-96. U.S. Geological Survey, Open-File Report 98-17, 1998.

LARA, L. B. L. S.; ARTAXO, P.; MARTINELli, L. A.; VICTÓRIA, R. L.; CAMARGO, P. B.; KRUSCHE, A.; AYRES, G. P.; FERRAZ, E. S. B.; BALLESTER, M. V. Chemical composition of rainwater and anthropogenic influences in the Piracicaba River Basin, Southeast Brazil. Atmospheric Environment, v. 35, p. 4937-4945, 2001. 
LARSEN, S. E.; KRONVANG, B.; WINDOLF, J.; SVENDSEN, L. M. Trends in diffuse nutrient concentrations and loading in denmark: Statistical trend analysis of stream monitoring data. Water Science, v. 39, n. 12, p. 197-205, 1999.

LIKENS, G.E.; BORMANN, F. H.; PIERCE, R.S.; EATON, J.S. Biogeochemistry of a Forested Ecosystem. New York : Springer-Verlag; 1977. 264p.

LUNDIN, M.; MOLANDER, S.; MORRISON, G. M. A set of indicators for the assessment of temporal variations in the sustainalility of sanitary systems. Water Science, v. 39, n. 5, p. 235-242, 1999.

MAASDAM, R.; CLAASSEN, T. H. L. Trends in water quality and algal growth in shallow frisian lakes, the Netherlands. Water Science, v. 37, n. 3, p. 177-184, 1998.

MANN, H. B. Nonparametric tests against trend. Econometrica, v 13, 1945.

MARENGO, J. A.; TOMASELLA, J.; UVO, C. R. B. On the suitability of nonparametric tests for detection of trends in brasilian rivers, In: CONGRESSO BRASILEIRO DE METEREOLOGIA, Campos de Jordão, S.P., 1996. Anais, 1996. p. 1492-1495.

MARTINELLI, L. A.; KRUSCHE, A. V.; VICTORIA, R. L.; CAMARGO, P. B.; BERNARDES, M.; FERRAZ, E. S.; MORAES, J. M.; BALLESTER, M. V. Effects of sewage on the chemical composition of Piracicaba River, SouthEast Brazil. Water, Air and Soil Pollution, v. 110, p.67-69, 1999.

MARTINELLI, L.A.; SILVA, A. M.; CAMARGO, P. B.; MORETTI, L. R.; TOMAZELLI, A. C.; SILVA, D. M. L.; FISCHER, E. G.; SONODA, K. C.; SALOMÃO, M. S. M. B. Levantamento das cargas orgânicas lançadas nos rios do Estado de São Paulo, Biota Neotropica, v. 2, n. 2, 2002.

MARTINS, J. V. O desenvolvimento de técnicas analíticas nucleares aplicadas à análise de anéis de crescimento de árvores da Amazônia e outros materiais, São Paulo, 1994. Dissertação de (Mestrado). Instituto de Física, Universidade de São Paulo.

MCLEOD, A. I.; HIPEL, K. W. Reference manual, The McLeod-Hipel Time Series Package, 1994. 117 p.

MCLEOD, A. I.; HIPEL, K. W.; BODO, B. A. Trend analysis methodology for water quality time series. Environmetrics, v. 2, n. 2, p. 169-200, 1991. 
MOMEN, B.; EICHLER, L. W.; BOYLEN, C.W.; ZEHR, J. P. Application of multivariate statistics in detecting temporal and spatial patterns of water chemistry in Lake George, New York. Ecological Modelling, v. 91, p. 183-192, 1996.

MORAES, J .M. ;PELLEGRINO, G. Q.; BALLES-TER, M. V.; MARTINELLI, L. A.; VICTORIA, R. L.; KRUSCH, A. V. Estudo preliminar da evolução temporal dos componentes do ciclo hidrológico da bacia do rio Piracicaba. In: SIMPÓSIO DE RECURSOS HÍDRICOS, 11, SIMPÓSIO DE HIDRÁULICA E RECURSOS HÍDRICOS DOS PAÍSES DE LÍNGUA OFICIAL PORTUGUESA, 2, Recife, PE,1995. Anais Porto Alegre: ABRH, 1995. p.27-32.

MORAES, J. M.; PELlEGRINO, G. Q.; BALLESTER, M. V.; MARTINELLI, L. A.; VICTORIA, R. L.; KRUSCHE, A. V., Trends in hydrological parameters of a southern Brazilian waterlhed and is relation to humam induced changes, Water Resources Management, v. 12, p 295-311, 1998.

OMETTO, J. P. H. B.; MARTINELLI, L. A.; BALLESTER, M. V. R.; GESSNER, A.; KRUSCHE, A. V.; VICTORIA, R. L.; WILLIAMS, M. Effects of land use on the water chemistry and macroinvertebrates in two streams of the Piracicaba river basin, south-east Brazil. Freshwater Biology, v. 44, p.327-337, 2000.

OSBURN, W.; TOTH, D.; BONIOL,D. Springs of the St. Johns River water management distict. Water Management District St. Johns River Report SJ2002-5, 2002.

PARK, G. S.; PARK, S. Y. Long-term trends and temporal heterogeneity of water quality in tidally mixed estuarine waters. Marine Pollution Bulletin, v. 40, n. 12, p.1201-1209, 2000.

PELLEGRINO, G. Q., Análise espaço-temporal de dados hidrológicos da bacia do rio Piracicaba, Piracicaba, 1995.

PETTITT, A. N. A non-parametric approach to the change-point problem. Applied Statistics. v. 28, n. 2, p. 126-135, 1979.

PLANO DE BACIA HIDROGRAFICA 2000-2003. Comitê de bacias dos rios Piracicaba, Capivari e Jundiaí. 
PROCHNOW, M.C.R. A qualidade das águas na bacia do rio Piracicaba. Rio Claro, 1981. Dissertação de (Mestrado) - Instituto de Geociências e Ciências Exatas, Universidade Estadual Paulista.

ROYSTON, Graphical detection of non-normality by using Michael's statistic. Applied Statistics, v. 42, n. 1, p. 153-158, 1993.

SALATI, E. Análise ambiental sintética e qualidade das águas do rio Corumbataí (SP) como subsídio para o planejamento regional integrado da bacia de drenagem do rio Corumbataí, São Carlos, 1996. Tese de (Doutorado) - Ciência da Engenharia Ambiental, Universidade Federal de São Carlos.

SÃO PAULO. Secretaria do Meio Ambiente. Relatório de qualidade de águas interiores do Estado de São Paulo, São Paulo: CETESB. 1992, 225p.

SÃO PAULO. Plano Estadual de Recursos Hídricos, Governo do Estado de São Paulo, São Paulo, 1990. 137p.

SCHULER, A. E. Análise da representatividade física dos parâmetros do Topmodel em uma bacia de meso escala localizada nas cabeceiras do rio Corumbataí, São Paulo.

SEN, P. K. Estimates of the regression coefficient based on Kendall's tau, Journal of the American Statistical Association, v. 63, p. 1379-1389, 1968.

SNEYERS, R. Sur l'analyse statistique des séries d'observations, Genève. s.ed. 1975. $192 p$.

StatSoft, Inc. STATISTICA for Windows [Computer program manual], 1999.

STUMM, W.; MORGAN, J.J.. Wiley-Interscience, New York: Aquatic Chemistry.. 1996, $1022 \mathrm{p}$.

TUKEY, J.. Addison-Wesley, Reading, Mas. Exploratory data analysis. 1977.

YUNG, Y. K.; YAU, K.; WONG, C. K.; CHAN, K. K.; YEUNG, I.; KUEH, C. S. W.; BROOM, M. J. M. Marine Pollution Bulletim, v. 39, n. 1/12, p. 315-325, 1999.

WESTMACOTT, J. R.; BURN, D. H. Climate change effects on the hydrologic regime within the Churchill-Nelson River Basin, Journal of Hydrology, v. 202, p. 263-279, 1997. 